Bogeneinteilung und Auflagenummern der Postwertzeichen ang ㅁopopura Bayerns

HE

6185

G3:5826

1921

NPM

von

Dr. Erich Stenger 
31.

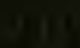




\section{Bogeneinteilung und}

Auflagenummern der

\section{Postwertzeichen Bayerns}

von

Dr. Erich Stenger

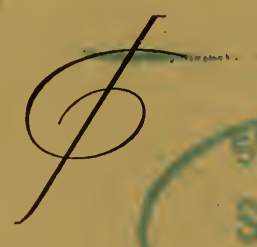
Verlag:
Briefmarken-Sammler-Verein Nürnberg E.V.
1921

\section{Gift of \\ GEORGE T TURNER}




\section{Inhalt.}

Vorwort . . . . . . . . . . . . . . . . 3

Einleitung . . . . . . . . . . . . . . . . . . 5

A. Bogeneinteilung. B. Auflagenummern. A. B.

Briefmarken . . . . . . . . . . . . . 732

I. Ziffernzeichnung . . . . . . . . . $7 \begin{array}{lll}7 & 32\end{array}$

II. Wappenzeichnung

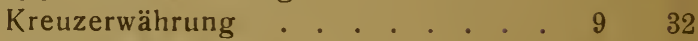

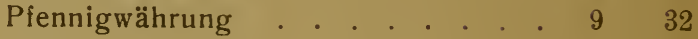

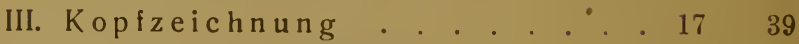

Luitpold-Ausgabe. . . . . . $17 \quad 39$

Markenheftchenbogen . . . . . 1861

Erinnerungsmarken . . . . . 1962

Ludwig-Ausgabe . . . . . . . . . . 1964

Markenheftchenbogen . . . . . . $21 \quad 82$

.,Volks st a a t" - Ausgabe . . . . . . 2064

"Freista a t"-Ausgabe . . . . . . . 2064

Wohltätigkeits-Marken . . . . . . . 2183

Bayern-Sarre......... . $21 \quad 84$

IV. Bilderzeichnung. . . . . . . . . $21 \quad 85$

Bayerische Ausgabe . . . . . . . $21 \quad 85$

„Deutsches Reich"-Ausgabe . . $22 \quad 85$

V. Germaniazeichnung . . . . . . . $24 \quad 89$

Dienstmarken . . . . . . . . . . . . . 2594

Eisenbahndienstmarken . . . . . . 2509

Allgemeine Ausgaben . . . . . . . $26 \quad 96$

Zahlmarken ... . . . . . . . . . . . . . 2796

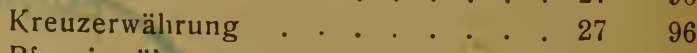

Pfennigwährung. . . . . . . . . . . . 2896

Telegraphenmarken . . . . . . . . . . . . . . . 2999

Silbergroschen-Kreuzerwährung $\quad$ • $\quad . \quad 29 \quad 99$

Pfennigwährung . . . . . . . . . . . .

Telephonbillets . . . . . . . . . . . . $30 \quad 39$

Schlußwort. Statistische Zusammenfassung. . . . 100

Nachweis aller Postwertzeichen Bayerns . . . . . . . 102 


\section{Vorwort.}

Bayern - unerschöpflich in seinen philatelistischen Möglichkeiten, unerschöpflich für den Sammler und Forscher - ist mein Sammelgebiet seit 30 Jahren. Die vorliegende Arbeit möge ein neuer Beitrag sein, von einem anderen als dem allgemein üblichen Standpunkt aus die Postwertzeichen Bayerns $z u$ betrachten, $z u$ sammeln und $z u$ sichten. Mancher Nutzen ist aus dem so gewonnenen Einblick in die Herstellungsweise dieser Marken zı ziehen.

Die Herausgabe des Werkes hat der

\section{Briefmarken-Sammler-Verein Nürnberg E.V.}

anläßlich des 27. Deutschen Philatelistentags und der 19. Tagung des Bundes Deutscher und Oesterreichischer Philatelistenvereine in Nürnberg übernommen. Es ist dem Verein dafür zı danken, daß er erneut wieder die Philatelie in großzügiger und uneigennütziger Weise fördert.

Charlottenburg, Pfingsten 1921.

Wilmersdorferstr. 73.

\section{Dr. Erich Stenger.}

A nmerkung: Sämtliche Katalognummern beziehen sich auf Gebrüder Senfs illustrierten Postwertzeichen$\mathrm{K}$ a talog 1921, soweit nicht anderes bemerkt wurde. 



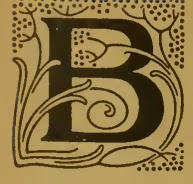

a y e r $\mathrm{n}$ ist für den Briefmarkensammler ein abgeschlossenes Gebiet, seit im Jahre 1920 die bayerische Post an die deutsche Reichspost übergegangen ist. Die letzte Ausgabe bayerischer Briefmarken in Bilderzeichnung erhielt durch den Aufdruck „Deutsches Reich“ Gültigkeit im ganzen Reichspostgebiet, wurde also zu einer Reichspostausgabe. Wenn ich sie dennoch hier behandle, so veranlassen mich neben „drucktechnischen" Gründen (Auflagenummern!) auch „postpolitische“, auf die ich an späterer Stelle eingehen werde.

Literatur. Schon in den Jahren 1911/12 habe ich die Bogeneinteilung und die Auflagenummern der Briefund Portomarken Bayerns bis einschließlich der damals im Verkauf gewesenen Luitpold-Ausgabe behandelt. (Berl. Briefm.-Ztg. 1911 S. 323, 360, 396, 415 und Allgemeiner Anzeiger für Philatelie 1.912.) Andere Darstellungen sind nicht erschienen, nur einzelne Fachzeitschriften (besonders die "Sammler-Woche") meldeten gelegentlich einzelne gerade im Schalterverkauf befindliche Auflagenummern wahllos und ohne Zusammenhang. Ein Versuch Herold's, die Plattennummern der beiden Marken zur 25 jährigen Regentschaft des Prinzregenten Luitpold zusammenzustellen, scheiterte am Materialmangel und brachte nur eine Liste zu tage, die 37 Zusammenstellungen nennen konnte, während ich schon 8 Jahre vorher 54 Verschiedenheiten veröffentlicht hatte. (Sammler-Woche 1920 S. 15 u. S. 86.)

Allgemeines über die Markenausgaben. Bayern war das erste deutsche, Briefmarken verausgabende Land; am 1. November 1849 erschien die älteste deutsche Briefmarke als erste Bayernmarke zu $1 \mathrm{Kr}$. schwarz. In Bezug auf das Markenbild können wir fünf Abschnitte unterscheiden: 
I. Ziffernzeichnung 1849-1866.

II. Wappenzeichnung 1867-1911.

(Kreuzer- und Pfennigwährung.)

III. Kopfzeichnung 1911-1920.

(Luitpold- und Ludwigausgabe, letztere nach der Revolution mit Aufdruck „Volksstaat“ bezw. „Freistaat Bayern“.)

IV. Bilderzeichnung 1920.

(Nach Ubergang der bayerischen Post an das Reich mit Aufdruck „Deutsches Reich“.)

V. Als Zwischenausgabe besonderer Art sind deutsche Germaniamarken mit Aufdruck „Freistaat Bayern" aus dem Jahre 1919 zu nennen.

Die Dienstmarken wurden zuerst als Eisenbahndienstmarken durch Aufdruck bezw. Lochung eines „E“ hergestellt, später ab 1916 kam eine Reihe in Wappenzeichnung zur Ausgabe, welche nach der Revolution den Aufdruck „Volksstaat Bayern“ erhielt und im Jahre 1920 durch eine Ziffernausgabe abgelöst wurde, die nach dem Aufhören der postalischen Selbständigkeit Bayerns mit dem Aufdruck "Deutsches Reich" weiterverwendet wurde.

Die $Z$ ahlmarken erschienen in ihrer ersten Ausgabe in Ziffernzeichnung (1862-1875), später entsprechend den gleichzeitigen Briefmarken in Wappenzeichnung.

Die Telegraphenmarken Bayerns, 1870 in Silbergroschen- und Kreuzerwährung, 1876 in Pfennigwährung verausgabt, sind nur in einer Zeichnung erschienen, darstellend ein eiförmiges Wappenschild mit Umschrift in breitem Bande und Verzierungen. (Ich führe die Telegraphenmarken im Anschluß an die eigentlichen „Post“wertzeichen an, wie sie auch im neuesten Senf-Katalog 1921 die ihnen gebührende Katalogisierung erfahren haben.) 


\section{A. Die Bogeneinteilung.}

Von allen Ausgaben bayerischer Brief-, Dienst-, Zahlund Telegraphenmarken gibt es noch genügende Mengen ganzer Schalterbogen, um die Bogeneinteilung feststellen zu können. Der am Postschalter zum Verkauf gelangende Bogen ist bezüglich der Größe meist nicht gleich dem aus der Druckpresse kommenden Bogen. Um die im zweiten Teil dieser Bearbeitung behandelten Auflagenummern richtig beurteilen zu können, bedürfen wir in vielen Fällen der Kenntnis des Aussehens der

Druckbogen = Bogen, wie sie aus der Druckpresse kommen,

Zähnungsbogen = Bogen, wie sie gezähnt werden, Schalterbogen = Bogen, wie sie zum Schalterverkauf gelangen.

\section{Briefmarken.}

I. Ziffernzeichnung.

1. Ausgabe $1849 / 58$.

2. $" 1862,66$.

Die Schalterbogen enthielten 90 einzelne Marken in der Einteilung:

$$
5 \times 9+5 \times 9
$$

d. h. der Schalterbogen zerfiel in zwei nebeneinanderstehende Bogenhälften, von denen jede 5 Marken nebeneinander in 9 Reihen untereinander enthält (entsprechend der hier gewählten Bezeichnungsweise werden auch die folgenden Angaben gemacht). Die Bogengröße (Seidenfadenpapier, Seidenfaden senkrecht laufend) betrug etwa $280 \times 215 \mathrm{~mm}$. (Auch hier wieder bezieht sich die erste Zahl auf die wagerechte, die zweite Zahl auf die senkrechte Bogenabmessung.)

Die Druckbogen hatten wahrscheinlich ursprünglich die doppelte Größe, enthielten also 180 einzelne Marken und wurden vor der Lieferung an den Schalter 
in zwei Hälften geschnitten. Beide Hälften zu je 90 Stück standen bezüglich der Orientierung der Marken zueinander kopfstehend.
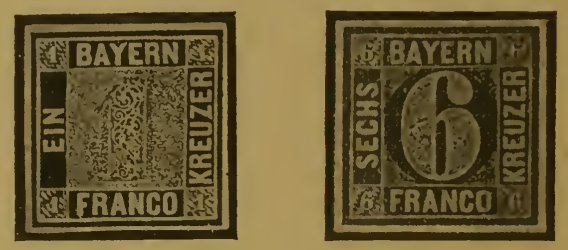

Die erste und zweite Ziffernausgabe Bayerns wurde von den gleichen Druckstöcken gedruckt. Beide Ausgaben unterscheiden sich nur durch die Farbänderung. Die Schalterbogen der ersten Ausgabe, aus zwei Bogenhälften von je 45 Marken bestehend (siehe vorher) weisen zwischen diesen beiden Bogenhälften einen $Z$ wischenraum von durchschnittlich $13^{1} / 2 \mathrm{~mm}$ von Randleiste zu Randleiste gemessen auf; wir können dies an erhalten gebliebenen Originalbogen und an gelegentlich vorkommenden gebrauchten Doppelstücken feststellen, von welchen je eine Marke der einen bezw. der anderen Bogenhälfte angehört. Anfänglich wurde die zweite Ziffernausgabe genau ebenso, also mit unveränderten"Druckstöcken und einem Zwischenraum

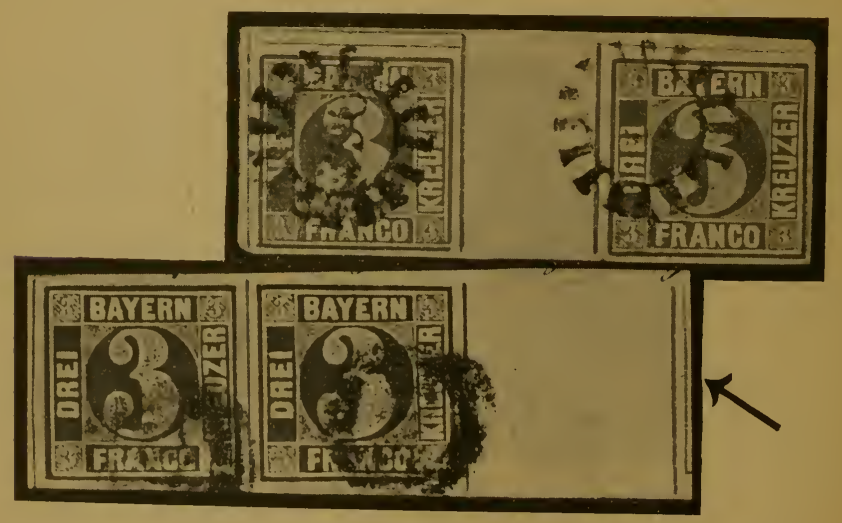

$3 \mathrm{Kr}$. blau $1849 / 58$ mit schmalem Zwischenraum.

$3 \mathrm{Kr}$. rot $1862 / 66$ mit verbreitertem $Z_{\text {wischenraum. }}$ 
der beiden Bogenhälften von ebenfalls etwa $13^{1} / 2 \mathrm{~mm}$ gedruckt. Später wurden die beiden Bogenhälften weiter auseinandergerückt, der $Z$ wischenraum betrug dann etwa $22 \mathrm{~mm}$, wie die Restbestandbogen dieser Ausgabe und entsprechende gebrauchte Stïcke meiner Sammlung beweisen. Diese Ånderung der Abstände beider Bogenhälften bedingte auch eine Ånderung im verwendeten Seidenfadenpapier, in welchem die Seidenfäden so verteilt sein mußten, daß jede senkrechte Markenreihe einen Seidenfaden enthielt.

II. Wappenzeichnung.

Kreuzerwährung:
1. Ausgabe $1867 / 68$
mit Seidenfaden
ungezähnt

$\begin{array}{lll}2 . & \quad 1870 / 73 \\ 3 . & \quad 1875\end{array}$

W. Z. gekreuzte Linien

W.Z. weite wagerechte

Pfennigwährung:

4. Ausgabe 1876/79

Wellenlinien

gezähnt

5.,$\quad 1881$

W. Z. enge senkr. Wellenl.

6. " 1888 u.f.

W. Z. enge wager. Wellenl.

Alle Kreuzerausgaben der Wappenzeichnung und von den Pfennigausgaben diejenigen mit weiten wagerechten und engen senkrechten Wellenlinien als Wasserzeichen (1867-1887) kamen zum Verkauf in Schalterbogen zu 60 Stück in der Einteilung:

$$
5 \times 6+5 \times 6
$$

Die Bogengröße betrug beim Seidenfadenpapier etwa $290 \times 190 \mathrm{~mm}$, beim Wasserzeichenpapier etwa $280 \times 198 \mathrm{~mm}$. Diese Ausgaben sind ursprünglich in Druckbogen zu 120 Stück hergestellt. Die Zähnungsbogen entsprachen den Schalterbogen. Die Bogeneinteilung aller bisher besprochenen Ausgaben läßt erkennen, daß 5 er-Streifen die größten w a ger echten Streifen sind, die ohne freies $Z$ wischenfeld vorkommen können.

Die 1876 vollzogene Währungsänderung brachte den Ubergang vom 60 teiligen Gulden zur 100 teiligen Mark; die bayerische Postverwaltung behielt jedoch die alte Guldeneinteilung mit der Grundzahl 60 in ihren Marken- 
bogen bei und ließ weiterhin dieselben nach Art der alten Kreuzereinteilung herstellen, anstatt Bogen, welche sich mit 100 Einzelmarken dem Dezimalsystem der kursierenden Münze angepaßt hätten, zum Schalterverkauf
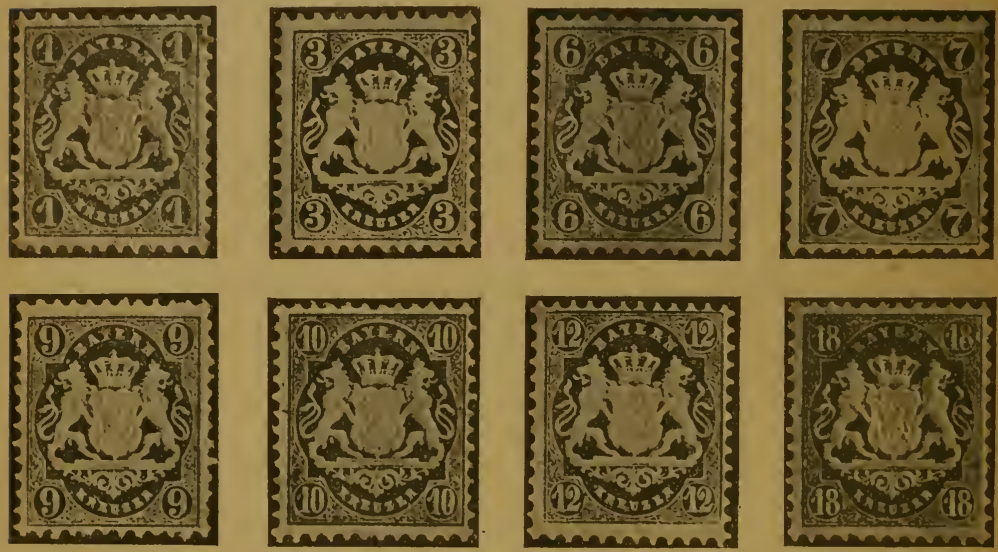

zu bringen. Diese so naheliegende Maßnahme, welche wohl aus Sparsamkeitsrïcksichten unterblieb, hätte den Schalterbeamten eine Unsumme von Arbeit und Berechnungen erspart.
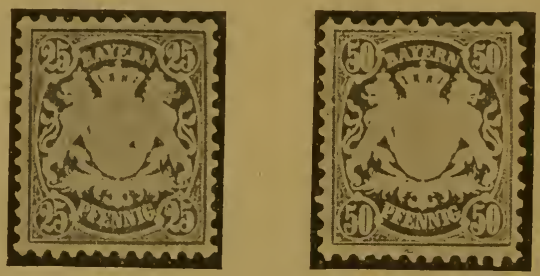

Erst mit der Ausgabe des Jahres 1888 beginnend, gekennzeichnet durch das neue Wasserzeichen: enge wagerechte Wellenlinien, bestanden die Schalterboge n aus 100 Einzelmarken in der Anordnung:

$$
\begin{gathered}
10 \times 5 \\
+ \\
10 \times 5
\end{gathered}
$$

Bogengröße etwa $245 \times 310 \mathrm{~mm}$. Diese Schalterbogen entstanden aus Druckbogen zu 200 Einzelmarken (2 Schalterbogen nebeneinander). Denn die Auflagezahlen, von 
welchen später berichtet wird, befinden sich oben und unten entweder in den rechten oder in den linken Ecken des Schalterbogens. Erst mit der Auflage 37 (1910), welche anfangs in der vorstehend beschriebenen Einteilung gedruckt wurde, kam man der leichteren Abrechnung weiter entgegen. Man teilte die Bogen folgendermaßen ein:

$$
10 \times 10
$$

und setzte auf den oberen Markenbogenrand Reihenwertzahlen, welche den Wert der senkrechten Markenreihen angeben und den Wert des Bogenrestes, von welchem, von rechts her beginnend, senkrechte Markenstreifen abgetrennt wurden, ablesen lassen (entsprechend dem seit Jahren im Deutschen Reich geübten Verfahren und anlehnend an die „Reihenzähler" vieler altdeutscher Ausgaben). Aus maschinentechnischen Gründen entstanden bei dieser Neueinteilung wieder zwei Ausgaben, die erste mit drei dicken Abschlußleisten auf dem unteren Markenbogenrand (wodurch der Markenbogen der jahrelang hergestellten Ausführung an Höhe gleichkam), die zweite mit nur einer unteren Abschlußleiste auf den Bogen etwas geringerer Höhe. (Siehe auch Abb. S. 35).

Einteilung der Schalterbogen der Auflage $37(=1910)$

I.

Oberer Bogenrand unbedruckt, Bogeneinteilung wie seit 1888

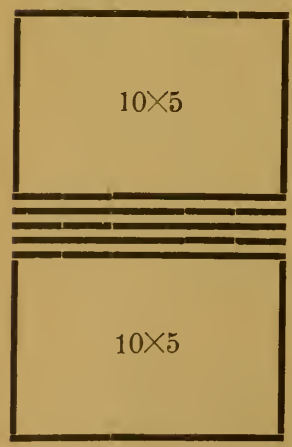

3 Streifen durch die Mitte.

Unterer Rand nicht durchgezäbnt.
II.

Oberer Bogenrand mit Reihenwertzahlen

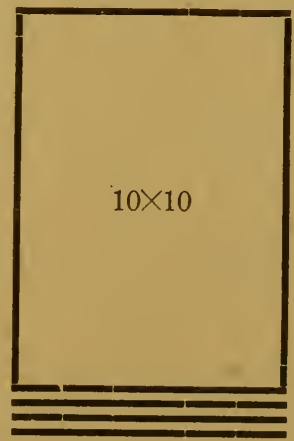

3 Streifen am unteren Rande.

Unterer Rand durchgezähnt.
III.

Oberer Bogenrand mit Reihenwertzahlen

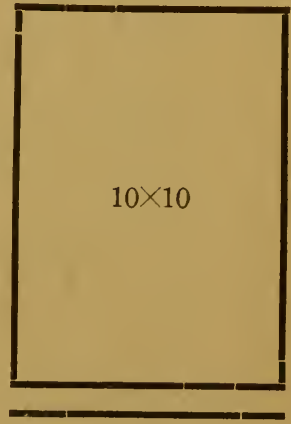

1 Streifen am unteren Rande.

Unterer Rand durchgezähnt. 


\section{Vergleich}

einiger Druckbogen-Arten mit Angabe ihrer Aufteilung in Zähnungs- und Schalterbogen.

1. Ziffern-Ausgaben $1849-66$.
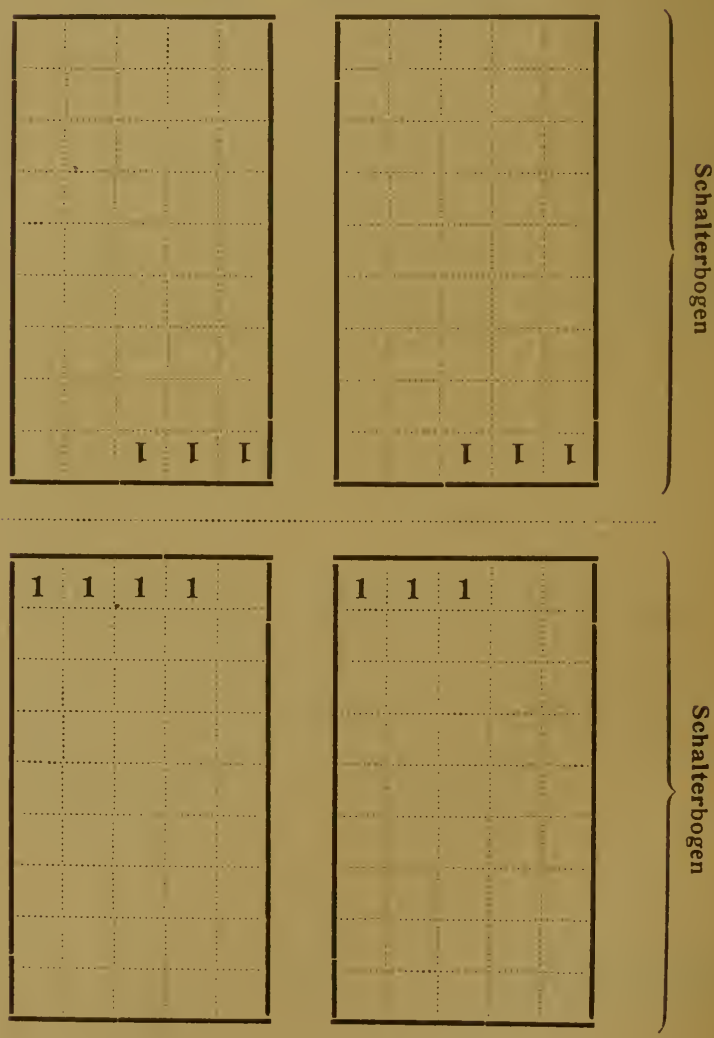
2. Wappenausgabe, Kreuzer- und Pfennig-Währung, 1867-87.
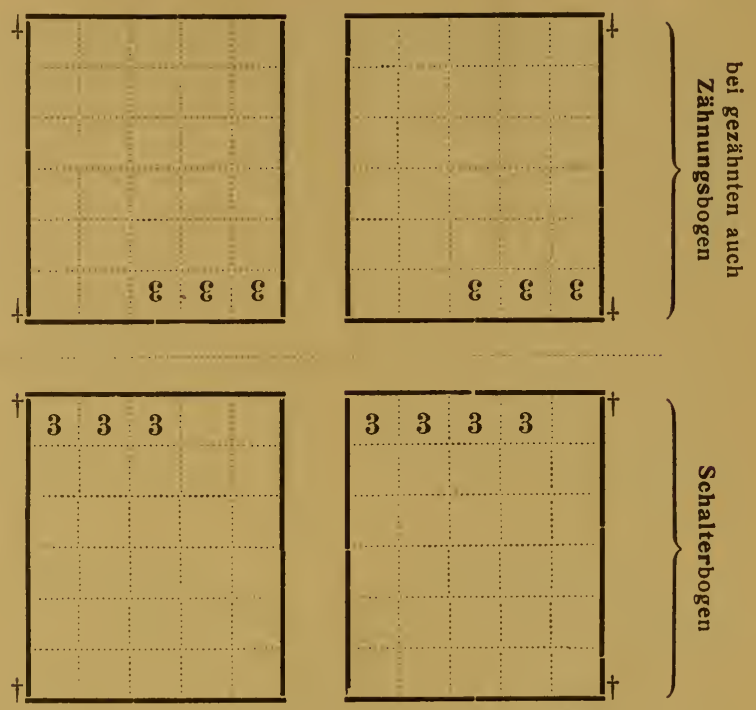

† Stellung der Jahresauflage-Nummern seit 1880.

3. Wappenausgabe (enge wager. Wellen) 1888-1910.
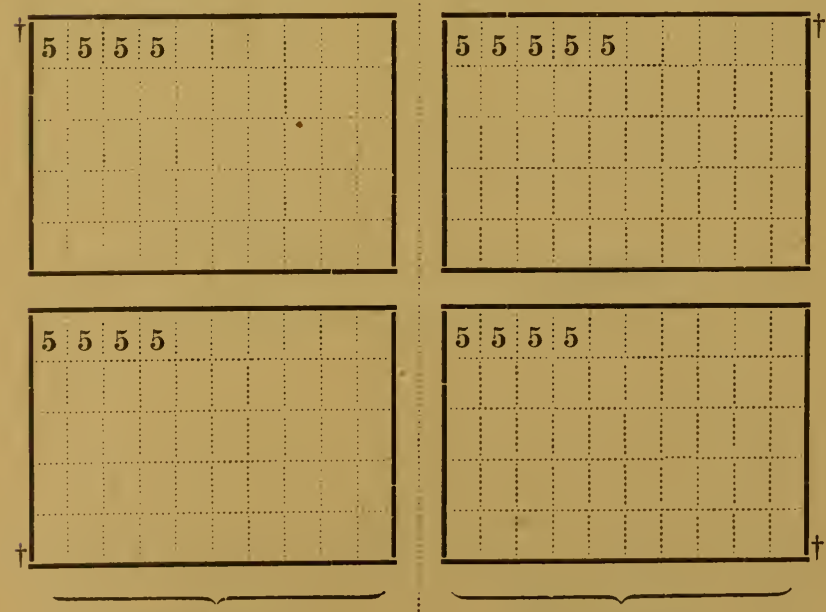

Schalterbogen

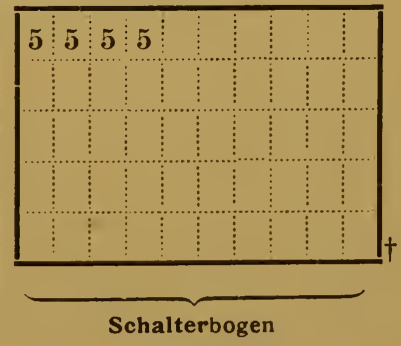

† Stellung der Jahresauflage-Nummern. 
4. Luitpold-Ausgabe, Pfennigwerte, 1911-1914.

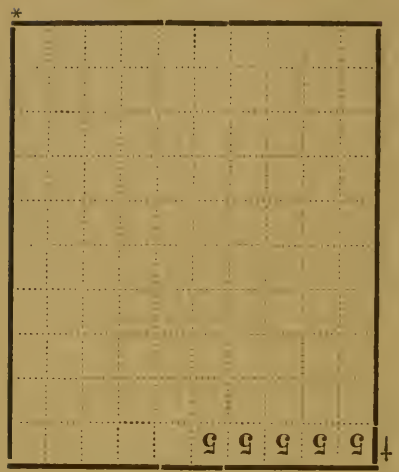

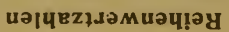

Reihenwertzahlen

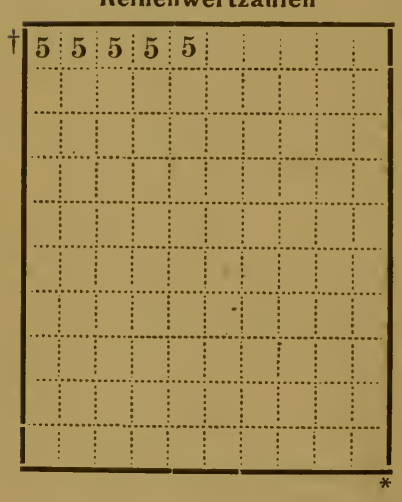

† Stellung der Auflage-Nummern.

* " " Plattennummern.

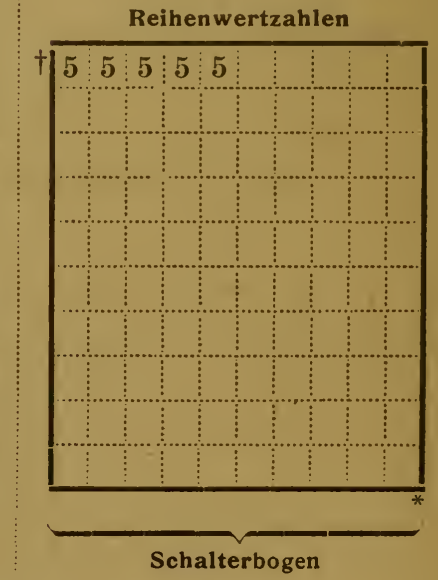

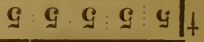

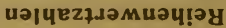

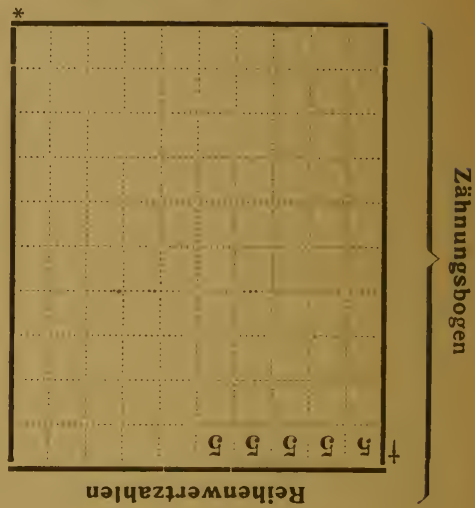

Reihenwertzahlen 
5. Luitpold-Ausgabe, Markwerte, 1911-14.

Druckbogen = Zähnungsbogen.

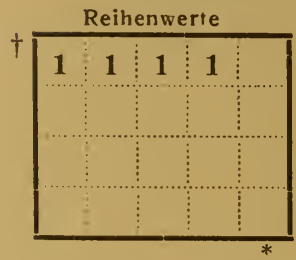

Reihenwerte
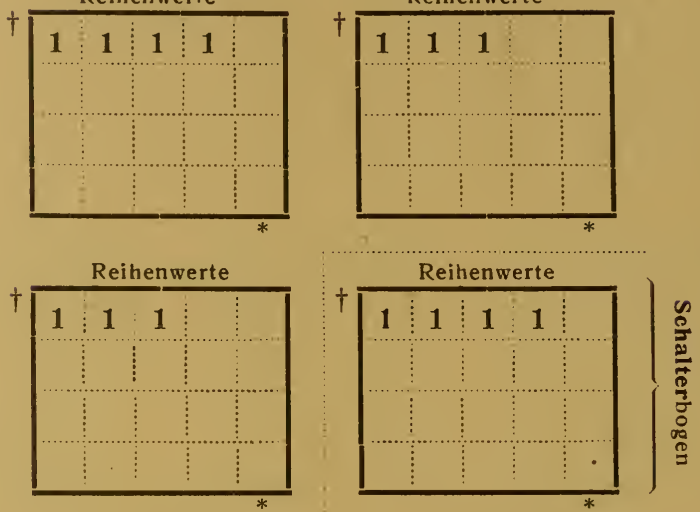

$\dagger$ Stellung der Auflage-Nummern.

* Stellung der Platten-Nummern.

7. Ludwig- und Bilderzeichnung, hohe Markwerte, 1914-21.

Druckbogen = Zälınungsbogen.
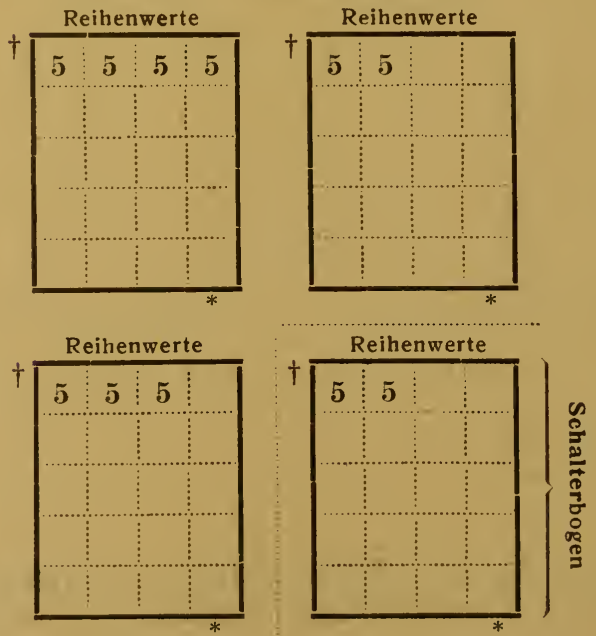

$\dagger$ bei Ludwig-Zeichnung Stellung der Auflage-Nummern.

* Stellung der Walzen- bezw. Platten-Nummern. 
6. Bilderzeichnung, Pfennigwerte, 1920-21.
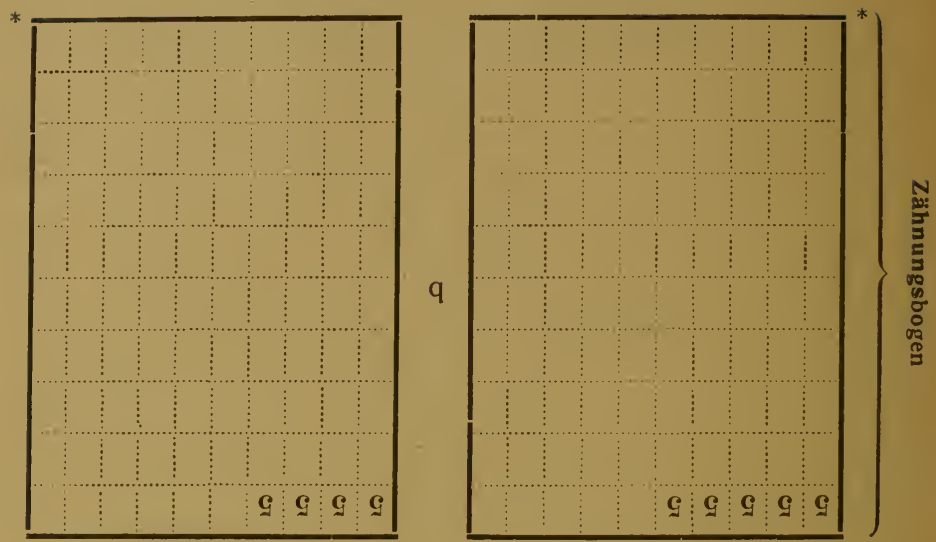

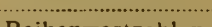

นว५чв+.әмиวч!วу
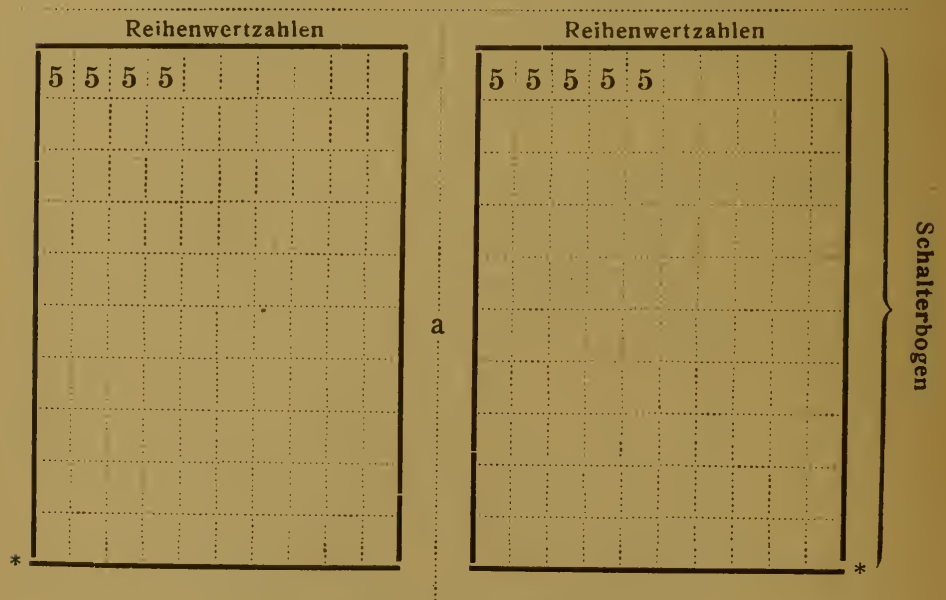

* Stellung der Platten-Nummern.

Anmerkung: Auf die Größenverhältnisse der einzelnen Wertzeichen ist in den Darstellungen keine Riicksicht genommen 
Die Markwerte der Wappenausgaben wurden in Bogen zu 50 Stück zum Schalterverkauf gebracht in der Einteilung

$$
10 \times 5
$$

Bogengröße etwa $285 \times 197 \mathrm{~mm}$ (also die gleiche Bogengröße, welche 60 Stück Wappen-Pfennigmarken aufnahm; das hierzu noch vorrätige Papier wurde nach 1888 zum Druck dieser Markwerte aufgebraucht - Wasserzeichen enge
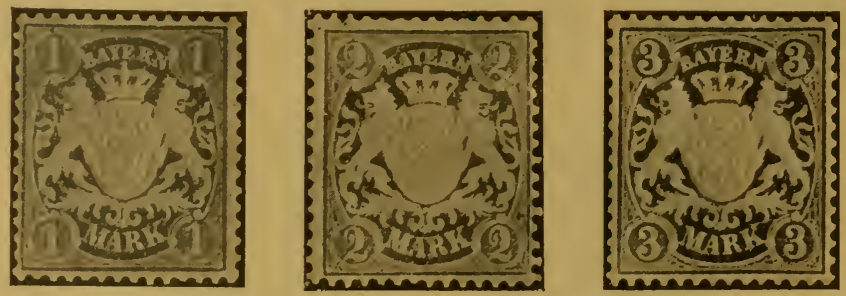

senkrechte Wellen -; erst das Jahr 1911 brachte kurz vor dem Ende der Wappenausgabe eine Neuauflage auf Papier mit wagerechten Wellenlinien - angeblich zum Aufbrauchen von Papiervorräten, welche ursprïnglich für den Druck von Postschecks bestimmt waren.

1II. Kopfzeichnung.

1. Ausgabe 1911 mit dem Bilde des Prinzregenten Luitpold (90. Geburtstag),

2. " 1911, Erinnerungsmarken zur 25jähr. Regentschaft des Prinzregenten Luitpold,

3. „ 1914 mit dem Kopie des Königs Ludwig, ab 1919 vorausgabt mit dem zweizeiligen Aufdruck: „Volksstaat" bezw. „Freistaat Bayern“.

Luitpold-Ausgabe. Die Pfennigwerte 3-25 Pfg. haben kleines, diejenigen von $30-80$ Pfg. größeres Format, Bogeneinteilung

$$
10 \times 10 .
$$

Schalterbogengröße der ersteren etwa $245 \times 295 \mathrm{~mm}$, der letzteren etwa $275 \times 325 \mathrm{~mm}$. Die kleinförmigen Marken sind in großen Bogen zu 400 Stuick gedruckt, die größerförmigen in solchen zu 400 Stück, anfangs allerdings in 
Bogen zu 200 Stück. Das Münzamt konnte nur Bogen zu 200 Stück gummieren und nahm deshalb eine Privatfirma zur Hilfe; gingen die großförmigen gummierten Bogen aus - es wurde nur auf vorher gummiertes
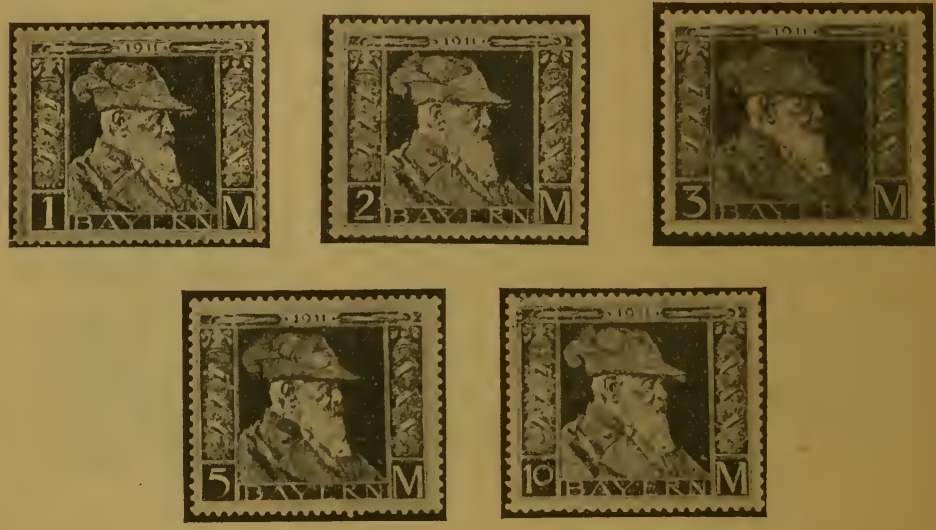

Papier gedruckt - so gummierte das Münzamt selbst die Bogen zu 200 Stück und ließ diese bedrucken. (Sauter, Illustr. Briefm.-Journal 1913, S. 101.) Die Markwerte kamen in Bogen zu nur 20 Stück in den Schalterverkauf in der Einteilung:

$5 \times 4$,

sind jedoch in Bogen vierfacher Größe, also zu 80 Stück, ursprünglich gedruckt. Die Größe des Schalterbogens ist schwankend und beträgt etwa $250 \times 200 \mathrm{~mm}$.

Die Zähnungsbogen der Pfennigwerte enthielten 200 Marken, diejenigen der Markwerte 80 Marken; auf Verlangen wurden derartige unzertrennte Zähnungsbogen an Sammler abgegeben (erstmalig bei dieser Ausgabe!).

Es sind noch zu erwähnen die Bogen, welche zur Herstellung der Briefmarkenheft chen der Luitpold-
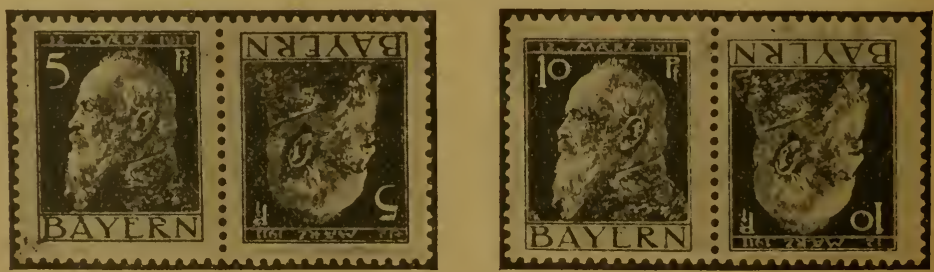
A us g a b e (Berl. Briefm.-Zeitung 1920 S. 226 u. f.) dienten. Entsprechend den kleinförmigen Briefmarkenwerten enthielten auch hier die

$\begin{array}{ll}\text { Druckbogen . . } 400 & \text { Markenfelder } \\ \text { Zähnungsbogen . } 200 \quad " \\ \text { Schalterbogen . . } 100 \quad "\end{array}$

(Bayern hatte von Anfang an diese Bogen zu Sammelzwecken zum Verkauf gestellt). Ich erwähne noch, daß von den 100 Markenfeldern des Schalterbogens 10 Felder $=$ die 4. senkrechte Markenfelderreihe unbedruckt blieben, da sie als Zusammenheftrand der Markenheftchen dienten, und daß die Marken der 8. senkrechten Markenfelderreihe (und der beiden folgenden Reihen) kopfstehend zu den vorhergehenden Reihen angeordnet sind (7. und 8. Reihe $=$ Kehrdrucke).

Erinnerungsmarken zur 25 jährigen Regentschaft. Die am 10. Juni 1911 ausgegebenen beiden Marken zu

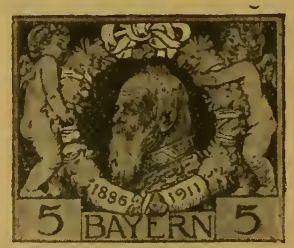

5 und 10 Pfennig hatten nur bis zum 30. Juni 1911 Gültigkeit; es sind Marken mit Kopfzeichnung, jedoch in vollständig anderer Ausführung als diejenigen der gleichzeitigen allgemeinen Ausgabe. Der Schalte rbogen enhielt 50 Stück dieser großförmigen Marken in der Einteilung:

$$
5 \times 10 \text {. }
$$

Bogengröße etwa $250 \times 390 \mathrm{~mm}$; der Druckbogen enthielt 200 Einzelmarken, lieferte also 4 Schalterbogen. Die Zähnung war teils Kamm-, teils Rẹihenzähnung.

L ud wi g-A us g a b e, im Schnellpressentiefdruck (Mezzotinto-Verfahren) hergestellt, auf endloser Papierbahn gedruckt, die Werte 2-80 Pfennig in je 2 Schalterbogen nebeneinanderstehend (Wasserzeichen enge wagerechte 
Wellenlinien). Diese Doppelbogen waren $Z$ ähnungs bogen. Der $S \mathrm{c}$ halt e rbogen bestand aus 100 Einzelmarken

$$
10 \times 10
$$

Bogengröße etwa $240 \times 290 \mathrm{~mm}$.

Die Werte $\mathrm{zu} 1-3 \mathrm{Mark}$ wurden in je 4 Schalterbogen zusammenhängend gezähnt (Wasserzeichen enge senkrechte Wellenlınien). Der $\mathrm{S} c h$ alt e r bogen bestand aus 50 Einzelmarken

$$
10 \times 5
$$

Bogengröße etwa $275 \times 175 \mathrm{~mm}$.

Die Werte zu 5-20 Mark wurden in je 4 Schalterbogen zusammenhängend gezähnt (Wasserzeichen enge wagerechte Wellenlinien). Der Schalterbogen bestand aus 20 Einzelmarken

$$
4 \times 5
$$

Bogengröße etwa $200 \times 235 \mathrm{~mm}$.

Die $Z$ ähnungsbogen der einzelnen Werte wurden auf besonderes Verlangen unzertrennt an Sammler abgegeben. (Siehe auch Abb. S. 66).

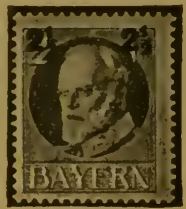

Der zweizeilige Aufdruck „Volksstaat Bayern“ bezw. „Freistaat Bayern“ wurde auf die Zähnungsbogen gesetzt, der Aufdruck „Für Kriegsbeschädigte“ ebenso auf den Zähnungsbogen der entsprechenden Werte. Der Aufdruck ,2 $21_{2}$ “ auf den Marken der Ludwig-Ausgabe zu 2 Pfennig wurde auf dem Schalterbogen zu 100 Einzelmarken angebracht, wobei man je 2 Bogenränder entfernte, um die Markenbogen mit ihren dadurch freiliegenden gezähnten Rändern gleichmäßig in die Druckpresse einlegen zu können und dadurch den Auldruck stets richtig auf die Marken zu bringen. Nur wenige Bogen,. angeblich für den Austausch im Weltpostverein (Bern) bestimmt, 
wurden vierrandig ïberdruckt, doch waren 2 Ränder während der Anbringung des Aufdruckes nach rückwärts umgeschlagen.

Auch in der Ludwig-Ausgabe (ohne Oberdruck!) sind Markenheftchen erschienen (siehe Berl. Briefm.Ztg. 1920 S. 228). Die Zähnungsbogen (wie auch die Druckbogen) enthielten 200 Markenfelder und wurden auf Verlangen zu Sammelzwecken abgegeben. Die allgemein zum Verkauf an Sammler bereit gestellten Bogen

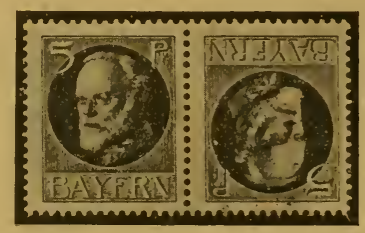

umfaßten entsprechend den normalen Briefmarkenbogen 100 Markenfelder, deren Einteilung (Freilassung zum Zusammenheften, Kehrdrucke) derjenigen der Luitpold-Ausgabe entsprach.

Von den Wohltätigkeitsmarken für Kriegsbeschädigte gilt das Gleiche, was vorher von den Volksstaatund Freistaatmarken gesagt wurde. Die Marken mit dem Kopf des Königs Ludwig, wie auch die verschiedenen Aufdrucke auf denselben, wurden von der Firma Bruckmann in München hergestellt.

Der Aufdruck „Sarre" auf den im Saargebiet verwen'deten Postwertzeichen der Ludwig-Ausgabe wurde in Saarbrücken auf die einzelnen Schalterhogen aufgedruckt. Auch hier wurden je 2 Bogenränder nach rückwärts umgeklappt, um den Aufdruck möglichst gleichmäßig auf die Marken setzen zu können.

IV. Bilderzeichnung.

1. Ausgabe 1920 mit verschiedenen Zeichnungen (sog. Abschiedsausgabe).

2. „ 1920 ebenso, jedoch mit zweizeiligem Aufdruck „Deutsches Reich“.

Schon in den einleitenden Worten habe ich darauf hingewiesen, daß Bayern in streng philatelistischem Sinne 
ein abgeschlossenes Sammelgebiet ist, nachdem die bayerische Post im Jahre 1920 in der deutschen Reichspost aufgegangen ist. Andererseits ist es naheliegend (ich möchte sagen: selbstverständlich), daß der Sondersammler baye-

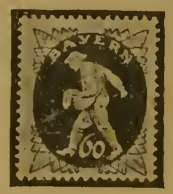

rischer Postwertzeichen die in Bayern auch nach dem Aufhören der Selbständigkeit der bayerischen Post nur für Bayern gedruckten Wertzeichen weiterverfolgt und als letzte Uberreste und Beweisstücke des ehemaligen Postreservatrechtes Bayerns im Anschluß an die eigentlichen bayerischen Wertzeichen sammelt. Diese Ausgaben stehen naturgemäß im engsten Zusammenhang mit ihren Vorgängern :

Das gleiche Markenbild wurde beibehalten, nur der Aufdruck „Deutsches Reich" weist auf die Gültigkeit im ganzen Reich hin.

Die Herstellung der Marken blieb in Bayern, die Aufdruckmarken sind teils solche der ersten Auflage, der man nachträglich den Aufdruck gab (Aufbrauchsausgabe!), teils neue Auflagen, welche sich durch die Auflagenummern nachweisbar an die zuerst ohne Aufdruck Verausgabten anschließen.

Diese Marken waren zum Verkauf an b a y e ris chen Postschaltern bestimmt. Daß sie gelegentlich auch an außerbayerischen Schaltern verkauft wurden (Postnachrichtenblatt des Reichspostministeriums 1920 S. 589) und daß die Briefmarken-Verkaufsstelle in Berlin auch diese Marken auf Bestellung an Sammler liefert (Nachrichtenblatt des Reichspostministeriums Abtlg. München 1921 S. 123), nimmt dieser Ausgabe keineswegs ihren rein bayerischen Charakter. Denn der Schalterverkauf an nichtbayerischen Orten hatte seine Ursache nur in der Not der Berliner Reichsdruckerei, welche nicht in der 
Lage ist, den Gesamtbedarf Deutschlands an Briefmarken und Ganzsachen einstweilen zu decken, sodaß Bayern im Anfang des Jahres 1921 sich zur Selbsthilfe gezwungen sah, seinen kaum unterbrochenen Marken- und Ganzsachendruck aufs neue in Betrieb zu setzen.

Ich glaube, daß diese Gründe ,drucktechnischer und postpolitischer Art" es als selbstverständlich erscheinen lassen, daß im Rahmen der vorliegenden Arbeit auch die bayerischen Marken mit Aufdruck „Deutsches Reich“ besprochen werden. Auch der Senf-Katalog 1921 vertritt diesen Standpunkt und führt diese „Deutsches Reich“marken unter Bayern auf.

Die Pfennigwerte der Bilderausgabe (Wasserzeichen enge wagerechte Wellenlinien, Senf-Katalog Nr. 178-186, bezw. 195-204) sind in Buchdruck hergestellt und in Bogen zu 400 Stück gedruckt. Die Größe dieser Druckbogen beträgt etwa $585 \times 480 \mathrm{~mm}$. Die Anordnung der diese Druckbogen bildenden 4 Einzelbogen von je 100 Stück ist folgende:

$$
\begin{array}{ccc}
001 & \mathrm{e} & 00 \mathrm{l} \\
100 & \mathrm{~b} & 100
\end{array}
$$

sodaß also je 2 Bogen nebeneinander mit den Kopfleisten (Reihenwertzahlen) kopfstehend zusammenhängen.

Die $Z$ ähnungsbogen entstehen durch wagerechte Teilung der Druckbogen und enthalten 2 Einzelbogen nebeneinander:

$$
100 \text { a } 100 \text { oder } 100 \text { b } 100
$$

Diese Bogen werden senkrecht geteilt und gelangen als Schalterbogen von

zum Verkauf.

$$
10 \times 10
$$

Die Werte zu 1 bis $2^{1} / 2$ Mark (Wasserzeichen enge senkrechte Wellenlinien, Senf-Katalog Nr. 187-190, bezw. 205-209) sind ebenfalls in Buchdruck, jedoch zweifarbig hergestellt (nur den Wert zu $2^{1} / 2$ Mark gibt es ohne und mit Aufdruck in Steindruck) und in Bogen der Größe von etwa $545 \times 360 \mathrm{~mm}$ zu 200 Stück gedruckt und gezähnt. 
Zum Schalterverkauf gelangen Bogen mit 50 Einzelmarken: $10 \times 5$.

Die Werte zu 3 bis 20 Mark (Wasserzeichen enge wagerechte Wellenlinien, Senf-Katalog Nr. 191-194 bezw. 210-214) sind ebenfalls in Buchdruck hergestellt und entsprechen in der Anordnung der Druck-, Zähnungs- und Schalterbogen den Markenwerten 5-20 Mark der vorher besprochenen Ludwig-Ausgabe.

Alle diese Angaben zur Bilderausgabe beziehen sich übereinstimmend auf die Ausgaben ohne und mit Aufdruck „Deutsches Reich“. Die Zähnungsbogen beider Ausgaben wurden auf besonderes Verlangen unzertrennt an Sammler abgegeben. (Siehe auch Abb. S. 88).

V. Germania-Zeichnung.

Während der Räteregierung in München im Mai 1919 konnte das Verlagsamt der bayerischen Post in München das übrige Bayern nicht mit Postwertzeichen versorgen. Man wandte sich um Hilfe an die Reichsdruckerei, welche damals noch nicht so überlastet war, wie nach der Ubernahme der gesamten bayerischen Post im Jahre 1920. Die Reichsdruckerei.stellte zuerst 13 Werte her, indem sie vorrätige Marken der Germania-Ausgabe mit dem zwei-

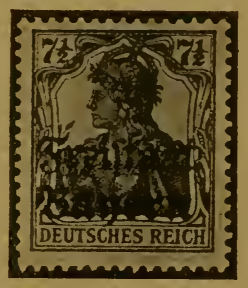

zeiligen Aufdruck: „Freistaat Bayern“ versah. Vier dieser Werte $\left(2^{1} / 2,5,7^{1} / 2,10\right.$ Pfennig) gelangten am 18. Mai in der Rheinpfalz zur Ausgabe. Die Hauptmenge dieser Marken, ergänzt durch eine zweite, drei weitere Werte enthaltende Auflage (jedoch ohne die Werte $2^{1} / 2,7 \frac{1}{2}$ und 10 Pfennig), um allen Sammlerbedürfnissen gerecht werden zu können, wurde erst im Herbste des Jahres 1919 in ganz 
Bayern zum Schalterverkauf gegeben. (Einzelheiten über diese beiden Druckauflagen sind bei der später folgenden Bearbeitung der Auflagenummern zu finden).

Die Germania-Marken wurden in einzelnen $S$ chalterbogen (bei den Pfennigwerten 100, bei den Markwerten 20 Einzelmarken enthaltend) überdruckt, es wurden mehrere Aufdruckplatten verwendet (für die Pfennigmarken 6, für die Markmarken 3-4 Platten).

\section{Dienstmarken.}

Die Bogeneinteilung der Dienstmarken Bayerns schließt sich eng an die jeweilig gleichzeitige Briefmarkenausgabe an.

Für die kgl. bayerische E is e $\mathrm{nb}$ a h n-Verwaltung:

Die 1908 verausgabten Wap pen marken mit Aufdruck „E“ (Senf-Katalog Nr. 1-5) sind in Schalterbogen zu je 100 Stück überdruckt.

Die 1912 verausgabten Luitpold marken mit eingelochtem „E“ (Senf-Katalog Nr. 6-11) sind in Schalterbogen zu je 100 Stück (und zwar querreihenweise) durchlocht. Je 2 Bogenränder wurden vor der Lochung abgerissen, um die Bogen gleichmäßig in die Lochungsvorrichtung einlegen und gleichmäßige, richtigstehende Lochung erreichen zu können.

Die 1914/15 verausgabten $\mathrm{Ludwigmarken}$ mit eingelochtem „E“ (Senf-Katalog Nr. 12-15) wurden ebenso hergestellt wie die entsprechenden Luitpold-E-Marken.

Das gleiche ist festzustellen von den im Senf-Katalog 1921 anschließend an die Eisenbahndienstmarken aufgeführten gelochten Marken für Kriegsbe schädigten-Ausschüsse (,K“), für den staatlichen Lastkraftwagenverkehr (,LK“), für B e a m tenräte (,R“) und für Betriebsräte (,B“, nicht katalogisiert), die es in den Ausgaben

Ludwig-Freistaat Bilderzeichnung und gibt. Deutsches Reich 


\section{$-26-$}

Die Allgemeine A usgabe der Dienstmarken (1916-19 und dann mit Aufdruck ,Volksstaat Bayern“, Senf-Katolog Nr. 16-43, Buchdruck) sind vermutlich in Bogen zu 200 Stück gedruckt und gezähnt

$$
\begin{aligned}
& \frac{0}{x} \\
& \underline{x} \\
& 0
\end{aligned}
$$

Ich schließe dies daraus, daß ich einen Bogen sah, bei welchem am unteren Bogenrande die Reihenwertzahlen des unten sich anschließenden Bogens infolge geringer Fehlschneidung zu sehen waren, es müssen also in der Druckplatte 2 Schalterbogen übereinander stehen. Alle Schalterbogen, die ich sah, zeigten stets den linken Bogen-

rand durchgezähnit, was auch auf die oben gezeigte Druckanordnung hinweist (nur 2 Bogen sah ich, bei welchen wohl durch zufällig unrichtiges Einlegen in die Zähnungsvorrichtung der rechte Seitenrand durchgezähnt war, nämlich Senf Nr. 27 und 36.) Ich glaube nicht, daß diese Marken in Zähnungsbogen an Sammler abgegeben worden sind. Der Schalterbogen besteht aus 100 Einzelmarken

$$
10 \times 10 \text {. }
$$

Der Aufdruck „Volksstaat Bayern“ wurde anfangs zum Aufbrauch der Schalterhogenvorräte auf die Schalterbogen mit je 100 Einzelmarken gesetzt (auch hier wurden 2 Bogenränder abgerissen, um die Bogen in die Aufdruckpresse genau passend einlegen zu können), später auf die Doppelbogen zu 200 Einzelmarken.

Druck und Aufdruck stammen aus der Druckerei des bayerischen Hauptmünzamtes. 
Die allgemeine Wappenausgabe wurde im Jahre 1920 durch die sogenannte Abschiedsausgabe in verschiedenen Ziffernzeichnungen abgelöst, welche nach Ubergang der bayerischen Post an das Reich mit einem zweizeiligen Aufdruck „Deutsches Reich“" weiterverwendet wurde. (Senf-Katalog Nr. 44-61, bezw. 62-79). Diese in Buchdruck hergestellte Ausgabe ist bezüglich der Bogeneinteilung in Pfennigwerte (5-90 Pfennig) und Markwerte (1-5 Mark) zu trennen.

Bei den Pfennigwerten enthält der Druckbogen 400
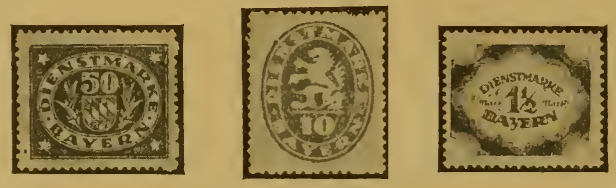

Marken und entspricht in seiner Anordnung genau den Druckbogen der Pfennigwerte der Bilderausgabe. Bei den Markwerten wiederholt sich die Bogeneinteilung der Werte zı $1-2^{1}{ }_{2}$ Mark der Bilderausgabe, der Druckbogen besteht also aus 200 Einzelmarken $=4$ Schalterbogen zu je 50 Marken (vielleicht bei der 1. Auflage nur aus 100 Marken $=2$ Schalterbogen zu je 50 Marken, weil die Auflagenummer 1 stets nur links gefunden wird).

Der Uberdruck „Deutsches Reich“ wurde vermutlich den Zähnungsbogen gegeben. Druck und Aufdruck dieser Dienstwertzeichen stammt aus der bayerischen ,Münze“.

\section{Zahlmarken.}

I. Zifferzeichnung.

1. Ausgabe 1862, 3 Kreuzer schwarz, ungezähnt, mit Seidenfaden. Entsprechend der Briefmarkenziffernausgabe gelangten Bogen zu 90 Stück Einzelmarken (Druckbogen doppelt so groß) zum Schalterverkauf. Bogeneinteilung:

$$
\begin{gathered}
9 \times 5 \\
+ \\
9 \times 5
\end{gathered}
$$


Seidenfaden wagerecht laufend, da das Papier der ersten Briefmarkenausgaben verwendet, die Marken aber, da hochförmig, auf die Bogen querstehend gedruckt wurden (man vergleiche die Bogeneinteilung der Ziffernbriefmarken und

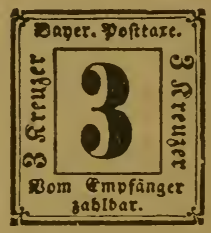

der ersten Portomarke:

$$
5 \times 9+5 \times 9 \text { und } \stackrel{20}{x}_{\sigma}^{20} \underset{\sigma}{x} \text {. }
$$

Bogengröße entsprechend den Ziffernbriefmarkenausgaben.

2. Ausgabe 1870,1 und 3 Kreuzer gezähnt, Wasserzeichen gekreuzte Linien. Die gezähnten Kreuzerportomarken auf Wasserzeichenpapier entsprechen den Kreuzerbriefmarken der Wappenausgabe auf Wasserzeichenpapier in Größe, Einteilung und Druckanordnung.

II. W a p penzeichnung.

Die Zahlmarken der Wappenausgabe in Pfennigwährung sind durch zweizeiligen roten Uberdruck

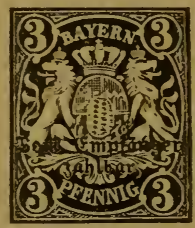

„Vom Empfänger zahlbar“

und Farbänderung aus den gleichzeitigen Wappenbriefmarken entstanden und nachweislich mit den gleichen Druckplatten gedruckt, entsprechen also in Bezug auf Bogeneinteilung diesen. Ich verweise deshalb auf die vorher gemachten Angaben. 


\section{Telegraphenmarken.}

Die Telegraphenmarken Bayerns zerfallen in die Silbergroschen-Kreuzer-Ausgabe von 1870 (Senf-Katalog Nr.1-8) und in die Pfennig-Mark-Ausgabe von 1876 (Senf-Katalog Nr. 9-25).

Vermutlich enthielt bei der 1. Ausgabe (Wasserzeichen "Schlingen") der

\section{Druckbogen 2 Schalterbogen}

in zu einander kopfstehender Anordnung.

Der Schalterbogen bestand aus

$$
4 \times 4+4 \times 4
$$

Marken $^{1}$ ) und wurde auch in dieser Größe gezähnt.

Es dürften keine Bogen, nicht einmal Bogenteile dieser Ausgabe sich in Sammlerhänden befinden.

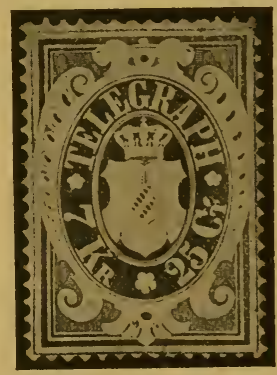

Die zweite Ausgabe (Wasserzeichen „Wellenlinien“) wurde in größeren Druckbogen hergestellt, bestehend wie vorher aus je 2 kopfstehend zu einander angeordneten Schalterbogen, deren jeder

$$
4 \times 5+4 \times 5
$$

Einzelmarken enthielt. Es finden sich noch große Bogenbestände dieser Ausgabe aus einem etwa 1880 erfolgten Verkauf der Restbestände unter Nennwert.

Von der 2. Ausgabe wurden einzelne Werte in ganz kleinen Mengen vermutlich zu Anfang des Drucks auf den Papierrestbeständen der 1. Ausgabe gedruckt. Da diese

1) Auch die ältesten „Gebührenmarken“ warén zu $4 \times 4$ Stǘck gedruckt. 
Bogen das Wasserzeichen „Schlingen" nur in" vier Reihen enthielten, die 2. Ausgabe entgegen der 1. Ausgabe jedoch aus 5 wagerechten Markenreihen bestand, so zeigt die 5. Markenreihe dieser sehr seltenen Ausgabe kein Wasserzeichen. (Senf-Katalog Nr. 9-15, A bezw. B.)

Die "Telephon-Billets" Bayerns zur Verrechnung der an öffentlichen Fernsprechstellen der Postämter usw. geführten Gespräche sind in Bogen zu 10 Scheinen:

$$
2 \times 5
$$

gedruckt und ebenso teils ungezähnt, teils gezähnt aın Schalter verwendet worden.

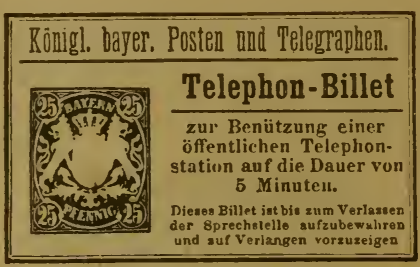




\section{B. Die Auflagenummern.}

Das Sammeln von Auflagenummern wurde von allen einsichtigen Sondersammlern seit vielen Jahren eifrig gepflegt und als eine der wichtigsten Forschungsquellen der neuzeitlichen Briefmarkenkunde erkannt. Die Bearbeitung neuerer Postwertzeichenausgaben kann nur auf dieser Grundlage erfolgen, soweit uns die einzelnen Ausgaben die Handhabe zu dieser grundlegenden Katalogisierungsmöglichkeit liefern. Ich selbst habe in meinem bayerischen Arbeitsgebiete stets die Auflagenummern berücksichtigt, und auch andere deutsche Gebiete sind von mir (Kriegsmarken, deutsche Kolonien) und anderen auf dieser Grundlage behandelt worden. Es erscheint unbegreiflich, wenn von irgendwelcher Seite der philatelistische Wert der Auflagenummern zu leugnen versucht wird.

Das Sammeln derartiger Auflagenummern, die zumeist als Kontrollnummern der Druckerei entstanden sind, ist anregend, während der Kurszeit der einzelnen Ausgaben verhältnismäßig einfach; bei einiger Ausdauer läßt sich eine lückenlose Sammlung gewinnen; der Versuch, sie späterhin einmal zusammenzubringen, ist wenig aussichtsreich. Dabei sind die Kosten bei rechtzeitiger Beschaffung núr entsprechend dem Nennwerte. Da die wirtschaftlichen Verhältnisse den meisten ernsten Sammlern die Möglichkeit nehmen, große Aufwendungen für ihre Sammlung zu machen, sei auch in dieser Richtung auf dieses wichtige, befriedigende und dabei billige Sammelgebiet hingewiesen.

Die Bedeutung der „Auflagenummern“ der Wertzeichen Bayerns ist ursprünglich die Angabe des Druckjahres. Die Auflagenummer ermöglicht also ohne weiteres, Farben-, Papier-, Zähnungs- und andere Unterschiede einwandfrei zeitlich richtig zu katalogisieren. Die Auflagenummern der bayerischen Wertzeichen befinden sich an den Bogenecken 
auf dem Bogenrandpapier, sodaß bei Bayern eine gleichförmige Sammlung von Bogeneckstücken oder Bogeneckviererblocks möglich ist. Die Auflagenummer als ,Jahrzahl" wurde ein Jahr lang beim Drucke beibehalten und findet sich in allen während des Jahres vorgekommenen Farbenschwankungen der einzelnen Werte. Erst bei den neuen Ausgaben ab 1911, bei welchen vom seither geübten Buchdruckverfahren zur Herstellung der Wertzeichen abgegangen wurde, finden wir eigentliche „A ufla g e nummern" (auf der linken oberen Bogenrandecke) und diesen untergeordnet "Plattennummern" (meist auf der rechten unteren Bogenrandecke), sodaß z. B. die „Auflagen“ 1, 2 oder 3 je in zahlreichen "Platten“ vorkommen können.

Die Bayern-Marken in Bilderzeichnung ab 1920 zeigen wieder in der linken oder rechten oberen oder unteren Bogenecke Druckauflage-Nummern, ebenso die gleichzeitigen Dienstmarken der Ziffernausgabe. Diesem allgemeinen Uberblick folgen die Einzelangaben bei Beschreibung der einzelner Ausgaben.

\section{Briefmarken.}

\section{I. $Z$ iffernzeichnung.}

Es gibt keine Briefmarkenbogen der Ziffernzeichnung, welche Auflagenummern tragen. Die einzelnen Markensorten wurden wohl jeweils nach Bedarf gedruckt. Daß bei der zweiten Ziffernausgabe eine Umordnung der Druckstöcke stattfand, wurde im ersten Teil dieser Arbeit bewiesen.

$$
\text { II. Wappenz e ichn ung. }
$$

Die Briefmarken in Kreuzerwährung haben keine Auflagenummern als Bogenkennzeichen. Erst nach Einführung der Pfennigwährung findet man Auflagezahlen auf den Bogenecken, welche, wie im folgenden dargelegt, die Angabe des Druckjahres bedeuten. Am 15. August 1874 wurde der Briefmarkenwert zu 1 Mark violett ungezähnt verausgabt. Die Markenbogen aus dem Jahre 1874 würden die Auflagezahl 1 tragen, wenn damals diese Bezeichnungs- 
weise schon eingeführt worden wäre; demnach ist:

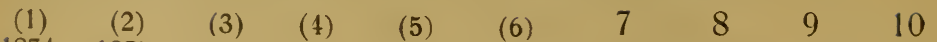
$\begin{array}{llllllllll}1874 & 1875 & 1876 & 1877 & 1878 & 1879 & 1880 & 1881 & 1882 & 1883\end{array}$

$\begin{array}{llllllllll}11 & 12 & 13 & 14 & 15 & 16 & 17 & 18 & 19 & 20\end{array}$
$\begin{array}{llllllllll}1884 & 1885 & 1886 & 1887 & 1888 & 1889 & 1890 & 1891 & 1892 & 1893\end{array}$ $\begin{array}{llllllllll}21 & 22 & 23 & 24 & 25 & 26 & 27 & 28 & 29 & 30\end{array}$ $\begin{array}{llllllllll}1894 & 1895 & 1896 & 1897 & 1898 & 1899 & 1900 & 1901 & 1902 & 1903\end{array}$

$\begin{array}{lllllll}31 & 32 & 33 & 34 & 35 & 36 & 37\end{array}$

$1904 \quad 1905 \quad 1906 \quad 1907 \quad 1908 \quad 1909 \quad 1910$.

Die kleinste von mir bisher gefundene Auflagezahl ist 7 auf einem Bogen der Marke 3 Pfennig, grün mit weiten Wellenlinien, Ausgabe 1876, gedruckt 1880 (=7). Wahrscheinlich ist erst im Jahre 1880 mit dieser Nummerierung begonnen worden ${ }^{1}$ ). (Bei den Ganzsachen setzt

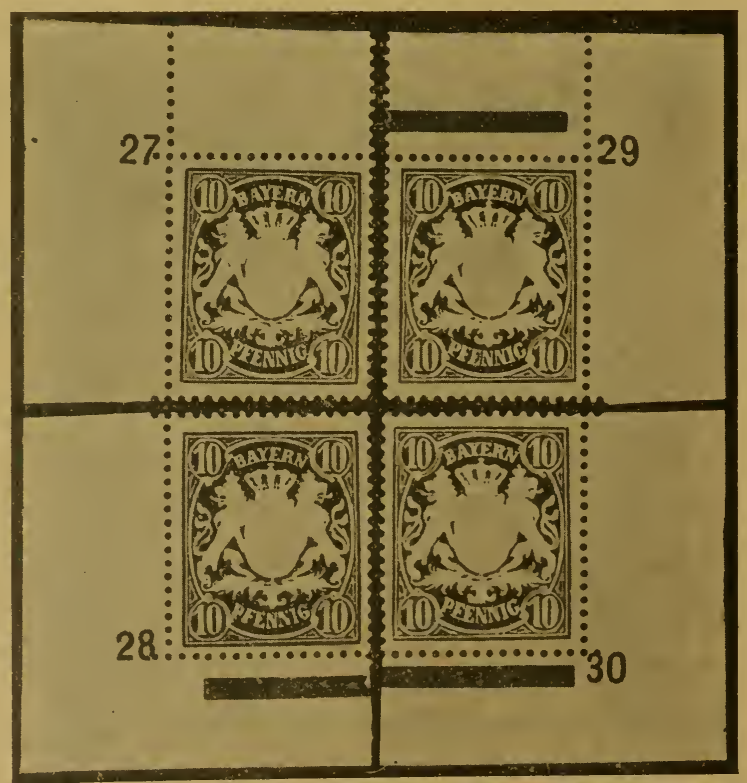

Vier Bogenecken mit Auflage-Nummern von vier aufeinanderfolgenden Auflagen.

1) Für jede, selbst die kleinste Berichtigung und Ergänzung ist der Verfasser (Charlottenburg 4, Wilmersdorfer Straße 73) dankbar. 
die Jahreszahlangabe erst im Jahre 1887 ein.) Die den Restbeständen entstammenden ganzen Bogen der Briefmarken 5 Pfennig blaugrün und 50 Pfennig ziegelrot (1876-1879) trugen keine Auflagezahl.

Im Folgenden gebe ich eine Liste der Auflagenummern der Wappenausgabe seit 1880 (Druckjahr = Auflagenummer 7). Die Katalognummern beziehen sich auf Senfs Postwertzeichenkatalog 1921. Die Tabellen sind so gedruckt, daß sie auch als Fehlliste verwendet und in Bezug auf etwa nicht aufgefïhrte Auflagenummern leicht ergänzt werden können.

1.

Die Schalterbogen der folgenden Pfennigwerte enthalten 60, der Markwerte 50 Einzelmarken (siehe über Bogeneinteilung vorher!). Die 'Auflagenummern befinden sich auf den vier Bogenecken. Gelblich-rötliches Papi er.

\begin{tabular}{|c|c|c|c|c|}
\hline $\begin{array}{l}\dot{Z} \\
\dot{\pi} \\
\end{array}$ & Wertbezeichnung & 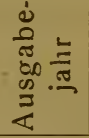 & 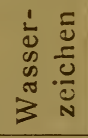 & $\begin{array}{l}\text { Vorkommende } \\
\text { Auflagenummern }\end{array}$ \\
\hline $\begin{array}{l}30 \\
31 \\
37 \\
38 \\
39 \\
40 \\
41 \\
4.2 \\
43 \\
44 \\
45 \\
46 \\
47 \\
45 \\
49 \\
50 \\
51 \\
52 \\
53\end{array}$ & 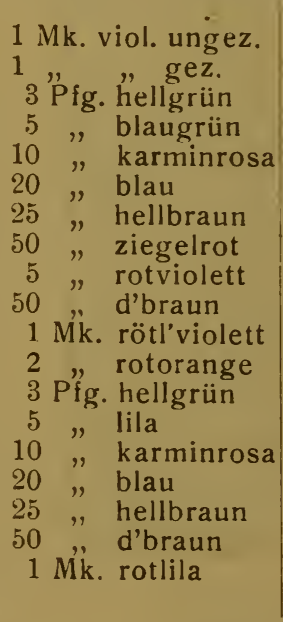 & $\begin{array}{c}1874 \\
1875 \\
1876 \\
" \\
" \\
" \\
" \\
1879 \\
" \\
" \\
1881 \\
" \\
" \\
" \\
"\end{array}$ & 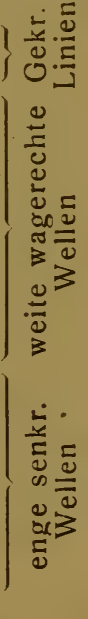 & 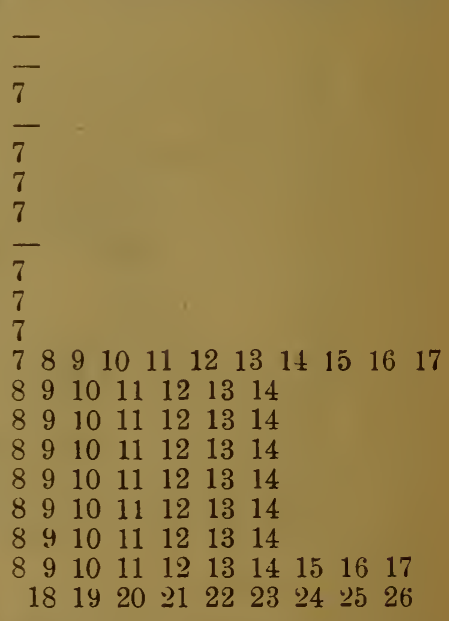 \\
\hline
\end{tabular}

Anmerkung. Die Werte 5 und 10 Pfennig der Auflage 14 sind in Blinddruck (farbloser Reliefdruck), der Wert zu 3 Pfennig in Auflage 13, zu 10 Pfennig in Auflage 14 ungezähnt bekannt. 
Die Schalterbogen der folgenden Pfennigwerte enthalten 100, der Markwerte 50 Einzelmarken (siehe über Bogeneinteilung vorher!). Die Auflagezahlen befinden sich auf je 2 Bogenecken rechts oder links. Bis einschließlich Auflage 26 gelblich-rötliches Papier. Die seltene enge $Z$ ähnung kommt in einem Teil der Auflage 15 vor.

\begin{tabular}{|c|c|c|c|c|}
\hline 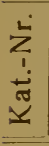 & Wertbezeichnung & 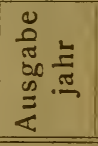 & 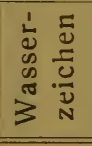 & $\begin{array}{l}\text { Vorkommende } \\
\text { Auflagenummern }\end{array}$ \\
\hline 54 & $3 \mathrm{Pfg}$. hellgrün & 1888 & & 1516 \\
\hline 55 & j , lila & $"$ & & 1516 \\
\hline 56 & 10, karminrosa & $n$ & $=$ & 151617181920212223242526 \\
\hline 57 & 20 , blau & ", & & 151617181920212223242526 \\
\hline 58 & 25, hellbraun & $"$ & $=$ & 1516 \\
\hline 59 & 50 d'braun & & & 1516 \\
\hline 60 & 3 , braun & 1890 & 33 & $\begin{array}{llllllllll}17 & 18 & 19 & 20 & 21 & 22 & 23 & 24 & 25 & 26\end{array}$ \\
\hline 61 & 5, dunkelgrün & " & $\stackrel{\infty}{ \pm}$ & $\begin{array}{l}17 \quad 181920212223242526 \\
\text { NB! } 61^{1} \text { siehe später }\end{array}$ \\
\hline 62 & 25 , orange & $"$ & & $\begin{array}{llllllllll}17 & 18 & 19 & 20 & 21 & 22 & 23 & 24 & 25 & 26\end{array}$ \\
\hline 63 & 50 " braunlila & $"$ & & $\begin{array}{llllllllll}17 & 18 & 19 & 20 & 21 & 22 & 23 & 24 & 25 & 26\end{array}$ \\
\hline 64 & $2 \mathrm{Mk}$. orangegelb & 1891 & $\begin{array}{l}\text { senkr. } \\
\text { Wellen }\end{array}$ & $\begin{array}{lllllllll}18 & 19 & 20 & 21 & 22 & 23 & 24 & 25 & 26\end{array}$ \\
\hline 65 & 2 Pfg. gra & 1900 & & 26 \\
\hline 66 & 30, olivgrün & - & $B=$ & gibt es $\mathrm{n}$ \\
\hline 67 & $40, "$ olivg & - & $B=$ & rö́tlich em Papier \\
\hline 68 & 80, lila & 1900 & & 26 \\
\hline $\begin{array}{l}69 \\
70\end{array}$ & $\begin{array}{l}3 \text { Mk. olivbraun } \\
5,, \text { hellgriin }\end{array}$ & $"$ & 我造 & $\left.\begin{array}{c}26 \\
26\end{array}\right\} \begin{array}{c}\text { gibt es noch weitere } \\
\text { Auflagen auf rötlich } \\
\text { gelbem Papier? }\end{array}$ \\
\hline
\end{tabular}

Bemerkungen zu vorstehender Tabelle 2:

Alle Marken auf gelblich-rötlichem Papier.

Bis Auflage 23 trägt bei den Pfennigwerten der die obere und untere Bogenhälfte (je 50 Stück) trennende durchgezähnte Papierstreifen zwei wagerechte schmale Linien in der Farbe der Marken; von Auflage 23 an jedoch drei breite Bänder in verschiedener Ausführung (bei allen Werten?). Bei Auflage 20 (und anderen?) der Marke 2 Mark orangegelb trägt der untere Bogenrand $z$ wei wagerechte Linien in der Farbe der Marke. 
3.

Alle folgenden Marken auf wei $B$ e m Papier. Bogeneinteilung wie vorher, einschließlich der hier aufgeführten Auflage $37 \mathrm{I}$ (siehe vorne, Bogẻneinteilung). Die Auflagen $37 \mathrm{II}$ und $37 \mathrm{III}$ folgen in Tabelle 4.

\begin{tabular}{|c|c|c|c|c|}
\hline 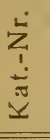 & Wertbezeichnung & 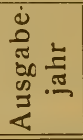 & 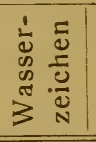 & $\begin{array}{l}\text { Vorkommende } \\
\text { Auflagenummern }\end{array}$ \\
\hline 60 & 3 Pfg. d'braun & 1900 & 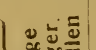 & 2728293031323334353637 \\
\hline 61 & 5 , d'grün & $"$ & 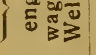 & 2728293031323334353637 \\
\hline $61 \mathrm{I}$ & $5 \quad, \quad$, & 1902 & $\begin{array}{l}\text { enge } \\
\text { senkr. } \\
\text { Wellen }\end{array}$ & 29 \\
\hline 56 & 10, karminrosa & 1900 & & 2728293031323334353637 \\
\hline 57 & 20 , blau & $"$ & $\bar{\Xi}$ & 2728293031323334353637 \\
\hline 62 & 25, orange & $"$ & $\begin{array}{l}3 \bar{v} \\
= \\
=\end{array}$ & 2728293031323334353637 \\
\hline 63 & 50 , braunlila & $"$ & & 2728293031323334353637 \\
\hline 53 & $1 \mathrm{Mk}$. rotlila & $"$ & 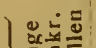 & 2728293031323334353637 \\
\hline 64 & 2 , orangegelb & $"$ & $\overline{\bar{c}} \overline{\bar{c}} \bar{\alpha}$ & 2728293031323334353637 \\
\hline 65 & 2 Pfg. grau & ", & & $\begin{array}{lllllll}27 & 28 & 29 & 30 & 31 & 32 & 33\end{array}$ \\
\hline 66 & 30, olivgrün & $"$ & 点 & 2728293031323334353637 \\
\hline $6 i$ & 40, olivgelb & " & $\infty 0^{3} \bar{\Xi}$ & 2728293031323334353637 \\
\hline 68 & 80 , lila & , & & 2728293031323334353637 \\
\hline 69 & 3 Mk. olivbraun & - & $\dot{\bar{c}}$ & (36) Welche Auflagen gibt es \\
\hline 70 & 5 , hellgrün & - & $\omega_{\infty}^{c}$ & 33 \\
\hline
\end{tabular}

Bemerkungen zu vorstehender Tabelle 3 :

Die Auflagen 37 der Werte 1 und 2 Mark haben mir nicht vorgelegen und sind fraglich.

Auflage 38 (=1911) wurde nicht mehr gedruckt.

Die Auflagen mit Reihenwertzahlen auf dem oberen Bogenrand (37 II und $37 \mathrm{III}$ ) finden sich in Tabelle 4. Die meistgebrauchten Werte zu 5 und 10 Pfennig haben während der Auflage 30 bezw. 27 beginnend auf dem oberen und unteren Bogenrand eine Querleiste in der Farbe der Marken. Die Marken zu 30 und 40 Pfennig sind mit Auflage 27 beginnend erschienen und nur auf wei $B$ em Papier gedruckt. 
4.

Alle folgenden Marken gibt es nur auf wei $\beta$ em Papier, alle Bogen tragen auf dem oberen Rande Reihe nwertzahle n (Reihenzähler). Die Pfennigwerte haben neue Bogeneinteilung ohne $Z$ wischenleiste in zwei Ausführungen (siehe unter Bogeneinteilung: Auflage 37 II und 37 III), kenntlich an dem unteren Bogenrand, der drei oder einen Querbalken trägt.

\begin{tabular}{|c|c|c|c|c|}
\hline $\begin{array}{l}Z \\
1 \\
\\
\end{array}$ & Wertbezeichnung & 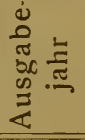 & 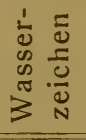 & $\begin{array}{l}\text { Vorkommende } \\
\text { Auflagenummern }\end{array}$ \\
\hline $\begin{array}{l}60 \\
61 \\
56 \\
57 \\
62 \\
66 \\
67 \\
63 \\
68 \\
75\end{array}$ & 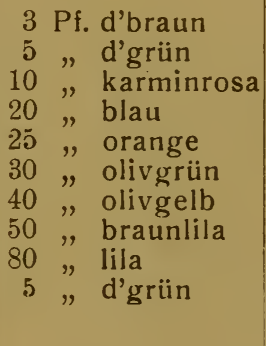 & 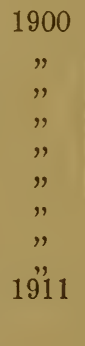 & 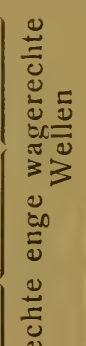 & $\begin{array}{l}37 \text { II } 37 \text { III } \\
37 \text { II } 37 \text { III } \\
37 \text { II } 37 \text { III } \\
37 \text { II } 37 \text { III } \\
37 \text { II } 37 \text { III } \\
37 \text { II } 37 \text { III } \\
37 \text { II } 37 \text { III } \\
37 \text { II ( } 37 \text { III ?) } \\
\text { (37 II ?) } 37 \text { III } \\
37 \text { III (nur in der } 3 \text {. Ausgabe mit } \\
\text { einem Querbalken unten.) }\end{array}$ \\
\hline & $\begin{array}{l}1 \text { Mk. rotlila } \\
2 \% \text { orangegelb }\end{array}$ & $\begin{array}{c}1910 \\
, "\end{array}$ & 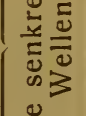 & $\begin{array}{l}37 \\
(37) \text { (diese Aufl. ist bisher noch } \\
\text { nicht gefunden worden). }\end{array}$ \\
\hline $\begin{array}{l}69 \\
70\end{array}$ & $\begin{array}{ll}3 & \text { olivbraun } \\
5 & \text { hellgrün }\end{array}$ & ", & $\begin{array}{l}0 \\
\text { so } \\
\end{array}$ & $\begin{array}{l}37 \\
37\end{array}$ \\
\hline $\begin{array}{l}71 \\
72 \\
73 \\
74\end{array}$ & $\begin{array}{lll}1 & \Rightarrow \text { rotlila } \\
2 & " \text { orangegelb } \\
3 & \text { olivbraun } \\
5 & " \text { hellgrün }\end{array}$ & $\begin{array}{c}1911 \\
" \\
"\end{array}$ & 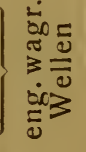 & $\begin{array}{l}37 \\
37 \\
37 \\
37\end{array}$ \\
\hline
\end{tabular}

Bemerkungen zu den vorstehenden Tabellen 3 und 4.

Die unteren Bogenränder der Auflagen 37 I (Bogeneinteilung in $2 \times 50$ Stück $=$ Tabelle 3 ) und 37 III (Bogeneinteilung in 100 Stück $=$ Tabelle 4 ) unterscheiden sich bei den Werten zu 5 und 10 Pfenuig, welche in beiden Ausgaben auf dem unteren Markenbogenrand eine Querleiste in der Farbe der Marken tragen, nur dadurch, daß bei der erstgenannten Ausgabe der untere Papierrand nicht durchgezähnt ist, während bei der letztgenannten die Zähnung bis zum Papierrand sich erstreckt. 
5.

Um dem allgemein eingetretenen Mangel an 5, 10 und 20 Pfennig-Marken abzuhelfen (Verkehrsministerialblatt für Bayern, postdienstl. Teil 1920 S. 49.) wurden im Jahre 1920 die Wappenmarken zu 5 und 10 Pfennig (Senf-Katalog $\mathrm{Nr} .61$ und 56) unter Ausgabe der noch lagernden Restbestände wieder kursfähig erklärt und gleichzeitig die Wappenmarke 3 Pfennig braun (Senf-Katalog Nr. 60) mit „20" viermal überdruckt als 20 Pfennig-Marke (SenfKatalog Nr. 177) neu verausgabt Man überdruckte (Bruckmann, München) die noch lagernden Bestände (je zwei Bogenränder wurden zu schon öfters erwähntem Zweck abgerissen), und ich fand folgende Auflagen:

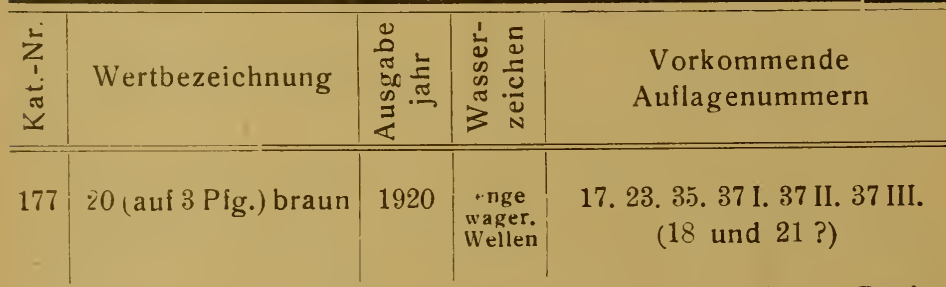

Anmerkung: Die Auflagen 17 und 23 auf rötlichem Papier, deren Vorkommen in je einzelnen Bogen noch nicht geklärt ist.

An allen Bogen, an welchen die Auflagenummer ursprünglich an der rechten oberen und unteren Ecke $s a ß$, läßt sich diese, da vor Uberdruckung abgerissen, nicht mehr feststellen. Es ist anzunehmen, daß sicher auch die Auflage 36 überdruckt wurde, vielleicht auch noch andere Auflagen vor 36 , soweit solche sich zufällig unter den Restbeständen fanden.

III. Kopfzeichnung.

1. Luitpold-Ausgabe.

Seit einer Reihe von Jahren suchte die oberste Postbehörde Bayerns nach einem Druckverfahren für Briefmarken, welches sich billiger stellte, als der Druck der Wappenmarken mit Reliefpressung. Man entschloß sich, die Ausgabe zum 90. Geburtstage des Prinzregenten Luitpold in Photolitographie (Lichtsteindruck) herzu- 
stellen. Das $\mathrm{Kgl}$. Hauptmü $\mathrm{zamt}$ in München, meist

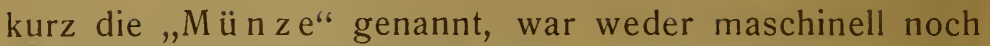
bezüglich seiner Hilfskräfte auf dieses Druckverfahren eingerichtet (druckte in dieser Zeit deshalb nur die Ganzsachen, Gebührenmarken u. dgl.) und während der ganzen Druckzeit dieser Ausgabe nicht in der Lage, sich an der Druckherstellung dieser Marken zu beteiligen. Man übertrug die gesammte Herstellung der Briefmarken der bekannten Münchner Firma Oskar Consée, welche das eingangs genannte Druckverfahren besonders gepflegt hatte. Da die Zeit bis zum Ausgabetag (12. III. 1911 war der Geburtstag des Regenten, zu welchem die neue Reihe fertiggestellt sein mußte) nur kurz war, griff das topographische Institut des Kriegsministeriums helfend ein und druckte einen Teil des ersten Bedarfes an Marken zu 30, 40, 50 und 80 Pfennig. Nur diese Werte wurden also anfänglich an zwei Stellen gedruckt.

Ich verdanke viele Angaben, Ermittelungen und Hinweise zu dieser wohl interessantesten Bayern-Ausgabe und stete Unterstiitzung in meinen Untersuchungen meinem im Weltkriege gefallenen Freund Ludwig Sauter, der in unermüdlicher Ausdauer wie kaum ein zweiter jede freie Stunde unserer gemeinsamen Arbeit widmete und mit nie versagendem Eifer an Ort und Stelle Aufklärung suchte. Ich verweise auf seine Vorveröffentlichungen über den Werdegang der bayerischen Luitpold-Marken im „Allgemeinen Anzeiger für Philatelie" 1911 S. 145 und später nochmals im „Illustrierten Briefmarken-Journal“1913 S. 99.

Die neuen Kataloge 1921, sowohl derjenige der Gebrüder Senf, wie auch der „S.W. Katalog“ berichten Falsches. Die in beiden Katalogen wiederkehrende Angabe, daß der Druck teilweise bei Consée, teilweise im Münzamt erfolgt sei, ist, wie vorher auseinandergesetzt, unrichtig ; sollte das topographische Institut dem Münzamt in irgend einer Form untergeordnet gewesen sein, so wäre trotzdem die Katalogangabe irreführend und vor allem auch unrichtig aus einem Grunde, den ich noch besprechen muß. Beide Kataloge wollen nämlich die beiden Druck- 
stätten auch an ihren Erzeugnissen selbst unterscheiden können (nach Senf sind sämtliche Werte außer 60 Pfennig bei Consée und ebenso sämtliche Werte einschließlich der später verausgabten Marke zu 60 Pfennig im Münzamt gedruckt; im S.W.-Katalog werden die Werte 3-50 Pfenni, und 80 Pfennig Consée und alle Werte 3-80 Pfennig dem Münzamt zugeschrieben, während über die hohen Werte nichts berichtet wird). Es führen beide Kataloge zwei verschiedene Markenzeichnungen an (S.W. nur für die Pfennigwerte, Senf auch für die Markwerte) und ziehen den unbegründeten Schluß, die eine Zeichnung (A) sei ConséeDruck, die andere (B) Erzeugnis der tatsächlich unbeteiligten Münze. So einfach liegen die Verhältnisse nicht. Nur die Tatsache der verschiedenen Zeichnungen (ich nenne sie im folgenden A und B) besteht, jedoch unabhängig von den beiden in Wirklichkeit beteiligten Druckstellen.

Die Zeichnungen $A$ und $B$ habe ich in stark vergrößerten Abbildungen nebeneinandergestellt. Die hauptsächlichen Unterschiede neben anderen befinden sich in der oberen Markeninschrift:

Zeichnung A $\quad$ Zeichnung B

Pfennigwerte:

Im Worte „M/ÆRZ“ zeigt das $\mathrm{E}$ einen mittleren kurzen Balken; der obere Bogen des $\mathrm{R}$ ist schmal.
Im Worte ,MÆRZ“ zeigt das $\mathrm{E}$ einen den äusseren gleichlangen Mittelbalken; der obere Bogen des $\mathrm{R}$ ist breit.

Markwerte:

In der Jahrzahl „,1911“ haben die "1" dünne oder nur angedeutete Fußstriche.
In der Jahrzahl ,1911“ haben die "," deutliche Fußstriche; die "9"“ ist klarer ausgearbeitet (ebenso auch die Zeichnung an Nase und Mund). 


\section{- $42-$}

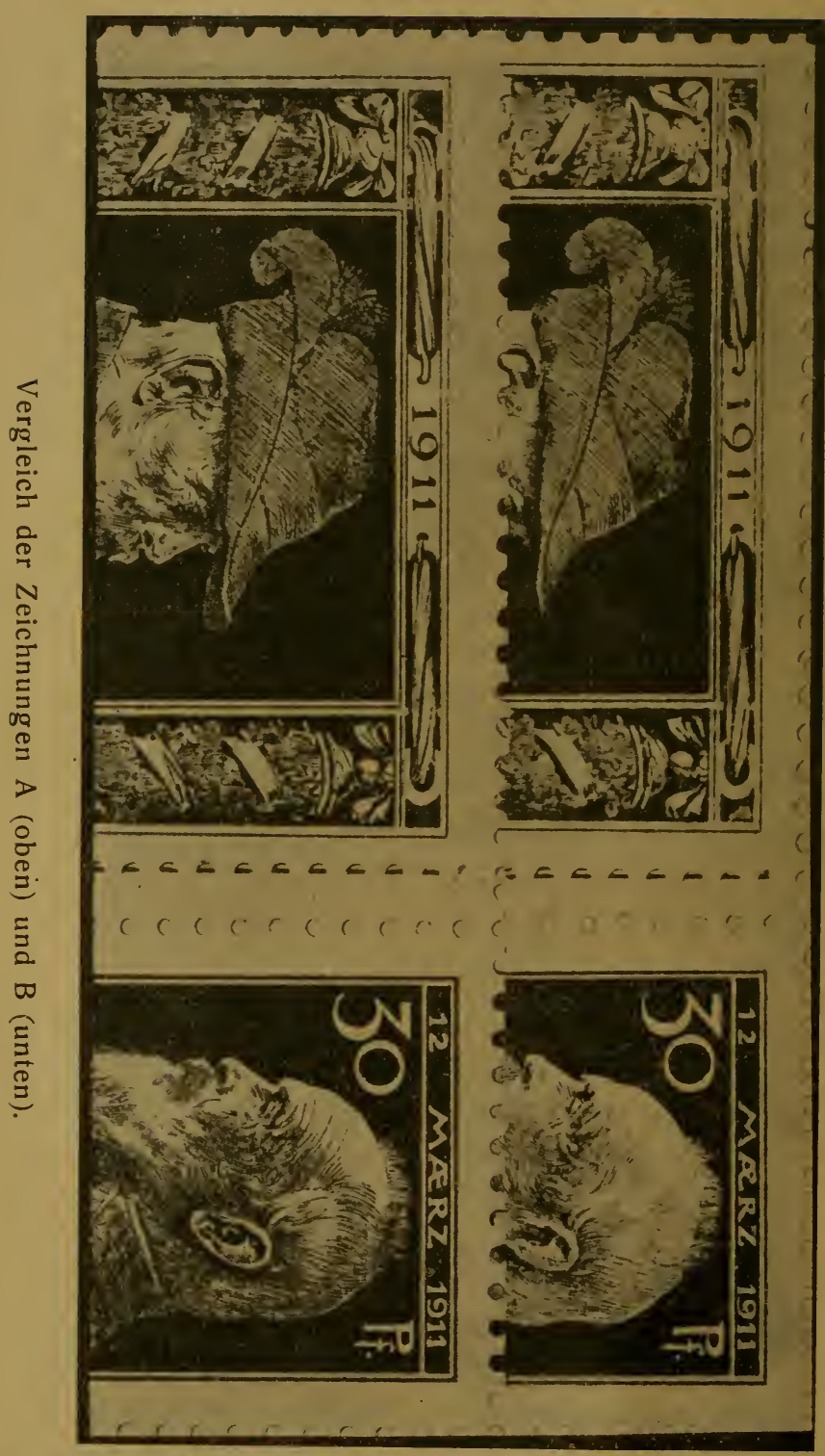


Dazu kommen bei den Pfennig- und Markwerten wahrnehmbare Größenunterschiede zwischen Zeichnung $A$, die stets ein wenig größer ist, und Zeichnung B.

Die Ansichten, wie diese deutlich unterscheidbaren Zeichnungen entstanden sind, gehen auseinander und es stehen sich verschiedene Äußerungen der Nächstbeteiligten schwer vereinbar gegenüber.

Herr Consée selbst teilte Sauter mit, daß in dem zum Markendruck verwendeten photolithographischen Verfahren eine Nachgravierung - wie sie im normalen Steindruck zur Ausbesserung abgenutzter Platten üblich ist - niemals stattgefunden hat. Und hiermit stimmt auch eine Auskunft des Verkehrsamts der bayerischen Posten und Telegraphen vom 28. Oktober 1912 an Sauter überein (Jllustr. Briefm.-Journ. 1913 S. 100).

Sauter selbst glaubt folgende Erklärung der Typenentstehung geben zu können (an genanntem Orte): „Dieser Unterschied ist rein zufällig; seine Ursache hat er zunächst darin, daß sich bei der Originalplatte (zur sehr umständlichen Druckplattengewinnung) etwas Druckfarbe an dem mittleren Balken des $\mathrm{E}$ ansetzte, die nicht rechtzeitig entfernt wurde, sodaß sich dann dieser Mangel durch alle späteren Abzüge hindurch behauptete; erst mit dem Moment, wo von einer neuen Originalplatte die Fettabzüge hergestellt wurden, fiel diese Eigentümlichkeit weg." Dieser Mangel habe sich später nicht mehr eingestellt, da man nach der überstürzten Herstellung der ersten Drucke die Platten sauberer gehalten habe. Es ist wohl auffällig bei dieser Erklärung, daß alle gleichzeitig gedruckten Markenwerte den gleichen typischen Mangel aufweisen, trotzdem jeder Markenwert seinen Ursprung von einer anderen Originalplatte ableitet.

Anders wieder lautet eine Mitteilung des Verkehrsamts der K. B. Posten und Telegraphen, welche Sauter etwa 1 Jahr später, im Dezember 1913 erhielt: An den Originalnegativen sind Retuschen vorgenommen worden, welche die Typenunterschiede erklären, clie Größenunterschiede 
seien durch ungenaues Einstellen bei der photographischen Wiedergabe zwecks Obertragung auf den Stein hervorgerufen.

Und so kam auch Sauter zur Ansicht, daß die bei allen Marken auftretenden Unterschiede (nicht auf einer Nachgravierung der Drucksteine bei Consée) auf eine Änderung im photographischen Negativ zurückzuführen seien und diese wieder auf eine Anderung in den Originalvorlagen. Und darauf verweisen auch die mehrfach erwähnten Größenunterschiede. Wäre durch ungenaues Einstellen bei der photographischen Aufnahme der Größenunterschied entstanden (Verkehrsamt), so müßté die Höhe und Breite der größeren und kleineren Marken das gleiche Verhältnis aufweisen. Ich habe jedoch an photographisch etwa 16 fach vergrößerten Marken beider Zeichnungen (gleiche Werte in gleicher Aufnahme) durch genaue Messung feststellen können, daß sich die Maße nicht im gleichen Sinn verändern, sondern daß ein anderes Größenverhältnis zwischen Höhe und Breite vorhanden ist. Einseitige Papierschrumpfung ist unwahrscheinlich, ebenso Größenveränderung in nur einer Richtung bei den mehrfach wiederholten Ubertragungen bis zur Entstehung des druckfertigen Steins. Es bleibt also die Annahme naheliegend, daß die Verschiedenheit der Zeichnung ihren Ursprung in zwei verschiedenen Originalzeichnungen der einzelnen Werte hat, von welchen die zweite (Zeichnung B) sorgfältiger ausgeführt war als die erste (Zeichnung A), deren Entstehurig überhastet war.

Während die Kataloge einen Zusammenhang zwischen den Zeichnungen A und B und den beiden Druckereien willkürlich zum Ausdruck bringen, kann dieser in Wirklichkeit gar nicht bestehen; denn die beiden Zeichnungen treten bei allen Werten (nur die später verausgabte Marke zu 60 Pfennig ist nur in Zeichnung B erschienen) auf, während nach $\mathrm{S}$ a ut ers Feststellung das topographische Institut nur Teilmengen der Werte zu 30, 40, 50 und 80 Pfennig gedruckt hat. Die Mitarbeit dieses für Lithographie eingerichteten Instituts war nur von kurzer Dauer; alles ïbrige und 
zwar in beiden Zeichnungen wurde bei Consée gedruckt. Das topographische Institut hatte die 4 Werte nur in Zeichnung A gedruckt; die Zeichnung B setzte erst ein, als der Markendruck nach Uberwindung der Anfangsschwierigkeiten, der Uberhastung und des ersten Ansturms in geregelte Bahnen einlief.

Die Einführung der Photolithographie beim Briefmarkendruck Bayerns machte eine neue und weitgehendere Auflagebezeichnung der einzelnen Markenbogen nötig als seither. Es hätte nahe gelegen, für das Jahr 1911 als Jahresauflage-Nummer die Zahl 38 zu wählen, anschließend an die Auflagenummer 37 der Drucke der Wappenausgabe aus dem Jahre 1910. Man begann jedoch mit einer neuen Nummerierung der Auflagen, wohl auch deshalb, weil nicht mehr die Münze druckte, sondern eine private Firma mit der Herstellung der Postwertzeichen betraut war. Wir finden bei den Luitpold-Marken die sogenannten

Jahresauflagenummern $\mathbf{1}$ und $\mathbf{2}$.

Mit ihnen sollte die Gesamtpapiermenge, welche innerhalb eines bestimmten Zeitraumes (die erste verwendete Papiermenge reichte für etwa $1^{1} / 2$ Jahre) zum Markendruck verwendet wurde, bezeichnet werden zwecks Abrechnung. Diese Jahresauflagenummern, die bei den Pfennigwerten gelegentlich, bei den Markwerten stets fehlten, fanden sich fast ausnahmslos an der linken oberen Bogenecke jedes Schalterbogens.

Eine zweite Bezeichnung der Bogen bezog sich auf die Druckplatte (lithographischer Stein), mit welcher der Bogen gedruckt war. Sie findet sich fast stets an der rechten unteren Bogenecke (selten links) und fehlt nur bei den zuerst hergestellten Platten der einzelnen Werte, wohl weil sich diese fortlaufende Nummerierung aller Druckplatten erst nach Beginn des Druckes als nötig erwiesen hatte. Gerade diese Plattennummern sind der größten Beachtung wert, geben sie doch als fortlaufende Reihe die Möglichkeit, ein Gesamtbild dieser so interessanten Aus- 


\section{$-46--$}

gabe zu schaffen in zeitlich richtiger Folge; nur sie gestatten das Ordnen nach Zeichnung $A$ und $B$ und nach Farben.

Die Zahl der Druckplatten ist bei den vielgebrauchten Werten sehr groß, übersteigt z. B. bei der Marke zu 5 Pfennig die Zahl 150. Die Technik der Lithographie gestattet, von einem Druckstein 3000-8000 gute Abzüge zu machen, im Mittel also etwa 5000 Drucke. Enthalten die Druckbogen z.B. 4 Schalterbogen $=400$ Einzelmarken, so ist nach Herstellung von durchschnittlich je 2 Millionen Briefmarken ein neu kopierter Druckstein und mit ihm eine neue Plattennummer nötig. Und jede Plattennummer kommt durchschnittlich dann auf etwa 20000 Schalterbogen vor. Vergleicht man die Zahl der Druckplatten einzelner Werte mit den von amtlicher Seite veröffentlichten Verbrauchszahlen der einzelnen Briefmarken, so findet man eine gute Ubereinstimmung, worauf ich schon früher hingewiesen habe.

Diese Plattennummer $\mathrm{n}$ sind zuerst in $\mathrm{r} \ddot{\mathrm{m}} \mathrm{m}$ is chen $Z$ iffern, erst später in arabischen $Z$ iffern angegeben worden.

Von besonderer Wichtigkeit ist der $\mathrm{Z}$ usammenhang Zwischen Jahresauflagenummer und Plattennum mer.

Mit der Jahresauflagenummer ,"1" korrespondieren römische Plattennummern; erst gegen Ende der Auflage "1" ging man in ununterbrochener Zahlenreihe zu arabischen Plattennummern über. Mit der Jahresauflagenummer, ,2" korrespondieren nur arabische Plattenummern, mit ", " beginnend. So gehört z. B. Plattennummer III stets der Auflage 1, Plattennummer 3 stets der Auflage 2 an. An Hand der später folgenden Tabellen der Auflage- und Plattennummern aller Werte ist die Plattennummer stets einwandirei der ersten oder zweiten Jahresauflage zuweisbar.

Diese Plattennummern, auf jedem Druckbogen zu z. B. 400 Marken viermal, also auf jedem Schalterbogen zu 100 Stück einmal vorkommend, sind scheinbar auf den 
druckfertigen Stein nachträglich handschriftlich aufgesetzt; denn man kann nicht nur verschiedene Handschriften unterscheiden, sondern auch die vier Ziffern eines Druckbogens unterscheiden sich untereinander, sodaß der weitgehende Sondersammler sogar auf diese Unterschiede eingehen und an Hand seiner Funde bei einzelnen Platten feststellen konnte, ob sie in Druckbogen zu 400 oder 200 Stück hergestellt waren.

Die Platten-Nr. 5 Pfennig IX, 10 Pfennig $X$ und 20 Pfennig VII, zeigen einen Stern $(*)$ vor der Nummer, Pl.-Nr. X der 10 Pfennig-Marke kommt auch ohne Stern vor. Die Bedeutung dieses besonderen Kennzeichens wurde verschieden beurteilt; Sauter meinte, die Bogen mit Stern kennzeichnen besonders schöne Drucke und man habe den Stern bei Abbrauch der Platte weggeschliffen. Daß die Sternplatten besonders sorgfältig auf lithographische Druckmängel (Plattenfehler im philatelistischen Sinne) durchgesehen seien, wird unwahrscheinlich durch die Tatsache, da $B$ in der Platte $* \mathrm{X}$ der 10 Pfennig-Marke der bekannteste Plattenfehler dieser Ausgabe „911“ statt 1911 sich findet.

Römische Plattennummern zeigen in der ersten Auflage ein "C" neben der Nummer (z. B. I C, II C). Nach Sauters Feststellungen an Ort und Stelle sei die Wahl dieses Buchstabens reiner Zufall und er beziehe sich keinesfalls auf die Firma Consée; was er eigentlich bedeuten solle, bezw. was durch ihn gekennzeichnet werden sollte, wurde nicht festgestellt, sodaß doch einstweilen noch die Annahme gerechtfertigt erscheint, die Firma Consée habe ihre Drucke auf diese Weise bezeichnet, besonders auch da dieses "C" nur bei den Werten 30, 40 und 50 Pfennig auftritt, die auch im topographischen Institut anfänglich hergestellt wurden.

Wohl aus drucktechnischen Gründen (oder um das Wasserzeichenpapier der Bogenränder für jeden Mißbrauch ungeeignet zu machen) ging man während des Druckes der Auflage 1 dazu über, die Markenbogenränder mit 
dünnen oder dicken Strichen (auch mehrfachen) gleichzeitig mit dem Markendruck zu versehen. Mit welcher Platte diese Strichumrahmungen jeweilig einsetzen, habe ich in den folgenden Tabellen der Plattennummern angegeben.

Ich habe bei der Besprechung der einzelnen Markenwerte auch festgestellt, mit welcher Platte die Zeichnung A aufhört, bezw. die Zeichnung B beginnt. Fast stets ist an jeder Einzelmarke leicht festzustellen, ob sie Zeichnung A oder B zeigt; verfolgt man die einzelnen Platten, so läßt sich, wie gesagt, feststellen, mit welcher Platte die Zeichnung B einsetzt; nur bei den in größten Mengen hergestellten Marken zu 5 und 10 Pfennig scheint Zeichnung A nach bereits in früheren Platten gedruckter Zeichnung $B$ gelegentlich wiederzukehren. So ist $z$. B. die 5 Pfennig-Marke bis zur Platte XXVII sicher in Zeichnung A gedruckt, während Platte XXVIII zum erstenmal die Eigenarten der Zeichnung $B$ aufweist; spätere Platten hingegen entsprechen wieder Zeichnung A. Sollte diese Abwechslung auch ein Beweis sein, daß zwei verschiédene Orginalzeichnungen vorhanden waren, welche bei diesen Massenauflagen abwechselnd als Vorlagen dienten?

Ich gehe nun über zur Beschreibung der einzelnen Markenwerte.

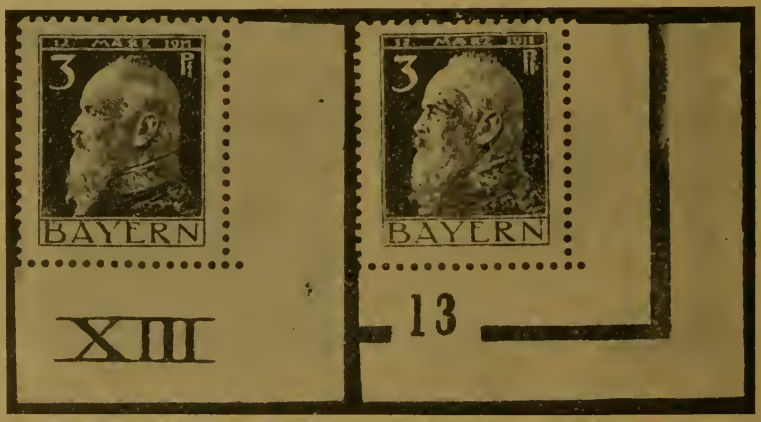

Römische und arabische Platten-Nummer. 
- $49-$

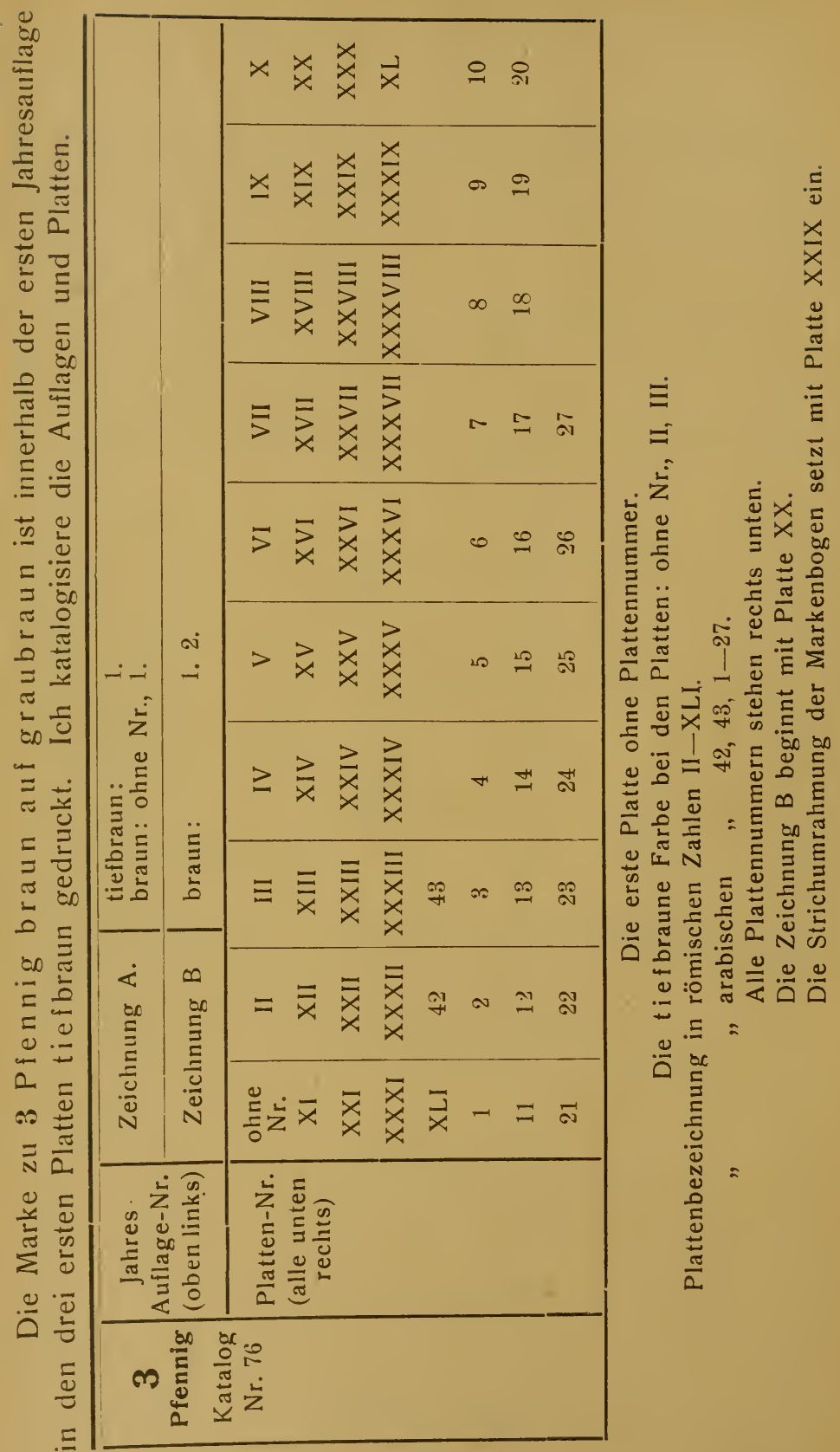


$-50$

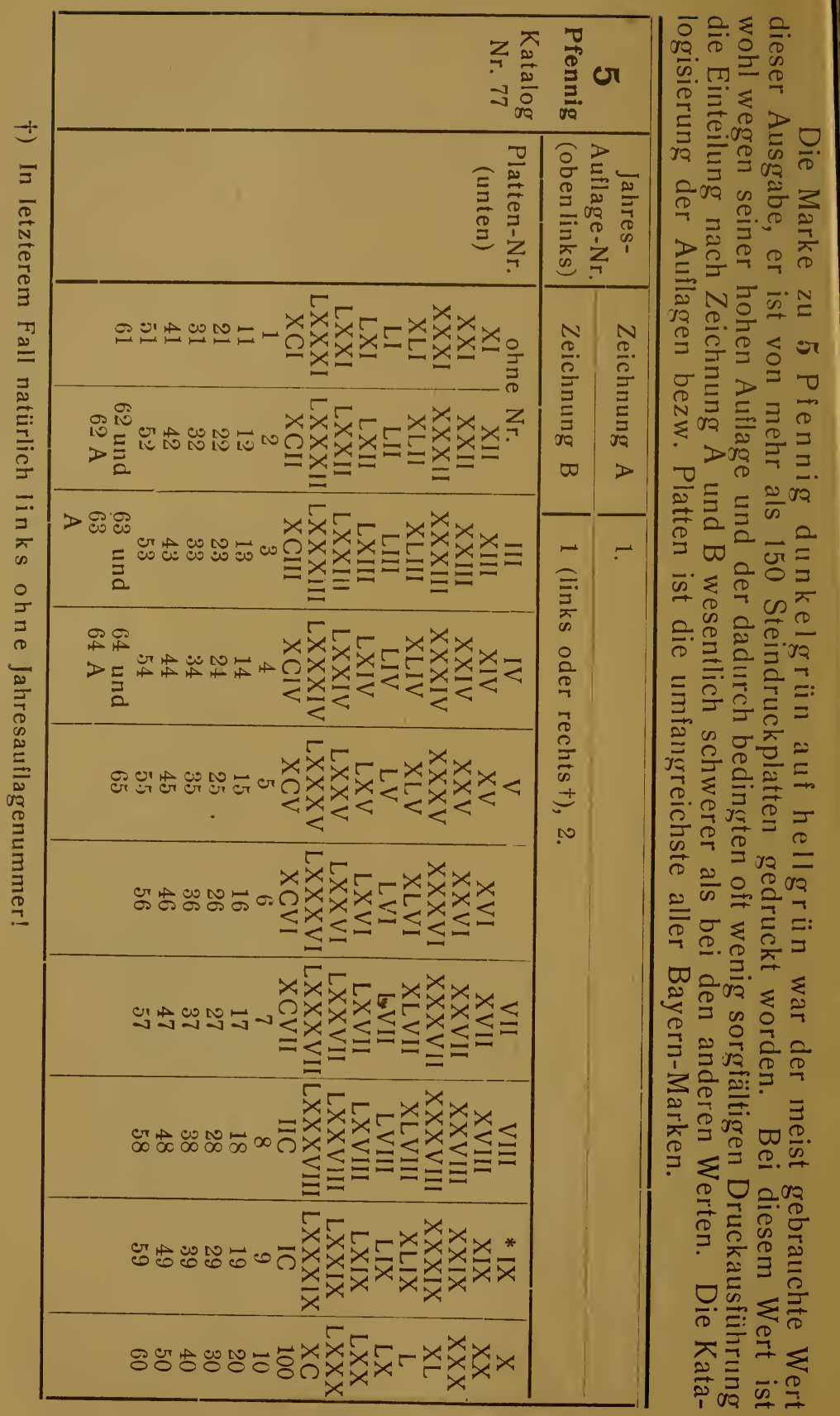


Bemerkungen zu vorstehender Tabelle:

5 Pfennig dunkelgrün auf hellgrün.

Da die Platten-Nummern I und II nicht gefunden wurden, ist es sicher, da $\beta$ diese ersten Platten nicht nummeriert waren. PlatteNr. VI fehlt in allen mir bekannten Sammlungen, scheint also nicht verausgabt zu sein. Platte-Nr. 14 hat mir nicht vorgelegen.

Platte-Nr. IX stets mit Stern.

Jahresauflage-Nr. 1 kommt bei einer Platte der Zeichnung B auch $\mathrm{rechts}$ stehend vor.

Platten-Nr. LXXVI kommt links und rechts unten vor.

Platten-Nr. XXXVIII, 5, 6, 7 stehen stets links (nie rechts) unten.

Platten-Nr. 62, 63, 64 auch mit Bezeichnung A, die während des Druckes angebracht wurde (vielleicht zur Kenntlichmachung späterer Drucke).

Platte-Nr. LXIX, sowie Teilauflage der Platten Nr. LXX und LXXI zeigen den unteren Bogenrand durchgezähnt.

Während des Drucks der Platte XXX tritt eine deutliche Papier- und Farbänderung ein.

Plattenbezeichnung in römischen Zahlen III-IC

$$
\text { " in arabischen " } 100,1-65 \text {. }
$$

Die Strichumrahmung der Markenbogen setzt mit Platte LXIX ein.

Die Zeichnung B fand ich zuerst bei Platte-Nr. XXVIII, doch ist bei späteren Platten wieder eine der Zeichnung $\mathrm{A}$ näherstehende Ausführung bemerkbar. 
$-52-$

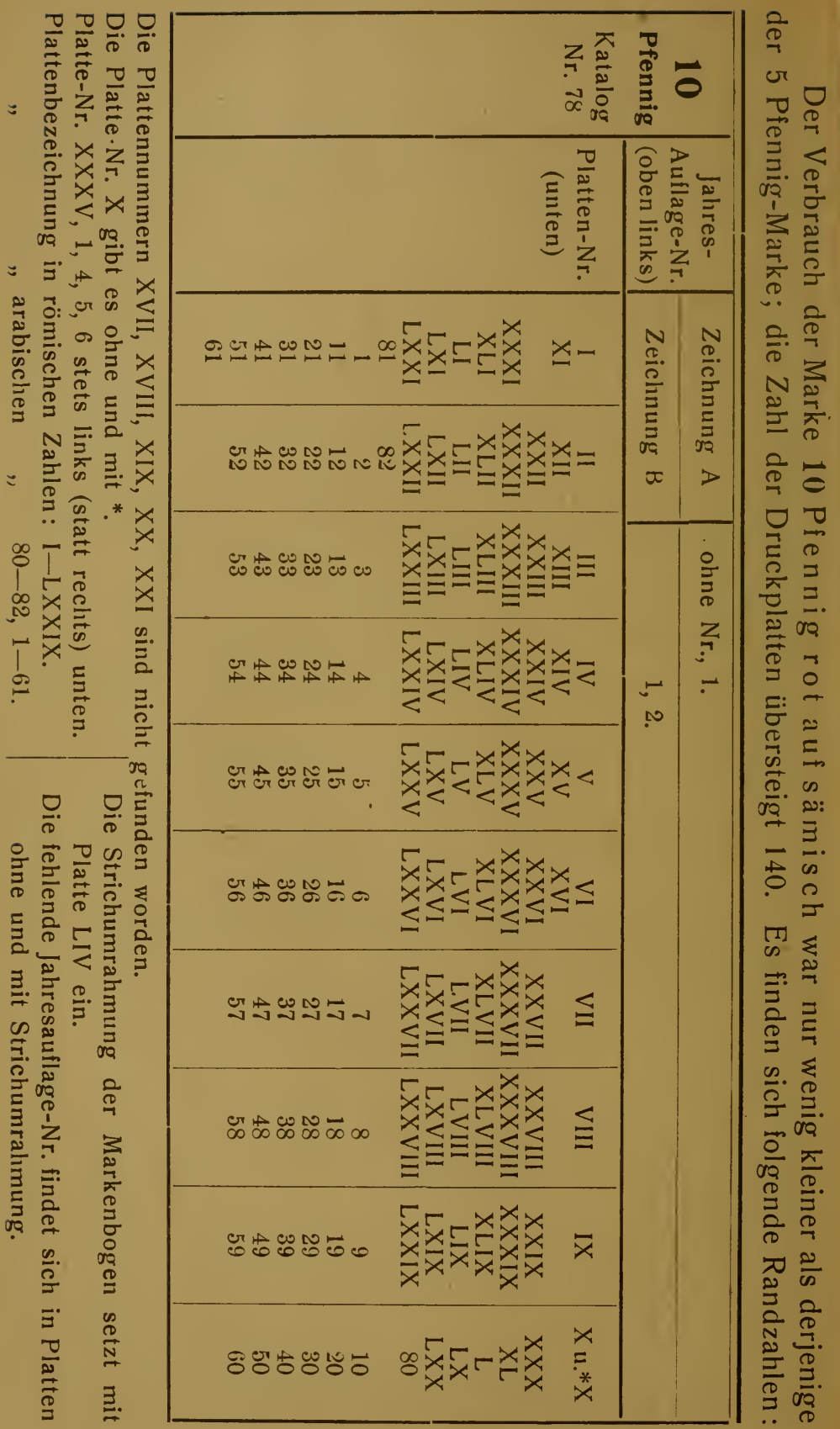


Auch bei dem Werte zu 10 Pfennig ist die Feststellung, mit welcher Platte der Druck der Zeichnung B begann, schwierig. Nachdem die Platten XXII-XXX der Zeichnung $B$ entsprachen, setzt diese erst wieder mit der Platte LXXIX ein.

Abhängig von den geringen Portosätzen der guten alten Zeit gehörte die Marke zu 20 Pfennig blau auf hellblau (in den ersten Platten ultramarin auf hellblau) zu den weniger gebrauchten Marken mit entsprechend geringer Druckplattenzahl. Ich fand:

\begin{tabular}{|c|c|c|c|}
\hline \multirow{3}{*}{$\begin{array}{c}20 \\
\text { Pfg. } \\
\text { Katal. } \\
\text { Nr. } 79\end{array}$} & \multirow{2}{*}{$\begin{array}{l}\text { Jahres- } \\
\text { Auflage-Nr. } \\
\text { (oben links) }\end{array}$} & Zeichnung A & ultramarin: $1 \quad$ blau 1 \\
\hline & & Zeichnung B & blau: ohne Nr., 1. 2. \\
\hline & $\begin{array}{c}\text { Platten-Nr. } \\
\text { (unten } \\
\text { rechts) }\end{array}$ & $\begin{array}{l}\text { ultramarin: II, I } \\
\text { blau: } \\
\quad \text { XI, XII, XIII, X } \\
1221\end{array}$ & $\begin{array}{l}\text { *VII, VIII, IX, X } \\
\begin{array}{cccccc} & \\
\text { XV, } & \text { XVI, } & \text { XVII, } & 18, \\
5 & 6 & 7 & 8 & 9 & 10\end{array}\end{array}$ \\
\hline
\end{tabular}

Nicht bekannt sind die Platten I (bezw. eine solche ohne Platten-Nr.), V und VI.

Platten-Nr. VII nur mit*.

Die Strichumrahmung der Markenbogen stellt sich mit der Platte XIV ein.

Die Zeichnung B tritt das erstemal mit Platte Nr. X auf.

Die Marke zu 25 Pfennig violettschwarz auf sämisch fand stets nur wenig Verwendung, daher sind auch nur wenige Platten aufzuzählen:

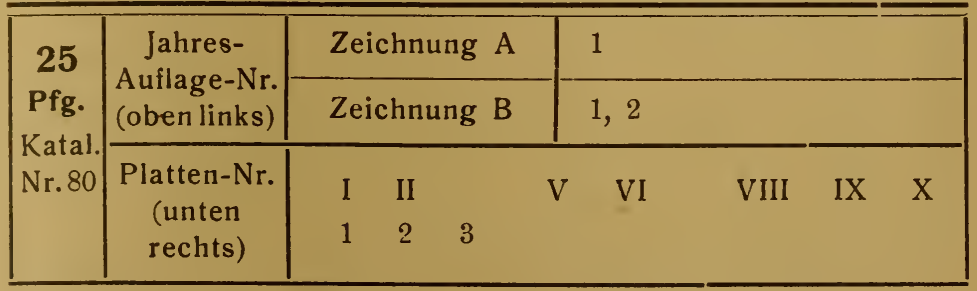

Nicht bekannt sind Platten-Nr. III, IV, VII.

Die Zeichnung B beginnt mit Platten-Nr. V.

Die Strichumrahmung findet sich zuerst auf Platte VIII. 
Die Marke zu 30 Pfennig dunkelorange auf sämisch verdient besondere Beachtung; ist sie doch die erste der ganzen Reihe, welche in zwei verschiedenen Druckereien hergestellt wurde. Nur die Drucke der ersten Platten, unter die Jahresauflage-Nr. 1 fallend, können beiden Druckstätten entstammen, während alle späteren Drucke (so auch die ganze Jahresauflage-Nr. 2) bei Consée hergestellt wurden. Es wird kaum möglich sein, die gefundenen Plattennummern der Jahresauflage 1:

$$
\text { ohne Nr., I C, II, II C, III, X, 11, } 12
$$

eindeutig einer der Druckereien zuzuweisen, solange wir nicht annehmen, daß die ersten Consée-Platten zur Unterscheidung von denjenigen des topographischen Instituts mit einem "C" "versehen wurden, und besonders auch da beide Plattenzeichnungen mit der gleichen Plattennummer vorkommen. Ich beschränke mich deshalb auf folgende Katalogisierung nach Zeichnungen:

\begin{tabular}{|c|c|c|c|}
\hline \multirow{4}{*}{$\begin{array}{c}30 \\
\text { Pfg. } \\
\text { Katal. } \\
\text { Nr. } 81\end{array}$} & $\begin{array}{l}\text { Zeich- } \\
\text { nung } \\
\text { A }\end{array}$ & $\begin{array}{l}\text { Jahres- } \\
\text { Auflage-Nr. } \\
\text { (oben links) }\end{array}$ & ohne $\mathrm{Nr}, 1$ (große Ziffer) \\
\hline & & $\begin{array}{l}\text { Platten-Nr. } \\
\quad \text { (unten) }\end{array}$ & $\begin{array}{l}\text { ohne Nr., Il (links), III (links) } \\
\text { I C, II C (beide rechts) }\end{array}$ \\
\hline & $\begin{array}{l}\text { Zeich- } \\
\text { nung } \\
\text { B }\end{array}$ & $\begin{array}{l}\text { Jahres- } \\
\text { Auflage-Nr. } \\
\text { (oben links) }\end{array}$ & ohne Nr., 1 (kleine Ziffer), 2 \\
\hline & & $\begin{array}{l}\text { Platten-Nr. } \\
\quad \text { (unten) }\end{array}$ & $\begin{array}{l}\text { ohne N., II (links), III (rechts), X (rechts), } \\
11 \text { (links und rechts) } 12 \text { (rechts), } \\
1,2,3,4,5 \text { (alle rechts) }\end{array}$ \\
\hline
\end{tabular}

Die Strichumrahmung der Markenbogen ist in Teilen der Platten I C, II C und X vorhanden und ist mit Platte 11 beginnend ganz durchgeführt. 
Das gleiche Bild wie beim vorhergehenden Wert findet sich aus gleichen Gründen bei der Marke zu 40 Pfennig olivgrün auf sämisch. Es finden sich:

\begin{tabular}{|c|c|c|l|}
\hline 40 & $\begin{array}{c}\text { Zeich } \\
\text { Pfg. } \\
\text { Katal. } \\
\text { Nr.82 }\end{array}$ & $\begin{array}{c}\text { Jahres- } \\
\text { Auflage-Nr. } \\
\text { (oben links) }\end{array}$ & ohne Nr., 1. \\
\hline & $\begin{array}{r}\text { Platten-Nr. } \\
\text { (unten) }\end{array}$ & ohne Nr., II (links), IC (rechts) \\
\hline $\begin{array}{c}\text { Zeich- } \\
\text { nung } \\
\text { B }\end{array}$ & $\begin{array}{c}\text { Jahres- } \\
\text { Auflage-Nr. } \\
\text { (oben links) }\end{array}$ & ohne Nr., 2. \\
\hline & $\begin{array}{r}\text { Platten-Nr. } \\
\text { (unten) }\end{array}$ & $\begin{array}{l}\text { I (links), II (links) } \\
1,2,3,4 \text { (alle rechts) }\end{array}$ \\
\hline
\end{tabular}

Die Strichumrahmung der Bogen findet sich auf den Platten $1,2,3,4$.

Auch die Marke zu 50 Pfennig braunrot auf graubraun ist in beiden Druckereien hergestellt worden.

Es finden sich:

\begin{tabular}{|c|c|c|l|}
\hline $\begin{array}{c}50 \\
\text { Pfg. } \\
\text { Katal. } \\
\text { Nr.83 }\end{array}$ & $\begin{array}{c}\text { Zeich- } \\
\text { nung } \\
\text { A }\end{array}$ & $\begin{array}{c}\text { Jahres- } \\
\text { Auflage-Nr. } \\
\text { (oben links) }\end{array}$ & 1 (groß und klein) \\
\cline { 2 - 4 } & $\begin{array}{c}\text { Platten-Nr. } \\
\text { (unten) }\end{array}$ & $\begin{array}{l}\text { ohne Nr., I (rechts), I (links), } \\
\text { I C (rechts), II (links), III (links) }\end{array}$ \\
\hline $\begin{array}{c}\text { Zeich- } \\
\text { nung } \\
\text { B }\end{array}$ & $\begin{array}{c}\text { Jahres- } \\
\text { Auflage-Nr. } \\
\text { (oben links) }\end{array}$ & ohne Nr., 1. 2. \\
\cline { 2 - 4 } & $\begin{array}{c}\text { Platten-Nr. } \\
\text { (unten) }\end{array}$ & $\begin{array}{l}\text { I (links), II (links), III (rechts), X (rechts) } \\
\text { XIII, 2, 3, 4, 5, 6, 7 (alle rechts), 15 (links), }\end{array}$ \\
\hline
\end{tabular}

NB! Platten-Nr. II (rechts) war mir fruher gemeldet worden, ich sah das Stück nicht. 
Die Strichumrahmung der Markenbogen beginnt mit PlattenNr. XIII. Bei dieser Marke lassen sich deutlich eine helle und eine dunkle Farbenart unterscheiden; der hellen Art gehören alle Drucke in Zeichnung $A$ an, sodaß in diesem Falle wohl mil Sicherheit $z u$ sagen ist, daß diese Drucke im topographischen Institut des Kriegsministeriums, die dunklen Drucke in Zeichnung B bei Consée gedruckt worden sind.

Die Marke zu 60 Pfennig dunkelgrün auf $\mathrm{s}$ ä $\mathrm{m}$ is ch, erst am 1. X. 1911 verausgabt, ist nur in Zeichnung $\mathrm{B}$ erschienen und wie die meisten Werte nur bei Consée gedruckt. Es finden sich:

\begin{tabular}{|c|c|c|l|}
\hline \hline $\begin{array}{c}\text { 60 } \\
\text { Pfg. } \\
\text { Kat. }\end{array}$ & $\begin{array}{c}\text { Zeichnung } \\
\text { Nr.84 }\end{array}$ & $\begin{array}{c}\text { Jahresaufl.-Nr. } \\
\text { (oben links) }\end{array}$ & ohne Nr., 1 \\
\cline { 2 - 4 } & & $\begin{array}{c}\text { Platten-Nr. } \\
\text { (unten) }\end{array}$ & I, II, III, VI (alle rechts) \\
\hline
\end{tabular}

Die Platten-Nr. IV und V sind nicht gefunden worden.

Die Strichumrahmung der Markenbogen findet sich nur auf der Platte-Nr. VI.

Als letzte der an zwei Druckorten hergestellten Marken ist der Wert zu 80 Pfennig dunkellila auf graubraun zu besprechen. Es finden sich:

\begin{tabular}{|c|c|c|c|}
\hline $\begin{array}{c}80 \\
\text { Pfg. } \\
\begin{array}{c}\text { Kat. } \\
\text { Nr.85 }\end{array}\end{array}$ & $\begin{array}{c}\text { Zeichnung } \\
\text { A }\end{array}$ & $\begin{array}{c}\text { Jahresaufl.-Nr. } \\
\text { (oben links) }\end{array}$ & ohne Nr., 1 (groß), ×1 (klein) \\
\cline { 2 - 4 } & $\begin{array}{c}\text { Platten-Nr. } \\
\text { (unten) }\end{array}$ & ohne Nr., II (links) \\
\cline { 2 - 5 } & $\begin{array}{c}\text { Zeichnung } \\
\text { Bahresaufl.-Nr. } \\
\text { (oben links) }\end{array}$ & $\begin{array}{c}\text { ohne Nr., 2 } \\
\text { Platten-Nr. } \\
\text { (unten) }\end{array}$ & $\begin{array}{c}\text { I, II, III (alle rechts) } \\
\text { I links und rechts zwischen } \\
\text { zwei Strichumrahmungs- } \\
\text { linien) }\end{array}$ \\
\hline
\end{tabular}

Die Strichumrahmung der Markenbogen findet sich nur in der Jahresauflage 2 = Platte I. Die auch bei diesem Wert auftretenden hellen und dunkeln Farbschattierungen lassen keinen bündigen Schluß auf den Druckort zu. 
Auch bei den Markwerten finden sich die verschiedenen Zeichnungen. Bei dem Werte zu 1 Mark braun auf graubraun finden sich:

\begin{tabular}{|c|c|c|c|}
\hline $\begin{array}{c}\text { Mk. } \\
\text { Mat. } \\
\text { Nr.86 }\end{array}$ & $\begin{array}{c}\text { Zeichnung } \\
\text { A }\end{array}$ & $\begin{array}{c}\text { Jahresaufl.-Nr. } \\
\text { (oben links) }\end{array}$ & ohne Nr. \\
\cline { 2 - 4 } & $\begin{array}{c}\text { Platten-Nr. } \\
\text { (unten) }\end{array}$ & ohne Nr., II (links) \\
\cline { 2 - 4 } & $\begin{array}{c}\text { Zeichnung } \\
\text { B }\end{array}$ & $\begin{array}{c}\text { Jahresaufl.-Nr. } \\
\text { (oben links) }\end{array}$ & ohne Nr., 2 \\
\cline { 2 - 4 } & $\begin{array}{c}\text { Platten-Nr. } \\
\text { (unten) }\end{array}$ & $\left.\begin{array}{c}\text { VI, VII, VIII, IX } \\
1,2,3,4,5\end{array}\right\}$ (alle rechts) \\
\hline
\end{tabular}

Sämtliche Bogen haben zwei oder drei Umrahmungslinien.

Die Marke zu 2 Mark dunkelgrün auf hellgrün bietet folgende Unterschiede:

\begin{tabular}{|c|c|c|c|}
\hline \multirow{4}{*}{$\begin{array}{c}2 \\
\text { Mk. } \\
\text { Kat. } \\
\text { Nr. } 87\end{array}$} & \multirow[t]{2}{*}{$\begin{array}{c}\text { Zeichnung } \\
\text { A }\end{array}$} & $\begin{array}{l}\text { Jahresaufl.-Nr. } \\
\text { (oben links) }\end{array}$ & ohne Nr. \\
\hline & & $\begin{array}{l}\text { Platten-Nr. } \\
\text { (unten) }\end{array}$ & ohne Nr., II (links) \\
\hline & \multirow[t]{2}{*}{$\begin{array}{c}\text { Zeichnung } \\
\text { B }\end{array}$} & $\begin{array}{l}\text { Jahresaufl.-Nr. } \\
\text { (oben links) }\end{array}$ & ohne Nr. \\
\hline & & $\begin{array}{l}\text { Platten-Nr. } \\
\text { (unten) }\end{array}$ & $\left.\begin{array}{l}\text { IV } \\
1,2\end{array}\right\}$ (alle rechts) \\
\hline
\end{tabular}

Eine Jahresauflagen-Nummer trägt die $2 \mathrm{Mk}$--Marke also nicht. Auch hier finden sich auf allen Bogen zwei oder drei Umrahmungslinien.

Das Gleiche gilt für die vier höchsten Werte dieser Reihe, die Marken zu 3 Mark karmin auf sämisch, 5 Markdunkelblau auf sämisch, 10 Mark orange auf gelblich und 20 Mark schwarzbraun auf gelblich. Auch diese Werte sind in beiden Zeichnungen erschienen, jedoch ohne Jahresauflage-Nummer. 
Es finden sich:

\begin{tabular}{|c|c|c|c|}
\hline \multirow{4}{*}{$\begin{array}{c}\mathbf{3} \\
\text { Mark } \\
\text { Katalog } \\
\text { Nr. } 88\end{array}$} & \multirow[t]{2}{*}{ Zeichnung A } & $\begin{array}{c}\text { Jahresaufl.-Nr. } \\
\text { (oben links) }\end{array}$ & ohne $\mathrm{Nr}$. \\
\hline & & $\begin{array}{l}\text { Platten-Nr. } \\
\text { (unten) }\end{array}$ & ohne Nr. \\
\hline & \multirow[t]{2}{*}{ Zeichmung B } & $\begin{array}{l}\text { Jahresaufl -Nr. } \\
\text { (oben links) }\end{array}$ & ohne Nr. \\
\hline & & $\begin{array}{l}\text { Platten-Nr. } \\
\text { (unten) }\end{array}$ & 1 (rechts) \\
\hline \multirow{4}{*}{$\begin{array}{c}5 \\
\text { Mark } \\
\text { Katalog } \\
\text { Nr. } 89\end{array}$} & \multirow[t]{2}{*}{ Zeichnung A } & $\begin{array}{c}\text { Jahresaufl.-Nr. } \\
\text { (oben links) }\end{array}$ & ohne $\mathrm{Nr}$. \\
\hline & & $\begin{array}{l}\text { Platten-Nr. } \\
\quad \text { (unten) }\end{array}$ & ohne Nr. \\
\hline & \multirow[t]{2}{*}{ Zeichnung B } & $\begin{array}{l}\text { Jahresaufl.-Nr. } \\
\text { (oben links) }\end{array}$ & ohne Nr. \\
\hline & & $\begin{array}{l}\text { Platten-Nr. } \\
\quad \text { (unten) }\end{array}$ & 2 (rechts) \\
\hline \multirow{4}{*}{$\begin{array}{c}10 \\
\text { Mark } \\
\text { Katalog } \\
\text { Nr. } 90\end{array}$} & \multirow[t]{2}{*}{ Zeichnung A } & $\begin{array}{c}\text { Jahresaufl.-Nr. } \\
\text { (oben links) }\end{array}$ & ohne Nr. \\
\hline & & $\begin{array}{l}\text { Platten-Nr. } \\
\quad \text { (unten) }\end{array}$ & ohne Nr. \\
\hline & \multirow[t]{2}{*}{ Zeichnung B } & $\begin{array}{c}\text { Jahresaufl.-Nr. } \\
\text { (oben links) }\end{array}$ & ohne Nr. \\
\hline & & $\begin{array}{l}\text { Platten-Nr. } \\
\text { (unten) }\end{array}$ & 2 (rechts) \\
\hline \multirow{4}{*}{$\begin{array}{c}20 \\
\text { Mark } \\
\text { Katalog } \\
\text { Nr. } 91\end{array}$} & \multirow[t]{2}{*}{ Zeichnung A } & $\begin{array}{c}\text { Jahresaufl.-Nr. } \\
\text { (oben links) }\end{array}$ & ohne $\mathrm{Nr}$. \\
\hline & & $\begin{array}{l}\text { Platten-Nr. } \\
\text { (unten) }\end{array}$ & ohne Nr. \\
\hline & \multirow[t]{2}{*}{ Zeichnung B } & $\begin{array}{l}\text { Jahresaufl.-Nr. } \\
\text { (oben links) }\end{array}$ & ohne Nr. \\
\hline & & $\begin{array}{l}\text { Platten-Nr. } \\
\text { (unten) }\end{array}$ & 2 (rechts) \\
\hline
\end{tabular}


Einige Bemerkungen zu den „Luitpold“-Marken. Die Zahl der regelrechten Plattenfehler ist bei diesen Massenauflagen in Steindruck, auch in Folge der überstürzten Herstellung, sehr groß. Einige sind allgemein bekannt geworden und haben Eingang in die Kataloge gefunden. So findet sich „911" statt 1911 bei dem Werte zu

3 Pfennig auf der 83. Marke eines Bogens in Zeichnung A 10 Pfennig , „30. , der Platte Nr. $\mathrm{X}$ und *X in Zeichnung A (nicht auch in Zeichnung B, wie Senf irrtümlich angibt als $\mathrm{Nr} .78$ I, II.)

Dieser belanglose Plattenfehler wurde bei der 10 PfennigMarke frühzeitig entdeckt, ist in Folge dessen häufig, während er bei der 3 Pfennig-Marke unbemerkt und deshalb selten blieb.

Bei der Marke zu 25 Pfennig gibt es in Platte-Nr. I auf der 75. Marke eine ,2" in 25 mit einem kräftigen Auswuchs am linken Fußende. (Zeichnung A.)

Selten und wirklich beachtenswert, da wohl nur durch gewollte Druckplattenretusche entstanden, ist die Marke zu 30 Pfennig mit breitem statt spitzem Bart des Regenten. Sie findet sich auf Feld 75 der Platte III (links) in Zeichnung A. (Senf Nr. 81 l.)

Die von Sondersammlern besonders geschätzten ,,ïb e rklebten Marken" enstanden aus angerissenen und vor dem Druck durch aufgeklebte Papierstreifen ausgebesserten Papierbogen, entstammen zumeist der anfänglich überhasteten Herstellung; denn die „weiß überklebten" zeigen fast alle die Zeichnung A, die „farbig überklebten" zum größeren Teil.

Die Platten-Nummern wurden vom Lithographen auf den druckfertigen Stein handschriftlich aufgesetzt. Wir können ganze Reihen ,gleicher Handschrift" beobachten und auch feststellen, wenn eine andere Hand diese Arbeit übernahm. Eine eigentürnliche, von allen anderen Platten- 


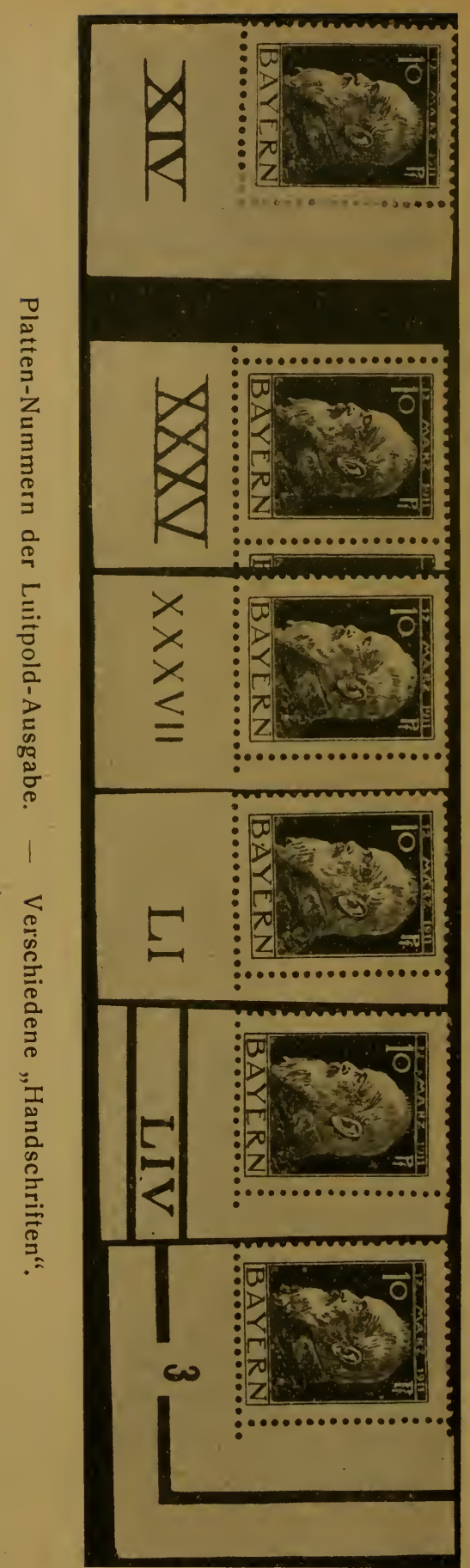


jezeichnungen abweichende Schrift in großen unbeholfenen Strichen findet sich gleichartig auf den Platten

3 Pfennig XVI, 5 Pfennig XXXVIII, 10 Pfennig XXXV.

Aus derartigen Vergleichen läßt sich ein Schluß ziehen auf gleichzeitige Drucklegung verschiedener Markenwerte.

Markenheftchen der Luitpoldausgabe wurden erstmalig im Dezember 1911 verausgabt (s. Berl. Briefm.-Zeitung 1920, S. 227). Es erschienen während der Kurszeit der Luitpold-Ausgabe 11 Heftchenauflagen mit Nummern 1-11. Erst bei Auflage 6 können wir deutlich die Markenzeichnung $B$ feststellen, und es gibt also die Kehrdrucke zu 5 und 10 Pfennig in beiden Zeichnungen, entstammend den während der ganzen Ausgabedauer der Markenheftchen zum freien Verkauf gestellten Markenbogen zur Herstellung der Heftchen. Diese großen Markenbogen zeigen eine zweifache Nummerierung:

1) am unteren Rande rechts:

„Markenheftchen 1. A uflage“

und entsprechend weiter mit den Zahlen der später folgenden Heftchen (also Auflagenummern!)

2) in der Mitte des oberen Bogenrandes die Zahlen

1 bezw. 2-7

(von Auflage 6 an nur die Zahlen 1-6),

welche die Reihenfolge der einzelnen Bogen bei Zusammenstellung der Heftchen innerhalb der Auflage angeben, also Zahlen, welche weder Auflagen bedeuten, noch eigentliche Plattennummern sind und uns deshalb hier weniger berühren. Ich bezweifle, daß alle Ganzbogen der Markenheftchen-Auflagen zum Verkauf gestellt worden sind. Vermutlich sind nur je nach dem Bedarf der Händler- und Sammlerkäufe von den gerade im Druck befindlichen Auflagen beliebige Bogen den Verkaufstellen übergeben worden. Ich selbst kenne Bogen aus den Auflagen 2, 3 und 8. 
2. Luitpold-Erinnerungsmarken.

Die Erinnerungsmarken an die 25 jährige Regentschaft vom 10. Juni 1911, welche nur in den beiden Werten 5 und 10 Pfennig (Senf Nr. 92 und 93) vorliegen, sind in Vierfarbenlithographie hergestellt. Der Druckbogen besteht aus vier Schalterbogen zu je 50 Einzelmarken. Nur einer dieser Schalterbogen trägt die auf die einzelnen Druckplatten bezüglichen Kontrollzahlen, meist die Angabe „Platte II" usw. in Schwarz, oit vereinigt mit Kontrollzahlen der einzelnen Farbenplatten; fast alle Kontrolldaten befinden sich rechts unten; wenn dies nicht der Fall ist, wird es besonders vermerkt. Es weist also nur jeder vierte Schalterbogen eine derartige Auflageangabe auf, außerdem wurde die Auflage I beider Werte ohne Kontrollangaben gedruckt. Durch Vereinigung verschiedener Druckplatten entstehen mannigfache Kontrollvermerke (bis zu vier Kontrollangaben auf- und nebeneinander); die folgende Tabelle gibt eine vollständige Liste der Kontrollangaben. Die Größe der Gesamtauflage eines jeden Wertes soll 10 oder 15 Millionen Stück betragen; diese Zahl liesse nach der früher aufgestellten Berechnung je 10 bis 15 Einzeldruckauflagen vermuten; auf jeden Fall scheint die Zahl der 5 Pfennig-Marken die größere zu sein. Die in den Tabellen in einer wagerechten Reihe nebeneinander stehenden Kontrollziffern befinden sich zusammen auf einem Schalterbogen.

Die folgenden Tabellen enthalten die Verschiedenheiten bezüglich der Auflagezahlen. Regulär sind alle diese Bogen nicht bis zum Papierrand, sondern nur soweit die Markenbilder reichen, in Kammzähnung gelöchert. Fast alle diese Bogen kommen aber auch mit Linienzähnung bis zum Papierrand in senkrechter und wagerechter Richtung vor. Die Tabellen geben in der letzten Spalte an, was ich an Kammzähnungen (K) und Linienzähnungen (L) feststellen konnte. 
5 Pfennig grün (Kat.-Nr. 92)

Plattenbezeichnungen der:

\begin{tabular}{|c|c|c|c|c|c|c|}
\hline 之 & $\begin{array}{c}\text { Schwarz- } \\
\text { druckplatte }\end{array}$ & $\begin{array}{l}\text { Hellgrün- } \\
\text { druckplatte }\end{array}$ & $\begin{array}{l}\text { Dunkelgrün- } \\
\text { druckplatte }\end{array}$ & $\begin{array}{c}\text { Gelb- } \\
\text { druckplatte }\end{array}$ & \multicolumn{2}{|c|}{ Zähnung } \\
\hline & \multicolumn{3}{|c|}{ Auflage I ist ohne Kontrolldaten } & gedruckt & K & - \\
\hline $\begin{array}{l}2 \\
3\end{array}$ & Platte II & Platte II & 5 Platte I & - & $\begin{array}{l}\mathrm{K} \\
\mathrm{K}\end{array}$ & - \\
\hline 4 & Platte II & $"$ & $5 . \quad 川 I$ & - & $\mathrm{K}$ & - \\
\hline 5 & $"$ III & $"$ iI & - & - & $\mathrm{K}$ & - \\
\hline 6 & $"$ III & 5 (in 2 Ausf.) & - & 5 (groß) & $\mathrm{K}$ & $\mathrm{L}$ \\
\hline & $"$ III & & - & 5 (klein) & $\mathrm{K}$ & $\mathrm{L}$ \\
\hline & $", \quad$ IIV & 5 & grün 5 & 5 & $\mathrm{~K}$ & $\mathrm{~L}$ \\
\hline & $"$ IV & 5 (klein) & - & j (klein) & $\overline{\mathrm{K}}$ & L \\
\hline & $"$ IV & 5 (grob) & - & 5 (grob) & $\mathrm{K}$ & $\overline{\mathrm{L}}$ \\
\hline & $"$ IV & 5 (groß) & - & 5 (klein) & - & $\mathrm{L}$ \\
\hline & $" \mathrm{~V}$ & - & - & 5 & & $\mathrm{~L}$ \\
\hline & $" \mathrm{~V}$ & 5 & grün 0 & $\begin{array}{l}5 \\
5\end{array}$ & $\mathrm{~K}$ & $\overline{\mathrm{L}}$ \\
\hline & ". Vl & - & - & - & $\mathrm{K}$ & $\bar{L}$ \\
\hline & $"$ VI & - & - & 5 & $\mathrm{~K}$ & $\mathrm{~L}$ \\
\hline & " VI & - & grün 5 & 5 & $\mathrm{~K}$ & L \\
\hline & $"$ VII & 一 & - & $\overline{5}$ & $\begin{array}{l}K \\
K\end{array}$ & L \\
\hline & $"$ VIII & - & - & 5 & $\mathrm{~K}$ & \\
\hline & & $\begin{array}{c}1 \mathrm{P} \\
\text { (kopfstehend } \\
\text { links unten) }\end{array}$ & - & - & K & \\
\hline
\end{tabular}

10 Pfennig rot (Kat.-Nr. 93)

Plattenbezeichnungen der:

\begin{tabular}{|c|c|c|c|c|c|c|}
\hline $\bar{z}$ & $\begin{array}{l}\text { Schwarz- } \\
\text { druckplatte }\end{array}$ & $\begin{array}{c}\text { Hellrot- } \\
\text { druckplatte }\end{array}$ & $\begin{array}{l}\text { Dunkelrot- } \\
\text { druckplatte }\end{array}$ & $\begin{array}{c}\text { Gelb- } \\
\text { druckplatte }\end{array}$ & \multicolumn{2}{|c|}{ Zähnung } \\
\hline 1 & \multicolumn{3}{|c|}{ Auflage $I$ ist ohne Kontrolldaten } & gedruckt & $\mathrm{K}$ & - \\
\hline 2 & Platte II & $\begin{array}{l}\text { Reste einer } 10 \\
\text { links unten) }\end{array}$ & & 10 (I. unten) & $\mathrm{K}$ & - \\
\hline 3 &,$\quad$ III & & & - & $\begin{array}{l}\mathrm{K} \\
\mathrm{K}\end{array}$ & $\mathrm{L}$ \\
\hline $\begin{array}{l}4 \\
5\end{array}$ & $\leadsto$ IV & & - & - & K & $\mathrm{L}$ \\
\hline 6 & $" \quad \mathrm{~V}$ & 10 (seitenvrk.) & - & Platte II & $\mathrm{K}$ & $\mathrm{L}$ \\
\hline 7 & $"$ VI & $10 \quad "$ & - & ? (unleserl.) & $\underset{K}{\mathrm{~K}}$ & \\
\hline $\begin{array}{l}8 \\
9\end{array}$ & $"$ VI & 10 (l.unten) & - & Platte & $\mathrm{K}$ & $\mathrm{L}$ \\
\hline 10 & - & $\begin{array}{l}10 \text { (1. unten } \\
\text { seitenverk.) }\end{array}$ & 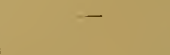 & 10 & $K$ & \\
\hline 11 & -- & $\begin{array}{l}1 \\
10 \text { (r. oben) }\end{array}$ & - & & $\begin{array}{l}\mathrm{K} \\
\mathrm{K}\end{array}$ & L \\
\hline 13 & - & & & 10 (r. oben) & N & \\
\hline
\end{tabular}


Die Viererblocks der ersten (nicht signierten) Druckauflagen sind daran kenntlich, daß die rechten unteren Bogenecken in beiden Richtungen außerhalb der Markenbilder nicht gezähnt sind, sowie an den Paß-(Anlege-) Marken rechts unten und rechts seitlich. - Die Auflagejahreszahl 1 der Jubiläumsausgabe 1911 fehlte bei dieser nur drei Wochen gültigen Ausgabe.

\section{Ludwiga us gabe,}

später mit zweizeiligem Aufdruck: „Volksstaat Bayern“ bezw. „Freistaat B ayern".

Was bei der Luitpoldausgabe bezüglich der Jahresauflagenummern und Plattennummern gesagt wurde, kann sinngemäß auf die Ludwigausgabe übertragen werden. Das hier verwendete Druckverfahren, der Schnellpressentiefdruck - Bruckmanns Mezzotintoverfahren - druckt mit Kupferwalzen. Die Zahlen, welche in der Photolithographie Platten bezeichneten, nennen uns hier die Zahl der verwendeten Walzen, sind also Walzennummern. Die Jahresauflagezahlen entsprechen denjenigen, welche in der Luitpoldausgabe zur Anwendung kamen und die in einem bestimmten Zeitabschnitt zum Verbrauch gelangte Papiermenge zu Verrechningszwecken kennzeichnen.

So finden wir bei der Ludwigausgabe gemeinsam mit den aus ihr durch entsprechenden Aufdruck entstandenen „Volksstaat"-und ,Freistaat"-Marken die Aufla g e num mern

$$
1,2,3 \text {, }
$$

deren jede entsprechend der Kurszeit dieser Kopfzeichnung einen Zeitraum von etwa 2 Jahren umfassen mag. Beachtenswert sind dabei Obergänge von einer Auflage zur andern, darin bestehend, daß die ursprüngliche Auflagenummer durchstrichen ist und die neue Auflagenummer daneben steht, und wohl dadurch entstanden, daß eine Kupferwalze der alten Auflage noch druckbrauchbar war, als die neue Auflage zu drucken begonnen wurde.

Wie groß die durchschnittliche Leistung einer Kupferwalze ist, entzieht sich meiner Kenntnis. Sicher ist, daß ihre Druckfähigkeit wesentlich länger anhält als diejenige 

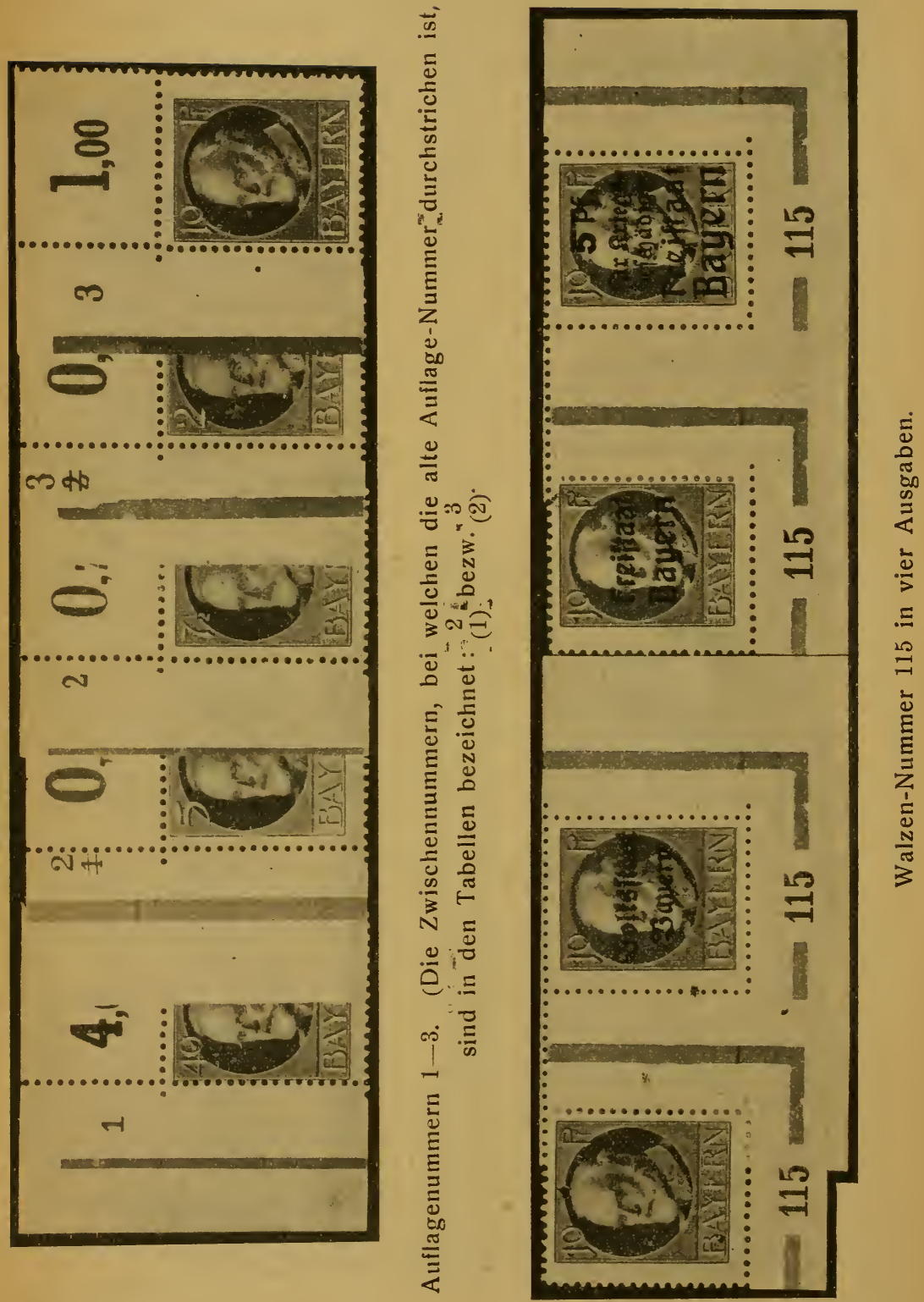
der Lichtsteindruckplatten; denn wir haben z. B. bei der 10 Pfennigmarke in doppelt so langer Gebrauchszeit und bei zweifellos gestiegener Verbrauchsmenge nur 120 Walzennummern gegen etwa 140 Steindruckplatten.

Entgegen der bei der Steindruckausgabe eingeführten Regel, daß mit der neuen Auflage auch eine mit ,1" neubeginnende Plattennummerierung eintrat, sind beim Mezzotintoverfahren die Druckwalzen durch die drei Auflagen fortlaufend weiternummeriert.

$\mathrm{Da}$ es von besonderem Interesse ist, den Zusammenhang zwischen der ursprünglichen Ludwigausgabe und den aus ihr entstandenen Volksstaat- und Freistaat-Ausgaben zu verfolgen, habe ich diese 3 Ausgaben in einer gemeinsamen Liste der Auflagen und Walzennummern vereinigt

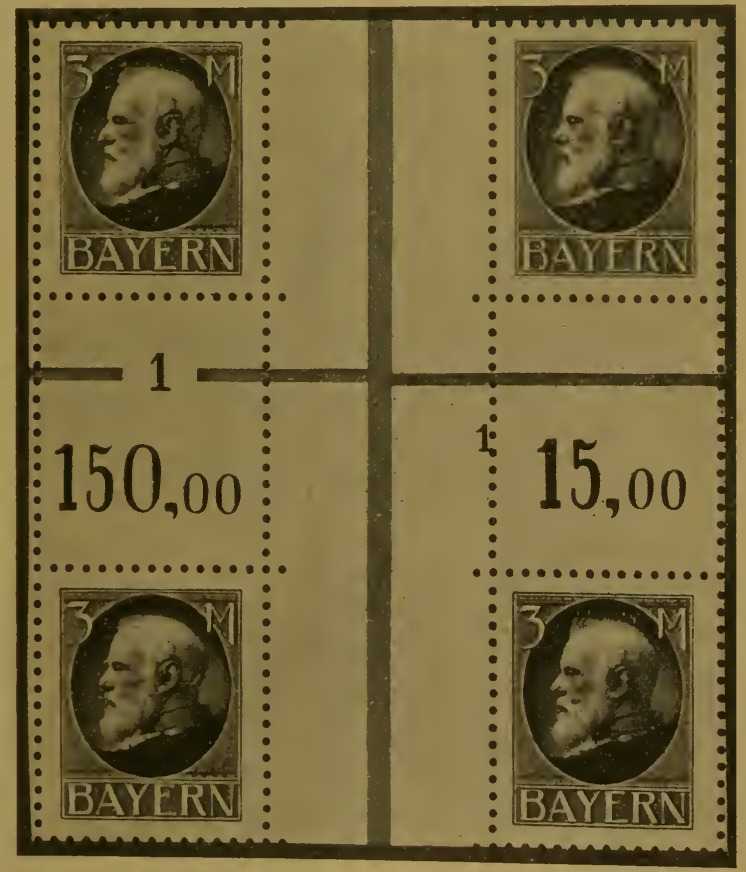

Auflage-Nummer (kleine Ziffer ,"1") und Walzen-Nummer (große Ziffer "1“) aus unzertrennten Druckbogen. 
(natürlich nach Werten getrennt) und gleichzeitig angegeben, welche Walzennummern mir un g e $\mathrm{z}$ äh $\mathrm{n} \mathrm{t}$ gemeldet worden sind (die Anordnung hat auch den Vorteil, daß jede im Falle neugefundene Walzennummer leicht eingetragen werden kann, und daß die Tabellen, wie auch die früheren, als Fehllisten verwendet werden können). So entsteht ein Uberblick, wie die einzelnen Ausgaben in einander greifen, wie man gelegentlich, um dringendem Markenbedarf möglichst schnell gerecht zu werden, auf die Anbringung des Aufdrucks verzichtete, - und was man zur Befriedigung der Händler- und Sammlerbedürfnisse druckte.

Die Auflagenummern befinden sich stets links oben, die Walzennummern stets rechts unten am Markenbogenrand. Die verwendeten Ziffern sind gleichartig, sie zeigen keine charakteristischen Unterschiede, wie auch die ganze Ausgabe in sich einfacher und eindeutiger ist als die Luitpoldausgabe. Den Druck der Ludwig-Ausgabe führte die Firma Bruckmann in München aus, ebenso die verschiedenen Aufdrucke auf diesen Wertzeichen.

Die Schalterbogen der Ludwig-Ausgabe sind auf 3 Seiten mit Strichumrahmung versehen, der obere Rand trägt an deren Stelle die Reihenwertzahlen.

2 Pfennig blaugrau (Kat.-Nr. 115)

Auflagenummern (links oben)

\begin{tabular}{|c|c|c|c|}
\hline Ludwig & $\begin{array}{c}\text { gezähnt } \\
\text { ungez. }\end{array}$ & $\begin{array}{lc}3 \\
2 \\
(2)\end{array}$ & $\begin{array}{l}3 \\
3\end{array}$ \\
\hline
\end{tabular}

Walzennummern (rechis oben)

\begin{tabular}{l||c|cccccc}
\hline Ludwig $\left\{\begin{array}{c}\text { gezähnt } \\
\text { ungez. }\end{array}\right.$ & 1 & 2 & 6 & 7 & 8 & 9 \\
\hline
\end{tabular}

Anmerkung: Dieser Wert wurde erst am 1.X.18. verausgabt. Die Walzennumern 3, 4, 5 wurden noch nicht gemeldet. Die Bogen mit diesen Nummern scheinen restlos mit ,2, $2_{2}^{1}$ " überdruckt worden zu sein. 
21/2 schwarz auf 2 Pfennig blaugrau (Kat.-Nr. 110) Auflagenummern (links oben)

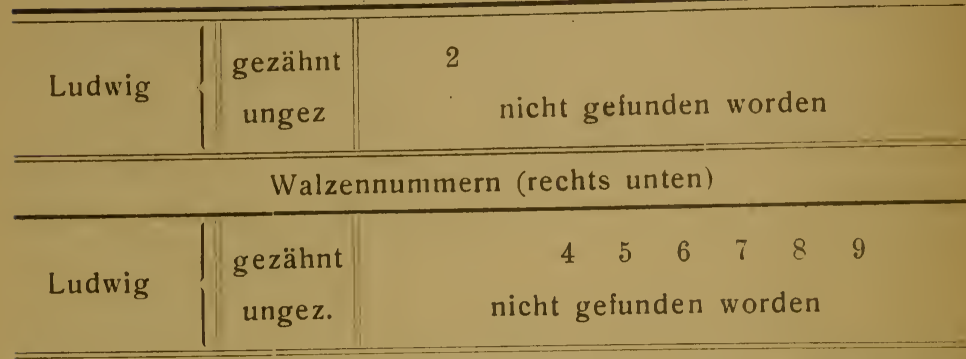

Anmerkung: Diese Aufdruckmarke war nicht in der Reihe der amtlich verausgabten, ungezähnten Marken enthalten. - Die fehlenden Auflage- und Walzennummern sind wohl ausnahms-

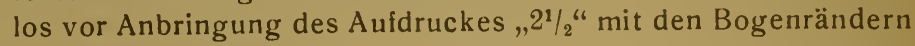
abgerissen worden.

3 Pfennig braun (Kat.-Nr. 94, 116, 155) Auflagenummern (links oben)

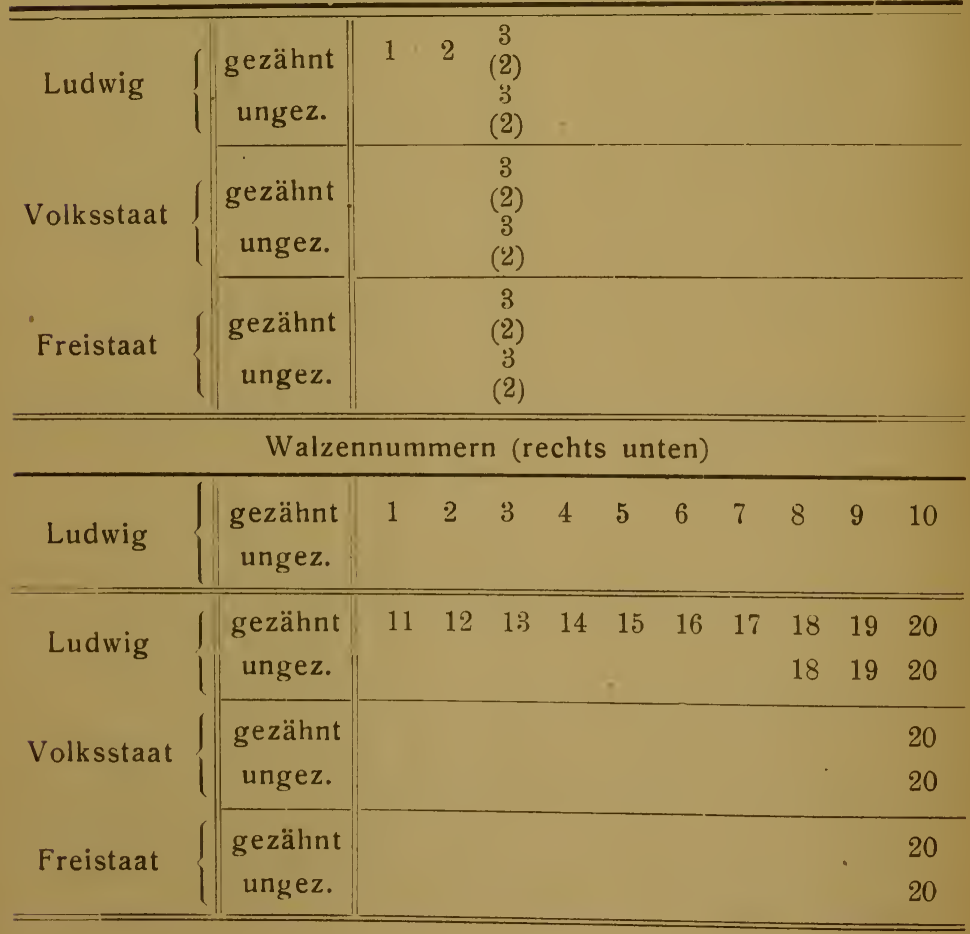


5Pfennig dunkelgrün (Kat.-Nr. 95)

Auflagenummern (links oben)

\begin{tabular}{|c|c|c|c|c|c|c|c|c|c|c|c|}
\hline Ludwig & $\begin{array}{l}\text { gezähnt } \\
\text { ungez. }\end{array}$ & & $\begin{array}{r}2 \\
\text { (1) } \\
\text { (die }\end{array}$ & $\begin{array}{c}2 \\
\text { obe }\end{array}$ & & & & & ben: & & ihnt) \\
\hline \multicolumn{12}{|c|}{ Walzennummern (rechts unten) } \\
\hline \multirow{6}{*}{ Ludwig } & \multirow{2}{*}{$\begin{array}{c}\text { gezähnt } \\
\text { gezähnt } \\
\text { ungez. }\end{array}$} & 1 & 2 & 3 & 4 & 5 & 6 & 7 & 8 & 9 & 10 \\
\hline & & 11 & & & & 15 & 16 & 17 & 18 & 19 & 20 \\
\hline & \multirow{4}{*}{$\begin{array}{c}\text { ge- } \\
\text { zähnt }\end{array}$} & 21 & 22 & 23 & 24 & 25 & 26 & 27 & 28 & 29 & 30 \\
\hline & & 31 & 32 & 33 & 34 & 35 & 36 & 37 & 38 & 39 & 40 \\
\hline & & 41 & 42 & 43 & 44 & 45 & 46 & 47 & 48 & 49 & 50 \\
\hline & & 51 & 52 & 53 & 54 & 55 & & rbän & ideru & ung!) & \\
\hline
\end{tabular}

5 Pfennig maigrün (Kat.-Nr. 113, 117, 156) Auflagenummern (links oben)

\begin{tabular}{|c|c|c|c|c|c|c|c|c|c|c|c|}
\hline Ludwig & $\begin{array}{c}\text { gezähnt } \\
\text { ungez. }\end{array}$ & & & & $\begin{array}{c}3 \\
\text { (2) }\end{array}$ & $\begin{array}{l}3 \\
3\end{array}$ & & & & & \\
\hline Volksstaat & $\begin{array}{c}\text { gezähnt } \\
\text { ungez. }\end{array}$ & & & & & $\begin{array}{l}3 \\
3\end{array}$ & & & & & \\
\hline Freistaat & $\begin{array}{l}\text { gezähnt } \\
\text { ungez. }\end{array}$ & & & & & $\begin{array}{l}3 \\
3\end{array}$ & & & & & \\
\hline \multicolumn{12}{|c|}{ Walzennummern (rechts unten) } \\
\hline Ludwig & $\begin{array}{l}\text { gezähnt } \\
\text { ungez. }\end{array}$ & & & & & $5 \tilde{5}$ & 56 & 57 & & & $\begin{array}{l}60 \\
60\end{array}$ \\
\hline Ludwig & \begin{tabular}{c|} 
gezähnt \\
ungez.
\end{tabular} & 61 & $\begin{array}{l}62 \\
62\end{array}$ & $\begin{array}{l}63 \\
63\end{array}$ & 64 & & $\begin{array}{l}66 \\
66\end{array}$ & & 68 & & 70 \\
\hline Volksstaat & $\begin{array}{l}\text { gezähnt } \\
\text { ungez. }\end{array}$ & & & $\begin{array}{l}63 \\
63\end{array}$ & 64 & 65 & $\begin{array}{l}66 \\
66\end{array}$ & 67 & 68 & & 70 \\
\hline Freistaat & $\begin{array}{c}\text { gezähnt } \\
\text { ungez. }\end{array}$ & & & & & & & $\begin{array}{l}67 \\
67\end{array}$ & $\begin{array}{l}68 \\
68\end{array}$ & 69 & 70 \\
\hline
\end{tabular}




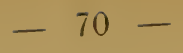

Walzennummern (rechts unten)

\begin{tabular}{|c|c|c|}
\hline Ludwig & $\begin{array}{c}\text { gezähnt } \\
\text { ungez. }\end{array}$ & $\begin{array}{ll}71 & 72 \\
71 & 72\end{array}$ \\
\hline Volksstaat & $\begin{array}{l}\text { gezähnt } \\
\text { ungez. }\end{array}$ & $\begin{array}{l}71 \\
71\end{array}$ \\
\hline Freistaat & $\begin{array}{l}\text { gezähnt } \\
\text { ungez. }\end{array}$ & $\begin{array}{l}71 \\
71\end{array}$ \\
\hline
\end{tabular}

Anmerkung: Farbänderung von dunkelgrün in maigrün innerhalb der Auflage 2, Walze 55.

„Volkssta at" beginnend mit Walzen-Nr. 63.

"Freista a t"

$" \quad "$

66.

71/2 Pfennig dunkelgriin (Kat.-Nr. 111, 118, 157)

Auflagenummern (links oben)

\begin{tabular}{|c|c|c|c|}
\hline Ludwig & $\begin{array}{c}\text { gezähnt } \\
\text { ungez. }\end{array}$ & $\begin{array}{cc} & 3 \\
2 & (2) \\
2 & \end{array}$ & $\begin{array}{l}3 \\
3\end{array}$ \\
\hline Volksstaat & $\begin{array}{c}\text { gezähnt } \\
\text { ungez. }\end{array}$ & $\begin{array}{c}3 \\
(2) \\
3 \\
(2) \\
\end{array}$ & $\begin{array}{l}3 \\
3\end{array}$ \\
\hline Freistaat & $\begin{array}{c}\text { gezähnt } \\
\text { ungez. }\end{array}$ & & $\begin{array}{l}3 \\
3\end{array}$ \\
\hline
\end{tabular}

\begin{tabular}{|c|c|c|c|c|c|c|c|c|c|c|c|}
\hline \multicolumn{12}{|c|}{ Walzennummern (rechts unten) } \\
\hline Ludwig & $\begin{array}{c}\text { gezähnt } \\
\text { ungez. }\end{array}$ & 1 & 2 & 3 & 4 & j & 6 & 7 & 8 & 9 & 10 \\
\hline Ludwig & $\begin{array}{c}\text { gezähnt } \\
\text { ungez. }\end{array}$ & $\begin{array}{l}11 \\
11\end{array}$ & & 13 & 14 & $\begin{array}{l}15 \\
15\end{array}$ & 16 & $\begin{array}{l}17 \\
17\end{array}$ & $\begin{array}{l}18 \\
18\end{array}$ & $\begin{array}{l}19 \\
19\end{array}$ & 20 \\
\hline Volksstaat & $\begin{array}{l}\text { gezähnt } \\
\text { ungez. }\end{array}$ & & & & & & & & & & $\begin{array}{l}20 \\
20\end{array}$ \\
\hline
\end{tabular}




\section{$-71-$}

Walzennummern (rechts unten)

\begin{tabular}{|c|c|c|}
\hline Ludwig & $\begin{array}{c}\text { gezähnt } \\
\text { ungez. }\end{array}$ & $\begin{array}{l}21 \\
21\end{array}$ \\
\hline Volksstaat & $\begin{array}{c}\text { gezähnt } \\
\text { ungez. }\end{array}$ & $\begin{array}{l}21 \\
21\end{array}$ \\
\hline Freistaat & $\begin{array}{c}\text { gezähnt } \\
\text { ungez. }\end{array}$ & $\begin{array}{l}21 \\
21\end{array}$ \\
\hline
\end{tabular}

Anmerkung: Dieser Wert wurde erst in der Druckzeit der Auflage 2 am 1. VIII. 16. verausgabt.

10 Pfennig rot (Kat.-Nr. 96)

Auflagenummern (links oben)

\begin{tabular}{|c|c|c|c|c|c|c|c|c|c|c|c|}
\hline Ludwig & $\begin{array}{c}\text { gezähnt } \\
\text { ungez. }\end{array}$ & 1 & 2 & & & & & & & & \\
\hline \multicolumn{12}{|c|}{ Walzennummern (rechts unten) } \\
\hline \multirow{7}{*}{ Ludwig } & \multirow{7}{*}{$\begin{array}{c}\text { ge- } \\
\text { zähnt }\end{array}$} & 1 & 2 & 3 & 4 & 5 & 6 & 7 & 8 & 9 & 10 \\
\hline & & 11 & 12 & 13 & 14 & 15 & 16 & 17 & 18 & 19 & 20 \\
\hline & & 21 & 22 & 23 & 24 & 25 & 26 & 27 & 28 & 29 & 30 \\
\hline & & 31 & 32 & 33 & 34 & 30 & 36 & 37 & 38 & 39 & 40 \\
\hline & & 41 & 42 & 43 & 44 & 45 & 46 & 47 & 48 & 49 & 50 \\
\hline & & 51 & 52 & 53 & 54 & 55 & 56 & 57 & 58 & 59 & 60 \\
\hline & & 61 & 62 & 63 & 64 & 65 & 66 & $(\mathrm{Fa}$ & rbän & der & ng !) \\
\hline
\end{tabular}

10 Pfennig karmin (Kat.-Nr. 114, 119, 158) Auflagenummern (links oben)

\begin{tabular}{|c|c|c|c|}
\hline Ludwig & $\begin{array}{c}\text { gezähnt } \\
\text { ungez. }\end{array}$ & $\begin{array}{l}2 \\
2\end{array}$ & $\begin{array}{l}3 \\
3\end{array}$ \\
\hline Volksstaat & $\begin{array}{c}\text { gezähnt } \\
\text { ungez. }\end{array}$ & & $\begin{array}{l}3 \\
3\end{array}$ \\
\hline Freistaat & $\begin{array}{l}\text { gezähnt } \\
\text { ungez. }\end{array}$ & & $\begin{array}{l}3 \\
3\end{array}$ \\
\hline
\end{tabular}


Walzenummern (rechts unten)

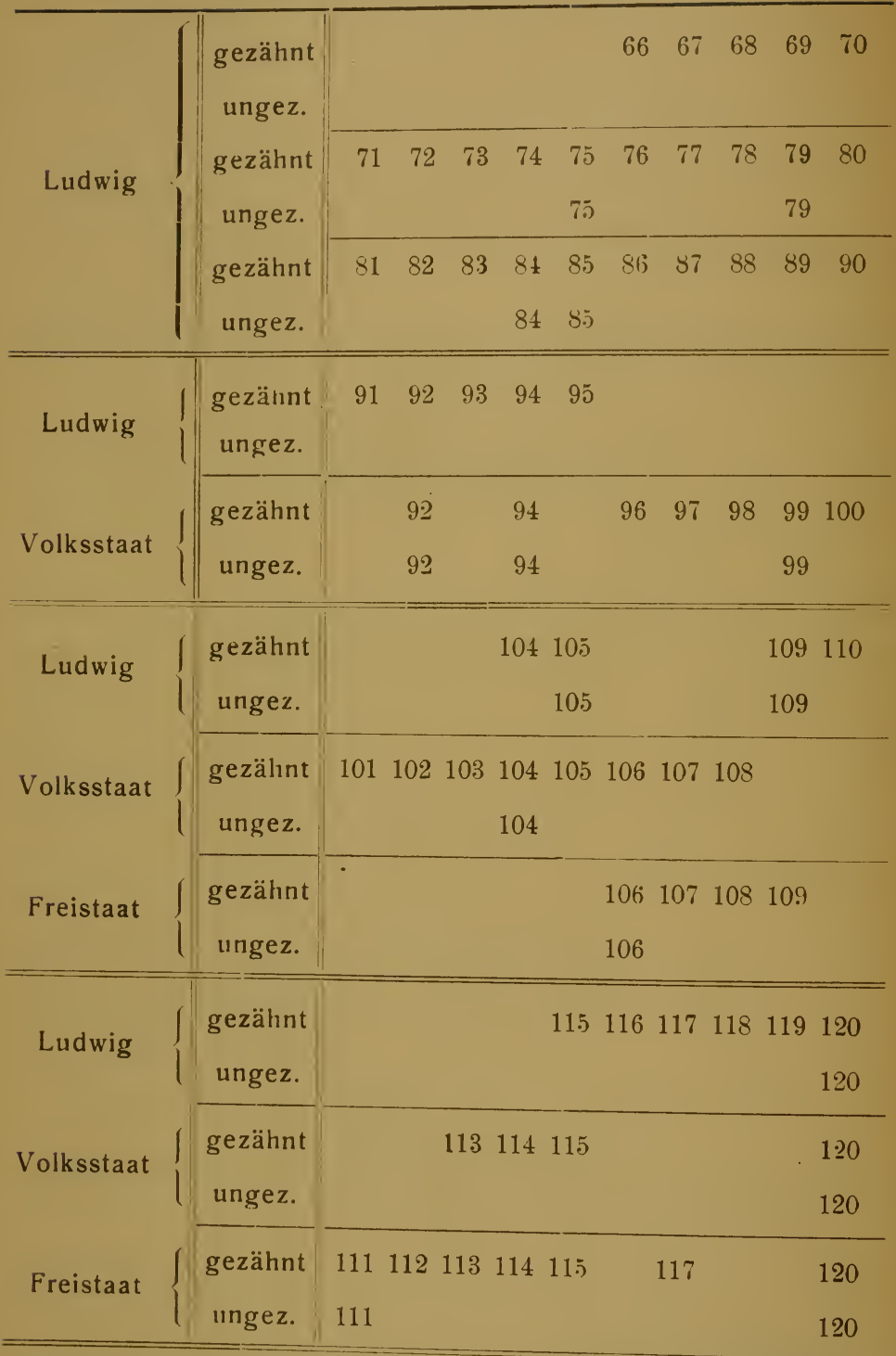

Anmerkung: Farbänderung von rot in karmin innerhalb der Auflage 2, Walze 66. "Volksstaat" beginnend mit Walze 92. "Freistaat" . " " 106. 
15 Pfennig rot (Kat.-Nr. 112, 120, 159) Auflagenummern (links oben)

\begin{tabular}{|c|c|c|c|c|c|c|c|c|c|c|c|}
\hline Ludwig & $\begin{array}{c}\text { gezähnt } \\
\text { ungez. }\end{array}$ & & $\begin{array}{l}2 \\
2\end{array}$ & $\begin{array}{c}3 \\
(2) \\
3 \\
(2) \\
\end{array}$ & $\begin{array}{l}3 \\
3\end{array}$ & & & & & & \\
\hline Volksstaat & $\begin{array}{c}\text { gezähnt } \\
\text { ungez. }\end{array}$ & & & & $\begin{array}{l}3 \\
3\end{array}$ & & & & & & \\
\hline Freistaat & $\begin{array}{c}\text { gezähnt } \\
\text { ungez. }\end{array}$ & & & & $\begin{array}{l}3 \\
3\end{array}$ & & & & & & \\
\hline \multicolumn{12}{|c|}{ Walzennummern (rechts unten) } \\
\hline \multirow{3}{*}{ Ludwig } & $\begin{array}{c}\text { gezähnt } \\
\text { ungez. }\end{array}$ & 1 & 2 & 3 & 4 & 5 & 6 & 7 & 8 & 9 & 10 \\
\hline & $\begin{array}{c}\text { gezähnt } \\
\text { ungez. }\end{array}$ & 11 & 12 & 13 & 14 & 15 & 16 & 17 & 18 & $\begin{array}{l}19 \\
19\end{array}$ & 20 \\
\hline & $\begin{array}{c}\text { gezähnt } \\
\text { ungez. }\end{array}$ & 21 & $\begin{array}{l}22 \\
22\end{array}$ & 23 & 24 & 25 & 26 & 27 & 28 & $\begin{array}{l}29 \\
29\end{array}$ & 30 \\
\hline Ludwig & $\begin{array}{c}\text { gezähnt } \\
\text { ungez. }\end{array}$ & 31 & 32 & 33 & 34 & 35 & $\begin{array}{l}36 \\
36\end{array}$ & $\begin{array}{l}37 \\
37\end{array}$ & 38 & & $\begin{array}{l}40 \\
40\end{array}$ \\
\hline Volksstaat & $\begin{array}{c}\text { gezähnt } \\
\text { ungez. }\end{array}$ & & & & & & & & & 39 & \\
\hline Ludwig & $\begin{array}{c}\text { gezähnt } \\
\text { ungez. }\end{array}$ & & & & & 45 & 46 & & & $\begin{array}{l}49 \\
49\end{array}$ & \\
\hline Volksstaat & $\begin{array}{c}\text { gezähnt } \\
\text { ungez. }\end{array}$ & 41 & 42 & 43 & 44 & $\begin{array}{l}45 \\
45\end{array}$ & 46 & $\begin{array}{l}47 \\
47\end{array}$ & 48 & 49 & ธ̄0 \\
\hline Freistaat & $\begin{array}{c}\text { gezähnt } \\
\text { ungez. }\end{array}$ & & & & & & & & 48 & & $\begin{array}{l}50 \\
50\end{array}$ \\
\hline
\end{tabular}


Walzennummern (rechts unten)

\begin{tabular}{|c|c|c|c|c|c|}
\hline Ludwig & $\begin{array}{c}\text { gezähnt } \\
\text { ungez. }\end{array}$ & & 53 & 54 & $\begin{array}{l}55 \\
55\end{array}$ \\
\hline Volksstaat & $\begin{array}{c}\text { gezähnt } \\
\text { ungez. }\end{array}$ & $51 \quad 52$ & & & 55 \\
\hline Freistaat & $\begin{array}{c}\text { gezähnt } \\
\text { ungez. }\end{array}$ & $51 \quad 52$ & $\begin{array}{l}53 \\
53\end{array}$ & & $\begin{array}{l}55 \\
55\end{array}$ \\
\hline
\end{tabular}

Anmerkung: Dieser Wert wurde erst in der Druckzeit der Auflage 2 am 1. VIII. 16. verausgabt.

Der Farbenfehldruck 15 Pfennig blutrot (Kat-Nr. 112 b) (nur als ,Ludwig"-Marke vorkommend) gehört der Auflage 3, Walze 55 an.

20 Pfennig blau (Kat.-Nr. 97, 121, 160) Auflagenummern (links oben)

\begin{tabular}{|c|c|c|c|c|c|c|c|c|c|c|c|}
\hline Ludwig & $\begin{array}{c}\text { gezähnt } \\
\text { ungez. }\end{array}$ & 1 & $\begin{array}{l}2 \\
2\end{array}$ & $\begin{array}{l}3 \\
(2) \\
\end{array}$ & $\begin{array}{l}3 \\
3\end{array}$ & & & & & & \\
\hline Volksstaat & $\begin{array}{l}\text { gezähnt } \\
\text { ungez. }\end{array}$ & & & & $\begin{array}{l}3 \\
3\end{array}$ & & & & & & \\
\hline Freistaat & $\begin{array}{c}\text { gezähnt } \\
\text { ungez. }\end{array}$ & & & & $\begin{array}{l}3 \\
3\end{array}$ & & & & & & \\
\hline \multicolumn{12}{|c|}{ Walzennummern (rechts unten) } \\
\hline \multirow{2}{*}{ Ludwig } & $\begin{array}{l}\text { gezähnt } \\
\text { ungez. }\end{array}$ & 1 & 2 & 3 & 4 & 5 & 6 & 7 & 8 & 9 & 10 \\
\hline & $\begin{array}{c}\text { gezähnt } \\
\text { ungez. }\end{array}$ & 11 & 12 & 13 & 14 & 15 & 16 & 17 & 18 & 19 & 20 \\
\hline
\end{tabular}


Walzennummern (rechts unten)

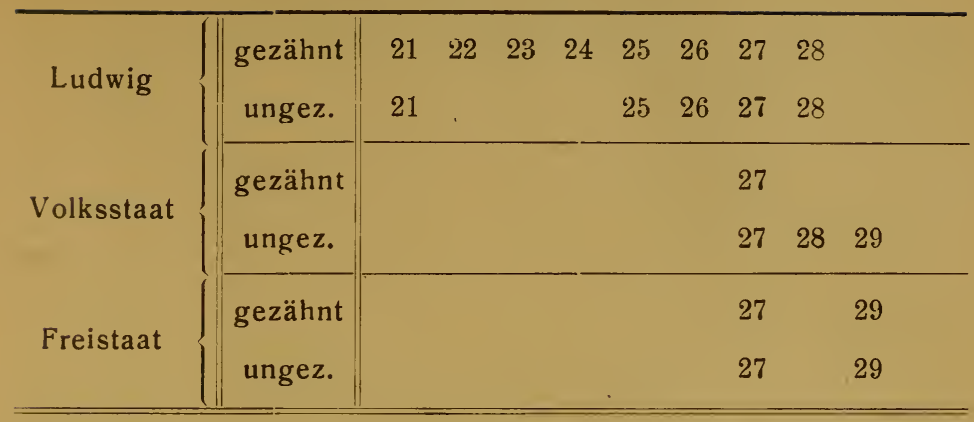

Anmerkung: Die letzte Walzennummer der Auflage 2 ist 26 ; Walze 27 gehört schon zur Auflage 3. Die gefundene Auflage $\mathrm{Nr} .{ }_{(2)}^{3}$ stammt von nachträglichen Drucken der noch brauchbaren Walze 26.

25 Pfennig grauschwarz (Kat.-Nr. 98, 122, 161) Auflagenummern (links oben)

\begin{tabular}{|c|c|c|c|c|}
\hline Ludwig & $\begin{array}{c}\text { gezähnt } \\
\text { ungez. }\end{array}$ & $\begin{array}{lc}1 & 2 \\
& (1)\end{array}$ & $\begin{array}{cc} & 3 \\
& (2) \\
& 3 \\
& (2)\end{array}$ & 3 \\
\hline Volksstaat & $\begin{array}{c}\text { gezähnt } \\
\text { ungez. }\end{array}$ & & $\begin{array}{c}3 \\
(2) \\
3 \\
(2)\end{array}$ & 3 \\
\hline Freistaat & $\begin{array}{c}\text { gezähnt } \\
\text { ungez. }\end{array}$ & & $\begin{array}{c}3 \\
(2) \\
3 \\
(2)\end{array}$ & $\begin{array}{l}3 \\
3\end{array}$ \\
\hline
\end{tabular}

Walzennummern (rechts unten)

\begin{tabular}{|c|c|c|c|c|c|c|c|c|}
\hline Ludwig & $\begin{array}{l}\text { gezähnt } \\
\text { ungez. }\end{array}$ & 1 & 2 & 3 & 4 & $\begin{array}{l}5 \\
5\end{array}$ & 6 & 7 \\
\hline Volksstaat & $\begin{array}{c}\text { gezähnt } \\
\text { ungez. }\end{array}$ & & & & & & 6 & 7 \\
\hline Freistaat & $\begin{array}{c}\text { gezähnt } \\
\text { ungez. }\end{array}$ & & & & & & 6 & 7 \\
\hline
\end{tabular}




\section{$-76-$}

30 Pfennig orange (Kat.-Nr. 99, 123, 162)

Auflagenummern (links oben)

\begin{tabular}{|c|c|c|c|c|c|c|c|c|}
\hline \multirow{2}{*}{ Ludwig } & \multirow{2}{*}{$\begin{array}{c}\text { gezähnt } \\
\text { ungez. }\end{array}$} & \multirow[t]{2}{*}{1} & \multirow{2}{*}{$\begin{array}{c}\stackrel{2}{2} \\
(1)\end{array}$} & 2 & \multicolumn{4}{|l|}{3} \\
\hline & & & & 2 & 3 & & & \\
\hline \multirow{2}{*}{ Volksstaat } & \multirow{2}{*}{$\begin{array}{c}\text { gezähnt } \\
\text { ungez. }\end{array}$} & & & & \multicolumn{4}{|l|}{3} \\
\hline & & & & & \multicolumn{4}{|l|}{3} \\
\hline \multirow{2}{*}{ Freistaat } & \multirow{2}{*}{$\begin{array}{l}\text { gezähnt } \\
\text { ungez. }\end{array}$} & & & & \multicolumn{4}{|l|}{3} \\
\hline & & & & & \multicolumn{4}{|l|}{3} \\
\hline \multicolumn{9}{|c|}{ Walzennummern (rechts unten) } \\
\hline \multirow{2}{*}{ Ludwig } & \multirow{2}{*}{$\begin{array}{l}\text { gezähnt } \\
\text { ungez. }\end{array}$} & \multirow[t]{2}{*}{1} & \multirow[t]{2}{*}{2} & \multirow[t]{2}{*}{3} & \multirow[t]{2}{*}{4} & 5 & 6 & 7 \\
\hline & & & & & & 5 & 6 & 7 \\
\hline \multirow{2}{*}{ Volksstaat } & \multirow{2}{*}{$\begin{array}{c}\text { gezähnt } \\
\text { ungez. }\end{array}$} & & & & & & & 7 \\
\hline & & & & & & & & 7 \\
\hline \multirow{2}{*}{ Freistaat } & \multirow{2}{*}{$\begin{array}{l}\text { gezähnt } \\
\text { ungez. }\end{array}$} & & & & & & & $i$ \\
\hline & & & & & & & & 7 \\
\hline
\end{tabular}

35 Pfennig orange (Kat.-Nr. 134)

\begin{tabular}{|c|c|c|c|}
\hline & & Aufl.-Nr. (1. oben) & Walzen-Nr. (r. unten) \\
\hline \multirow{2}{*}{ Volksstaat } & gezähnt & 3 & 1 \\
\hline & ungez. & 3 & 1 \\
\hline
\end{tabular}

Anmerkung: Auch ohne Aufdruck bekannt geworden!

40 Pfennig oliv (Kat.-Nr. 100, 124, 163)

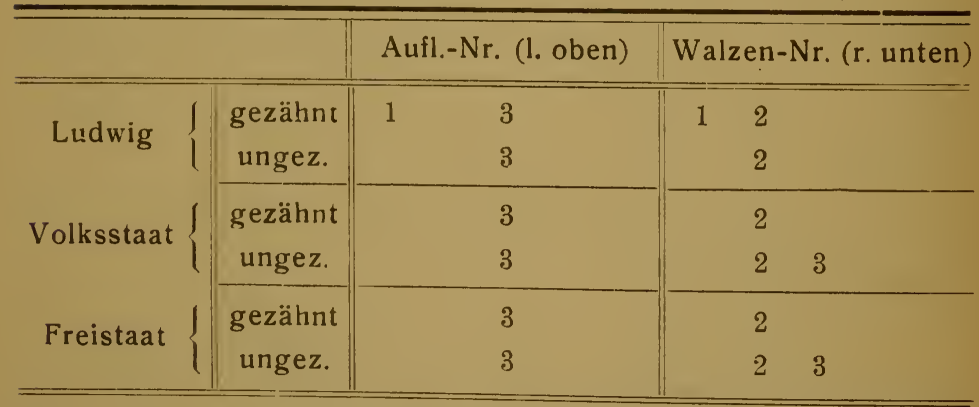

Anmerkung: Während der Auflagezeit 2 wurde dieser Wert nicht gedruckt. 
50 Pfennig rotbraun (Kat.-Nr. 101, 125, 164)

Auflagenummern (links oben)

\begin{tabular}{|c|c|c|c|c|c|c|c|c|}
\hline Ludwig & $\begin{array}{c}\text { gezähnt } \\
\text { ungez. }\end{array}$ & 1 & 2 & $\begin{array}{l}3 \\
3\end{array}$ & & & & \\
\hline Volksstaat & $\begin{array}{c}\text { gezähnt } \\
\text { ungez. }\end{array}$ & & & $\begin{array}{l}3 \\
3\end{array}$ & & & & \\
\hline Freistaat & $\begin{array}{c}\text { gezähnt } \\
\text { ungez. }\end{array}$ & & & $\begin{array}{l}3 \\
3\end{array}$ & & & & \\
\hline \multicolumn{9}{|c|}{ Walzennummern (rechts unten) } \\
\hline Ludwig & $\begin{array}{l}\text { gezähnt } \\
\text { ungez. }\end{array}$ & 1 & 2 & 34 & 5 & 6 & & 8 \\
\hline Volksstaat & $\begin{array}{c}\text { gezähnt } \\
\text { ungez. }\end{array}$ & & & & & & $\begin{array}{l}7 \\
7\end{array}$ & 8 \\
\hline Freistaat & $\begin{array}{c}\text { gezähnt } \\
\text { ungez. }\end{array}$ & & & & & & & $\begin{array}{l}8 \\
8\end{array}$ \\
\hline
\end{tabular}

60 Pfennig dunkelgrün (Kat.-Nr. 102, 126, 165)

\begin{tabular}{|c|c|c|c|c|c|c|c|}
\hline \multirow[b]{2}{*}{ Ludwig } & \multirow[b]{2}{*}{$\begin{array}{c}\text { gezähnt } \\
\text { ungez. }\end{array}$} & \multicolumn{2}{|c|}{ Aufl.-Nr. (I. oben) } & \multicolumn{4}{|c|}{ Walzen-Nr. (r. unten) } \\
\hline & & 1 & $\begin{array}{lc} & 2 \\
& (3) \\
& 2 \\
2 & (3)\end{array}$ & 1.2 & $\begin{array}{l}3 \\
3\end{array}$ & 4 & $\begin{array}{l}5 \\
5\end{array}$ \\
\hline Volksstaat & $\begin{array}{c}\text { gezähnt } \\
\text { ungez. }\end{array}$ & & $\begin{array}{c}2 \\
(3) \\
2 \\
(3) \\
\end{array}$ & & & & \\
\hline Freistaat & $\begin{array}{c}\text { gezähnt } \\
\text { ungez. }\end{array}$ & & $\begin{array}{c}2 \\
(3) \\
2 \\
(3)\end{array}$ & & & & \\
\hline
\end{tabular}




\section{$-78-$}

75 Pfennig rotbraun (Kat.-Nr. 135)

\begin{tabular}{|c|c|c|c|}
\hline & & Aufl.-Nr. (1. oben) & Walzen-Nr.(r. unten) \\
\hline \multirow{2}{*}{ Volksstaat } & \multirow{2}{*}{$\begin{array}{c}\text { gezähnt } \\
\text { ungez. }\end{array}$} & 3 & 12 \\
\hline & & 3 & 1 \\
\hline
\end{tabular}

Anmerkung: Auch ohne Aufdruck bekannt geworden!

75 Pfennig olivbraun (Kat.-Nr. 166)

\begin{tabular}{|c|c|c|c|}
\hline & & Aufl.-Nr. (1. oben) & Walzen-Nr. (r.unten) \\
\hline \multirow{2}{*}{ Freistaat } & gezähnt & 3 & 3 \\
\hline & ungez. & 3 & 3 \\
\hline
\end{tabular}

Anmerkung: Auch ohne Aufdruck bekannt geworden!

80 Pfennig dunkelviolett (Kat.-Nr. 103, 127, 167)

\begin{tabular}{|c|c|c|c|c|c|c|c|}
\hline & & Aufl.-N & r. (1. oben) & Wal & en & vr. & unten) \\
\hline \multirow{2}{*}{ Ludwig } & gezähnt & 12 & 3 & 1 & 2 & 3 & \\
\hline & ungez. & & 3 & & & 3 & 4 \\
\hline \multirow{2}{*}{ Volksstaat } & gezähnt & . & 3 & & & 3 & \\
\hline & ungez. & & 3 & & & 3 & 4 \\
\hline \multirow{2}{*}{ Freistaat } & gezähnt & & 3 & & & 3 & \\
\hline & ungez. & & 3 & & & 3 & 4 \\
\hline
\end{tabular}

1 Mark braun (Kat.-Nr. 104, 128, 168)

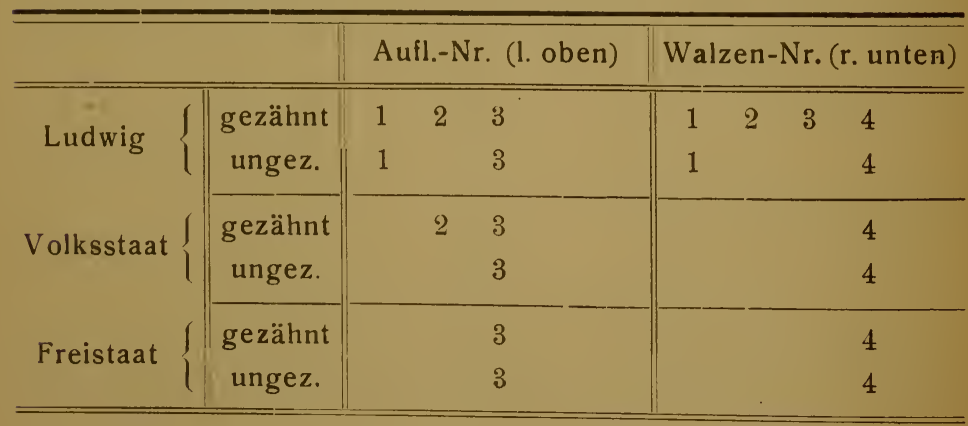


1,25 Mark auf 1 Mark maigrün (Kat.-Nr. 174)

\begin{tabular}{c||c||c}
\hline \hline \multirow{3}{*}{ Freistaat } & Aufl.-Nr. (l. oben) & Walzen-Nr. (r. unten) \\
\hline \hline
\end{tabular}

Anmerkung: Auch ohne Aufdruck bekannt geworden!

1,50 Mark auf 1 Mark orange (Kat.-Nr. 175)

\begin{tabular}{l||c||c|c}
\hline \hline \multirow{3}{*}{ Freistaat } & Aufl.-Nr. (l. oben) & Walzen-Nr. (r. unten) \\
\hline
\end{tabular}

Anmerkung: Auch ohne Aufdruck bekannt geworden!

2 Mark dunkelviolett (Kat.-Nr. 105, 129, 169)

\begin{tabular}{|c|c|c|c|}
\hline & & Aufl.-Nr. (1. oben) & Walzen-Nr. (r. unten) \\
\hline \multirow{2}{*}{ Ludwig } & gezähnt & 1 & 1 \\
\hline & ungez. & 1 & 1 \\
\hline \multirow{2}{*}{ Volksstaat } & gezähnt & 1 & 1 \\
\hline & ungez. & 1 & 1 \\
\hline \multirow{2}{*}{ Freistaat } & gezähnt & 1 & 1 \\
\hline & ungez. & 1 & 1 \\
\hline
\end{tabular}

2.50 Mark auf 1 Mark schiefer (Kat.-Nr. 176)

\begin{tabular}{l||c||c}
\hline \hline \multirow{2}{*}{ Freistaat } & Aufl.-Nr. (l. oben) & Walzen-Nr. (r. unten) \\
\hline \hline
\end{tabular}

Anmerkung: Auch ohne Aufdruck bekannt geworden! 
3 Mark rot (Kat.-Nr. 106, 130, 170)

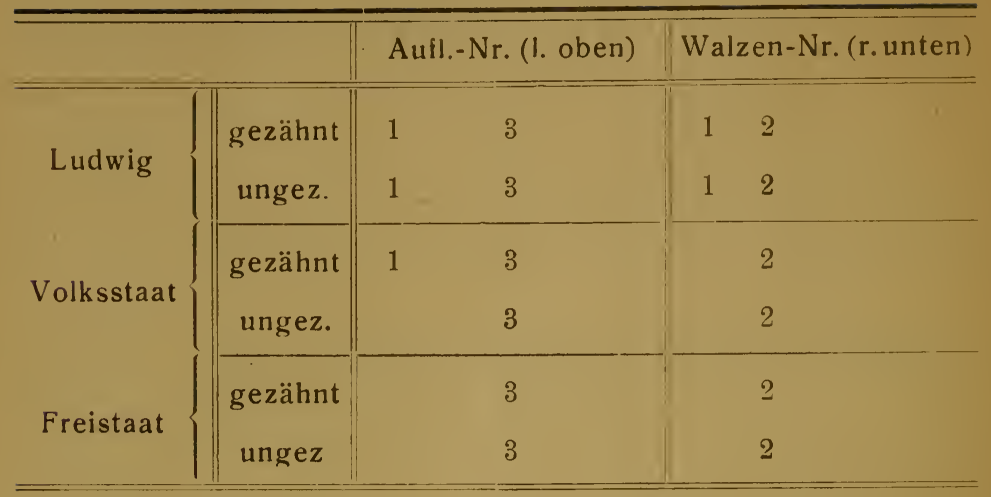

5 Mark dunkelblau (Kat.-Nr. 107. 131, 171)

\begin{tabular}{|c|c|c|c|c|c|}
\hline & & \multicolumn{2}{|c|}{ Aufl.-Nr. (1. oben) } & \multicolumn{2}{|c|}{ Walzen-Nr.(r. unten) } \\
\hline Ludwig & $\begin{array}{c}\text { gezähnt } \\
\text { ungez. }\end{array}$ & $\begin{array}{l}1 \\
1\end{array}$ & $\begin{array}{l}3 \\
3\end{array}$ & $\begin{array}{l}1 \\
1\end{array}$ & $\begin{array}{l}2 \\
2\end{array}$ \\
\hline Volksstaat & $\begin{array}{c}\text { gezähnt } \\
\text { ungez. }\end{array}$ & & $\begin{array}{l}3 \\
3\end{array}$ & & $\begin{array}{l}2 \\
2\end{array}$ \\
\hline Freistaat & $\begin{array}{c}\text { gezähnt } \\
\text { ungez. }\end{array}$ & & $\begin{array}{l}3 \\
3\end{array}$ & & $\begin{array}{l}2 \\
2\end{array}$ \\
\hline
\end{tabular}

10 Mark grün (Kat.-Nr. 108, 132, 172)

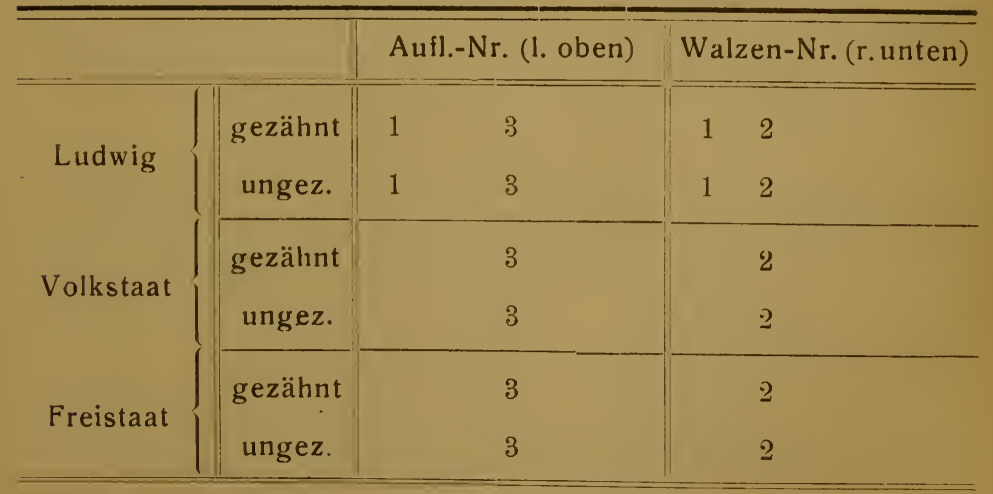


20 Mark dunkelbraun (Kat.-Nr. 109, 133, 173)

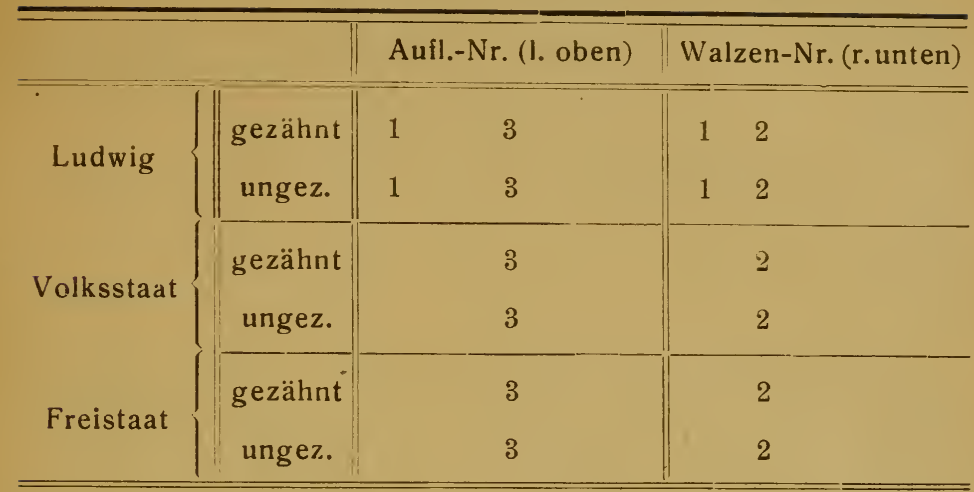

Anmerkung: Die Werte zu 3,5, 10 und 20 Mark wurden während der Auflagezeit 2 nicht gedruckt.

Die Verausgabung der ungezähnten Marken der Ludwig-, Volksstaat- und Freistaat-Serie erfolgte nur zu Sammelzwecken und zwar nicht im allgemeinen Verkauf, sondern gegen vorhergehende Bestellung an einer mit diesem Verkauf beauftragten Dienststelle in München. Diese „geschnittenen " Marken hatten naturgemäß volle Frankierungskraft, wurden jedoch vielen Bestellern erst nach Außerkurssetzung geliefert. Vergleicht man die Walzennummern der gezähnten und ungezähnten Marken, so findet man eine Reihe von Nummern, die nur "geschnitten" verausgabt sind, also nur zu Sammelzwecken gedruckt, nicht allgemein käuflich waren und in großen Mengen erst nach Außerkurssetzung den Bestellern geliefert wurden. Diese Marken sind zweifellos in philatelistischem Sinne nicht vollwertig, und es liegt die Vermutung nahe, daß einzelne derselben auch unter die auf dem Sammlertag in Gotha am 8. VIII. 09. angenommene Neudruck-Definition fallen:

Neudrucke sind Abzüge von Postwertzeichen, hergestellt unter Verwendung der echten Stempel zu einer Zeit, als der Druck gleichartiger Postwertzeichen zwecks postalischer Verwendung bereits endgültig eingestellt worden war. (Dr. May, Dresden.) 


\section{$-82-$}

Ich fand folgende Walzennummern nur ungezähnt:

15 Pfg.

20

25, , (alle Aufl.-Nr. 3) 7

40,

50

80,
Ludwig Volksstaat 55 28

Es handelt sich wohl um Werte, welche im unfertigen (ungezähnten) Zustande nicht mehr in genügender Zahl vorhanden waren, um den Händler- und Sammlerbestellungen zu genügen, und die deshalb nachgedruckt werden mußten. Ich glaube allerdings, daß vielleicht die eine oder andere dieser Walzennummern noch ge$z$ ähnt gefunden wird und auf diese Weise die ungezähnte Marke gleicher Walzennummer vollwertig macht.

Ohne auf mancherlei kleine meist belanglose Druckmängel im Aufdruck der Volksstaat- und Freistaat-Ausgaben einzugehen, möchte ich hier nur eine ganz vereinzelt voryekommene Aufdruckabart nennen: bei der VolksstaatMarke zu 15 Pfennig, Walzennummer 42, Feld 9 (also unter Reihenwertzahl 13,50) ist die Entfernung der untereinanderstehenden Wörter "Volksstaat" und „Bayern“ $2 \frac{1}{2} \mathrm{~mm}$ statt regelrecht $1 \frac{1}{2} \mathrm{~mm}$, ein auffallender, nur einmal beobachteter Unterschied.

Markenheftchen der Ludwigausgabe.

Es erschienen nur zwei Heftchen der Ludwigausgabe, (s. Berl. Briefm.-Ztg. 1920 S. 229) mit den Heftchennummern 12: enthaltend 10 Marken zu 10 Pfg. dunkelgrün । 20 " zu 5 Pfg. rot 13: enthaltend $10 \quad, \quad$ zu $15 \mathrm{Pfg}$. dunkelgrün $12 \quad, \quad z u \quad 7 / 2$ Pfg. rot Mk. 2.40 "Die Blindfelder wurden zu Anzeigen nicht mehr benützt" und sind durch Rechtecke mit breitlinigen Diagonalen ausgefüllt. Auch bei dieser Ausgabe waren die Marken- 


\section{$-83-$}

bogen zur Herstellung der Heftchen im freien Verkauf. Diese Bogen zeigen genau entsprechend den regelrechten Briefmarkenbogen

1) Auflagenummer links oben

2) Walzennummer rechts unten.

Ich bezweifle, daß sämtliche Walzennummern als ganze Bogen verkauft wurden; man wird auch hier nur dem gelegentlich aufgetretenen Neubedarf entsprechend die gerade im Druck befindlichen Bogen in größerer Menge zum Verkauf bereitgestellt haben. Die Werte zu 5 und $10 \mathrm{Pfg}$. sind nur in der ersten, ursprünglichen Farbe (dunkelgrün und rot) in Markenheftchen verwendet worden; es soll auch ein Bogen der 5 Pfennig-Marke ungezähnt bekannt sein. Die Werte zu $7 \frac{1}{2}$ und 15 Pfennig wurden in geringer Menge in ungezähnten Bogen vom Verlagsamt verkauft (siehe Tabelle). Ich kenne von Heftchenbogen folgende Randnummern:

\begin{tabular}{|c|c|c|c|c|c|c|}
\hline & Auflage-Nr. (1. oben) & \multicolumn{5}{|c|}{ Walzen-Nr. (r. unten) } \\
\hline $5 \mathrm{Pfg.}$ & 1 & 1 & 2 & 3 & 4 & 8 \\
\hline 10 Pfg. & 1 & 1 & & & 4 & \\
\hline $71 / 2$ Pfg. $\left\{\begin{array}{l}\text { gezähnt } \\
\text { ungezähnt }\end{array}\right.$ & $\stackrel{2}{2}$ ohne $\mathrm{Nr}$. & 1 & 2 & & & \\
\hline $15 \mathrm{Pfg} \cdot\left\{\begin{array}{l}\text { gezähnt } \\
\text { ungezähnt }\end{array}\right.$ & $\begin{array}{c}2 \\
\text { ohne } \mathrm{Nr} .\end{array}$ & 1 & 2 & 3 & 4 & \\
\hline
\end{tabular}

Fast könnte man vermuten, daß auch auf die ungezähnten Bogen der Werte zu $7 \frac{1}{2}$ und 15 Pfennig die. Neudruck-Definition zutrifft.

Wohltätigkeitsmarken für Kriegsbeschädigte (Kriegsfürsorgemarken) mit einem entsprechenden Aufdruck und Aufschlag von 5 Pfennig für Kriegsbeschädigte wurden vom 25. August 1919, die Marke zu 20 und 5 Pfennig vom 22. Dezember 1919 an zum Verkauf gestellt. 


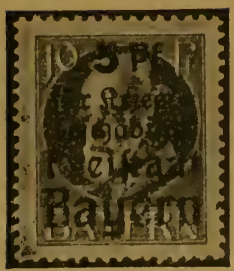

Sie weisen folgende Auflage- bezw. Walzennummern auf:

\begin{tabular}{|c||c||r|rrrr|}
\hline \hline Kat.-Nr. & & Auflage-Nr. (1. oben) & Walzen-Nr. (r. unten) \\
\hline 152 & 10 u. 5 Pfg. & 3 & 104 & 111 & 115 & \\
153 & 15 u. 5 Pfg. & 3 & 48 & 49 & 53 & 54 \\
154 & 20 u. 5 Pfg. & 3 & 27 & & & \\
\hline
\end{tabular}

Im Anschluß an die Ausgaben mit dem Bildnisse des Königs Ludwig führe ich hier die im

$$
\text { bayerischen Saargebiet (Saarpialz) }
$$

aus diesen Marken hergestellten Wertzeichen an, welche den schwarzen Aufdruck „Sarre“ unter gleichzeitiger mehrfacher Durchstreichung des Wortes "Bayern" zeigen. (Senf-Katalog Saargebiet Nr. 18-31). Ich verdanke Herrn Dr. E. Dub in Oberstein und E. Seyfried in Landstuhl die Ergänzung meiner eigenen Feststellungen über das Vorkommen von Auflage- und Walzennummern.

\begin{tabular}{|c|c|c|c|c|c|c|}
\hline & & \multicolumn{2}{|c|}{ Aufl.-Nr. (I. oben) } & \multicolumn{3}{|c|}{ Walzen.-Nr. (r. u.) } \\
\hline & Pfg. & & 3 & & 71 & \\
\hline 10 & $\eta$ & & 3 & 117 & 119 & 120 \\
\hline & $\begin{array}{l}\text { gelblichrot, rot } \\
\text { rot }\end{array}$ & & 3 & & 54 & \\
\hline 15 & $"\left\{\begin{array}{c}\text { blutrot (Farben- } \\
\text { fehldruck) }\end{array}\right.$ & & 3 & & 55 & \\
\hline 20 & $"$ & & $\begin{array}{l}3 \\
3\end{array}$ & & 28 & \\
\hline 25 & $"$ & & (2) & & 6 & \\
\hline 30 & $"$ & & 3 & & 7 & \\
\hline 40 & $"$ & & 3 & & 2 & \\
\hline 50 & $"$ & & $\begin{array}{l}3 \\
3\end{array}$ & & 7 & 8 \\
\hline 60 & $"$ & 2 & $\begin{array}{c}5 \\
(2)\end{array}$ & & 3 & 5 \\
\hline & Mk. & & 3 & & 4 & \\
\hline 2 & $"$ & & 1 & & 1 & \\
\hline 3 & $"$ & & 3 & & 2 & \\
\hline 5 & $"$ & & 3 & & 2 & \\
\hline 10 & $"$ & & 3 & & 2 & \\
\hline
\end{tabular}


Die mit dem gleichen Aufdruck versehenen, nicht zur Ausgabe gelangten Werte haben folgende Randnummern:

\begin{tabular}{|c||c||c|}
\hline & Aufl.-Nr. (l. oben) & Walzen-Nr. (r.unten) \\
\hline 2 Pfennig & 3 & 8 \\
3 & $(2)$ & 20 \\
$71 / 2,$. & 3 & 21 \\
20 Mark & 3 & - \\
\hline
\end{tabular}

Von der Marke zu 20 Mark wurde nur 1 Bogen überdruckt, aus welchem der rechte untere Eckviererblock mit der Walzennummer (vermutlich 2) herausgetrennt war.

IV. Bilderzeichnung, später mit zweizeiligem Aufdruck „Deutsches Reich“.

Nachdem die Revolution und ihre Folgen die Marken mit dem Bild des Königs Ludwig in solche des Volksstaats, bezw. Freistaats Bayern umgewandelt hatten und außerdem Veranlassung waren zur Ausgabe der Marken des Deutschen Reichs mit Aufdruck „Freistaat Bayern“ (deren Bearbeitung im Abschnitt $\mathrm{V}$ folgt), erschien erst im Frühjahır 1920 für nur kurze Umlaufsdauer die Markenausgabe in Bilderzeichnung als erste und einzige selbständige Ausgabe des Freistaats. Mit dem Ubergang der bayerischen Post an das Reich verloren auch diese Marken ihre Gültigkeit, wurden zum Aufbrauch mit dem zweizeiligen Aufdruck ,Deutsches Reich"versehen und auch um überzuleiten zu dem Zeitpunkt, von welchem an die Reichsdruckerei in Berlin die Briefmarkenversorgung Bayerns mit Wertzeichen des Deutschen Reichs übernehmen sollte. Im Sommer 1920 wurde der Druck der bayerisch-deutschen Marken eingestellt, da man mit vollständiger Belieferung aus Berlin rechnen zu können glaubte. Da die Reichsdruckerei jedoch sich außer Stande sah, den Markenbedarf Bayerns mitzudecken, war Bayern gezwungen, Ende 1920 oder Anfangs 1921 erneut Briefmarken der Bilder- 
ausgabe mit Aufdruck „Deutsches Reich" herzustellen, und bei Abschluß dieses Buches dauert diese Briefmarkenherstellung noch an, nachdem Bayern nun schon über 1 Jahr seine Postselbständigkeit aufgegeben hat.

Aus früher erwähnten Gründen führe ich auch diese bayerisch-deutschen Marken hier aui, obwohl sie strenggenommen deutsche und nicht bayerische Postwertzeichen sind. Ihr Zusammenhang mit Bayern ist jedoch in jeder Beziehung ein so enger, daß ich ihre Mitbearbeitung an dieser Stelle für -fast selbstverständlich halte. Da diese Ausgabe noch nicht zum Abschluß gelangt ist, sondern auf scheinbar unbestimmte Zeit weitergedruckt wird, werden sich noch neue Plattennummern finden, die in meiner Tabelle leicht nachgetragen werden können.

Der $4 \times 100$ Marken der Pfennigwerte enthaltende Druckbogen besteht aus zwei $2 \times 100$ Marken enthaltenden kopfstehend zu einander angeordneten Zähnungsbogen, von welchen die äußeren unteren Ecken (selten die oberen) mit der Nummer der verwendeten Druckplatte versehen sind. Die Markwerte mit dem Bilde der Madonna zeigen teils links, teils rechts, teils beiderseitig die Plattennummern, die hohen Markwerte zu 4-20 Mark weisen links oben Auflagenummern, rechts unten Plattennummern auf, in gleicher Art wie die Bogen der hohen Markwerte der Ludwigausgabe.

Bei der Aufzählung der Platten-Nummern der Werte zu 5 Pfennig bis 80 Pfennig ist $z u$ beachten, daß die Zahlen und Buchstaben links oder rechts, oben oder unten stehen können, daß sie jedoch auf einem Schalterbogen nicht gleichzeitig links und rechts vorkommen. Die Stellung der Zahlen und Buchstaben in der Tabelle läßt deren Stellung auf dem Markenbogen erkennen; z. B.

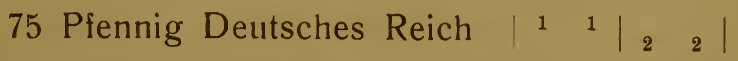

bedeutet, daß Plattennummer 1 entweder links oder rechts oben, Plattennummer 2 entweder links oder rechts 
un te n vorkommt. Die Bezeichnung $\left|\begin{array}{lll}1 & 1 \\ b & b\end{array}\right|$ bedeutet, daß entweder links oder rechts 1 oben und gleichzeitig b unten steht.

Die seltene Zeichnung der 20 Pfennig-Marke (bei Senf noch nicht katalogisiert) kommt als Block von 25 Marken (rechtes, oberes Bogenviertel) auf Bogen mit Platten-Nr. 1 (links unten), aus dem Doppelbogen „b“ (siehe Bogeneinteilung) stammend, vor; diese Marke ist noch nicht mit Aufdruck „Deutsches Reich“ gefunden worden.

Platten-Nummern der Bilderausgabe:

\begin{tabular}{|c|c|c|c|c|c|c|}
\hline Kat.- \r. & \multirow{2}{*}{$\frac{\text { Wert }}{5 \mathrm{Pfg} .}$} & \multirow{2}{*}{$\frac{\mid \begin{array}{c}\text { Bay- } \\
\text { ern }\end{array}}{-1}$} & \multicolumn{4}{|c|}{ Deutsches Reich } \\
\hline $178 / 195$ & & & $1 \quad 1$ & $\begin{array}{ll}2 & 2 \\
\end{array}$ & $\begin{array}{lll}3 & 3 \\
\end{array}$ & \\
\hline $179 / 196$ & 10 & $1 \quad 1$ & 11 & $\begin{array}{ll}2 \quad 2 \\
\end{array}$ & & \\
\hline $180 / 197$ & 15, & $1 \quad 1$ & 11 & & & \\
\hline $181 / 198$ & 20, & $1 \quad 1$ & $1 \quad 1$ & $2 \quad 2$ & & \\
\hline $182 / 199$ & $30 \quad$, & $1 \quad 1$ & $1 \quad 1$ & $2 \quad 2$ & & \\
\hline $183 / 200$ & $40 \quad$. & $1 \quad 1$ & 1 & $\begin{array}{ll}2 \quad 2 \\
\end{array}$ & auch & \begin{tabular}{ll|ll} 
& 1 & 1 & 1 \\
$a$ & $a$ & $b$ & $b$ \\
\end{tabular} \\
\hline $184 / 201$ & 50 & $1 \quad 1$ & $1 \quad 1$ & $2 \quad 2$ & $\begin{array}{ll}3 \\
\end{array}$ & $\begin{array}{l}\text { auch l. und r. unter } \\
\text { a oder b in schwarz }\end{array}$ \\
\hline $185 / 202$ & $60, y$ & $1:$ & & $\begin{array}{lll}2 & 2 \\
\end{array}$ & auch & \begin{tabular}{ll|ll}
1 & 1 & 2 & 2 \\
& & $a$ & $a$ \\
\end{tabular} \\
\hline $186 / 203$ & $75 \quad$. & \begin{tabular}{|l|l|}
1 & 1 \\
\end{tabular} & $\begin{array}{lll}1 & 1 \\
\end{array}$ & $2 \quad 2$ & & \\
\hline$-/ 204$ & $80 \quad .$. & - & 1 & $2 \quad 2$ & & \\
\hline $187 / 205$ & $1 \mathrm{Mk}$. & 1 & $\begin{array}{ll}1 & 1 \\
1\end{array}$ & 2 & & \\
\hline $188 / 206$ & $11 / 4$, & 1 & 1 & 1 & & \\
\hline $189 / 207$ & $11 / 2$, & 1 & 1 & -1 & & ohne \\
\hline$-/ 208$ & $2 \quad$, & - & $\begin{array}{ll}1 & 1 \\
\end{array}$ & -- & 2 & rechts und links! \\
\hline 190209 & $2 \frac{1}{2}, B$ & 1 & 1 & 2 & & \\
\hline & $21 / 2, S$ & \begin{tabular}{|ll}
1 & 1 \\
\end{tabular} & 11 & & & \\
\hline
\end{tabular}

Anmerkung: $B=$ Buchdruck, $S=$ Steindruck.

Einige der Pfennigwerte dieser Ausgaben sind ungezähnt bekannt geworden. 
Auflage-und Platten-Nummern der Bilderausgabe.

\begin{tabular}{|c|c|c|c|c|c|}
\hline \multirow[b]{2}{*}{ Kat.-Nr. } & \multirow[b]{2}{*}{ Wert } & \multicolumn{2}{|c|}{ Bayern } & \multicolumn{2}{|c|}{ Deutsches Reich } \\
\hline & & $\begin{array}{l}\text { Aufl.-Nr. } \\
\text { (1. oben) }\end{array}$ & $\begin{array}{l}\text { Platt.-Nr. } \\
\text { (r. unten) }\end{array}$ & $\begin{array}{l}\text { Aufl.-Nr. } \\
\text { (l. oben) }\end{array}$ & $\left|\begin{array}{l}\text { Platt.-Nr. } \\
\text { (r. unten) }\end{array}\right|$ \\
\hline $191 / 210$ & $3 \mathrm{Mk}$ & 1 & 1 & 1 & 1 \\
\hline$-/ 211$ & 4, & - & - & 1 & 1,2 \\
\hline $192 / 212$ & 5, & 1 & 1 & 1 & 1 \\
\hline $193 / 213$ & 10 & 1 & 1 & 1 & 1 \\
\hline $194 / 214$ & 20, & 1 & 1 & 1 & 2 \\
\hline
\end{tabular}

Anmerkung: Die Werte zu 80 Pfg., 2 und $4 \mathrm{Mk}$. sind ohne Aufdruck „Deutsches Reich" nicht verausgabt worden.

Die durch die Portoerhöhung meist gebrauchten Werte „Deutsches Reich" zu 40 und 60 Pfennig haben zahlreiche Auflagen aufzuweisen.

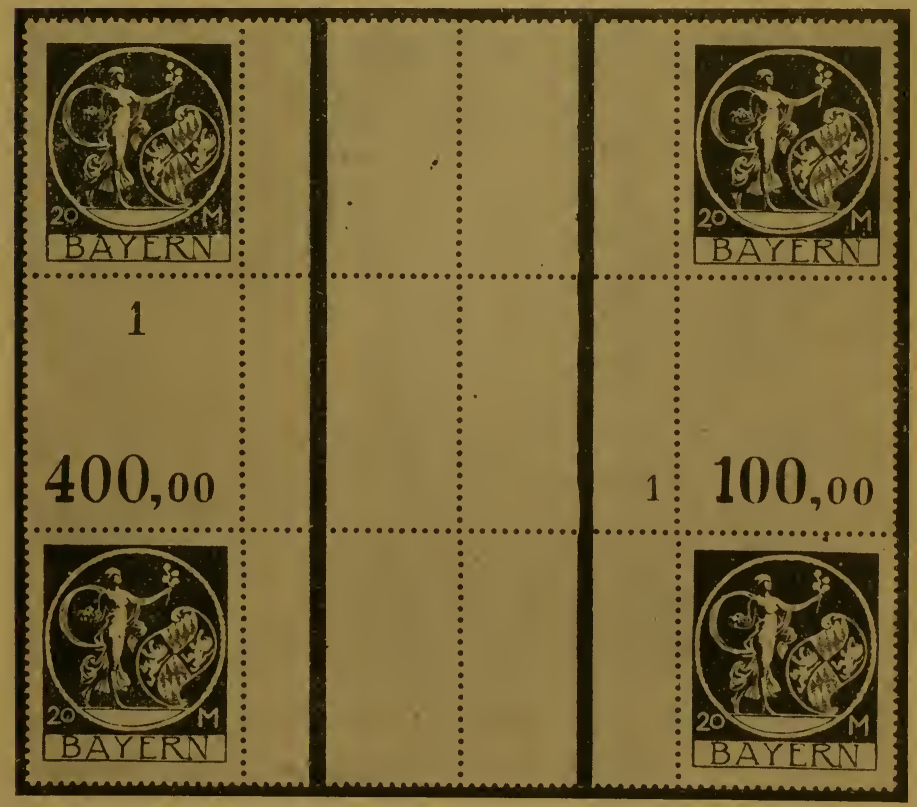

Auflage-Nummer (kleine Ziffer ,1“) und Platten-Nummer (große Ziffer ", ${ }^{\text {") }}$ ) aus unzertrennten Druckbogen. 
V. Germania-Zeichnung

mit zweizeiligem Aufdruck ,Freistaat Bayern“.

Die Entstehungsgeschichte dieser Ausgabe wurde schon im ersten Teil dieser Arbeit kurz erzählt. Zeitlich fällt diese Ausgabe zusammen mit der Ludwig-Ausgabe mit Aufdruck ,Freistaat Bayern“.

Die Germania-Ausgabe besteht aus 16 Werten (SenfKatalog Nr. 136-151), von welchen 13 Werte in 2 Auflagen gedruckt sind:

1. A uf lage: Bedarfs a usgabe, hergestellt in der Reichsdruckerei in Berlin unter der Buchungsnummer, für uns Auflagenummer 1224.19. in die Verpackungsumschläge eingezählt am 2.-12. Mai 1919, umfassend die 13 Werte:

$2^{1} / 2,3,5,7 \frac{1}{2}, 10,20,25,40,80$ Pfg., 1, 2, 3, 5 Mk.

2. A uflage: Sammleraus gabe, Auflage-Nr. 3103.19. in die Verpackungsumschläge eingezählt am 7. bis 16. August 1919 (vermutlich Reste am 1. Okt. 1919), umfassend die 13 Werte:

3, 5, 15, 20, 25, 35, 40, 75, 80 Pfg., 1, 2, 3, $5 \mathrm{Mk}$.

In vorstehender Angabe, welche Werte in jeder der beiden Auflagen erschienen sind und welche Auflagenummern diese beiden Auflagen kennzeichnen, ist in der Hauptsache die Aufstellung der Auflagenummern gegeben. Ich führe diese jedoch weiter aus und erfreue mich dabei der Mitarbeit des Herrn Jakob Sessler in Nürnberg. Die Auflagenummern der in der Reichsdruckerei hergestellten Postwertzeichen sind „Auftragsnummern“, das heißt laufende Nummern, unter welchen (im Hauptbuch der Reichsdruckerei, daher bei den meisten Auflagenummern „H“ vor der Zahl, auch von Hausnummer oder Hausauftrag abgeleitet) der betreffende Druckauftrag gebucht wurde. Diese Nummer, einschließlich der ihr beigesetzten Jahrzahl (hier ,19") gibt eine Handhabe, die Entstehungszeit festzustellen, verschiedene Auflagen zu unterscheiden und in die richtige zeitliche Reihenfolge zu bringen. 


\section{$-90-$}

Wie schon erwähnt ist der Aufdruck „,Freistaat Bayern“ in zwei Druckaufträgen, also in 2 Auflagen hergestellt worden. Der Aufdruck, wie auch seine Auflagenummer sind in dieser Ausgabe stets schwarz; die Auflagenummern finden sich bei dieser Ausgabe stets am unteren Bogenrand. Die Aufdruckfarbe schwankt (wie bei den letzten Ausgaben der deutschen Kriegsmarken) zwischen einem schwach glänzenden und völlig stumpfen, rußigen Schwarz. Die Aufdruckauflagenummer ist bei vorliegender GermaniaAusgabe fast stets begleitet von einer Nummer $1-6$, mit welcher die jeweilig zum Aufdruck verwendete Druckplatte bezeichnet ist. Fehlt diese Begleitzahl, so ist dies in der Spalte ,gefundene Platten" der Aufdruckauflagenummern mit "0" angegeben. (Tabelle).

Wie der Aufdruck seine Auftrags- bezw. Auflagenummer besitzt, so zeigen die Markenbogen selbst, soweit sie im sogenannten „Plattendruck“ (P) ausgeführt sind, eine ihre Entstehungszeit festlegende Auftrags- bezw. Auflagenummer in einer beim Markendruck selbst verwendeten Druckfarbe. Auch diese Auflagenummern habe ich festgestellt und in Spalte „Bogen-Nummer" der Tabelle angegeben. Die Kenntnis dieser Zahlen kann wichtig sein beim Nachweis falscher Aufdrucke. Die im sogenannten „Walzendruck“ (W) hergestellten Markenbogen, kenntlich an den den oberen und unteren Bogenrand völlig deckenden senkrechten Strichen in den Farben des Markenbildes (die seitlichen Bogenränder sind frei von Strichen und Leisten) haben keine Auflagenummern (sind nur von einer Zählmaschine fortlaufend nummeriert). In der bayerischen Germania-Ausgabe sind nur die Werte 25, 40, 75 und 80 Pfennig sowie ein ganz kleiner Teil der 1. Auflage des Wertes zu 20 Pfennig im Walzendruck hergestellt. - Die in Kupferdruck hergestellten Mark-Werte haben keine B o g e n - Auflagenummern.

Vermutlich ist als erster für Bayern überdruckter Wert in der ersten Druckauflage die Marke zu 5 Pfennig überdruckt worden, und zwar wurde mit dem Druck begonnen, 

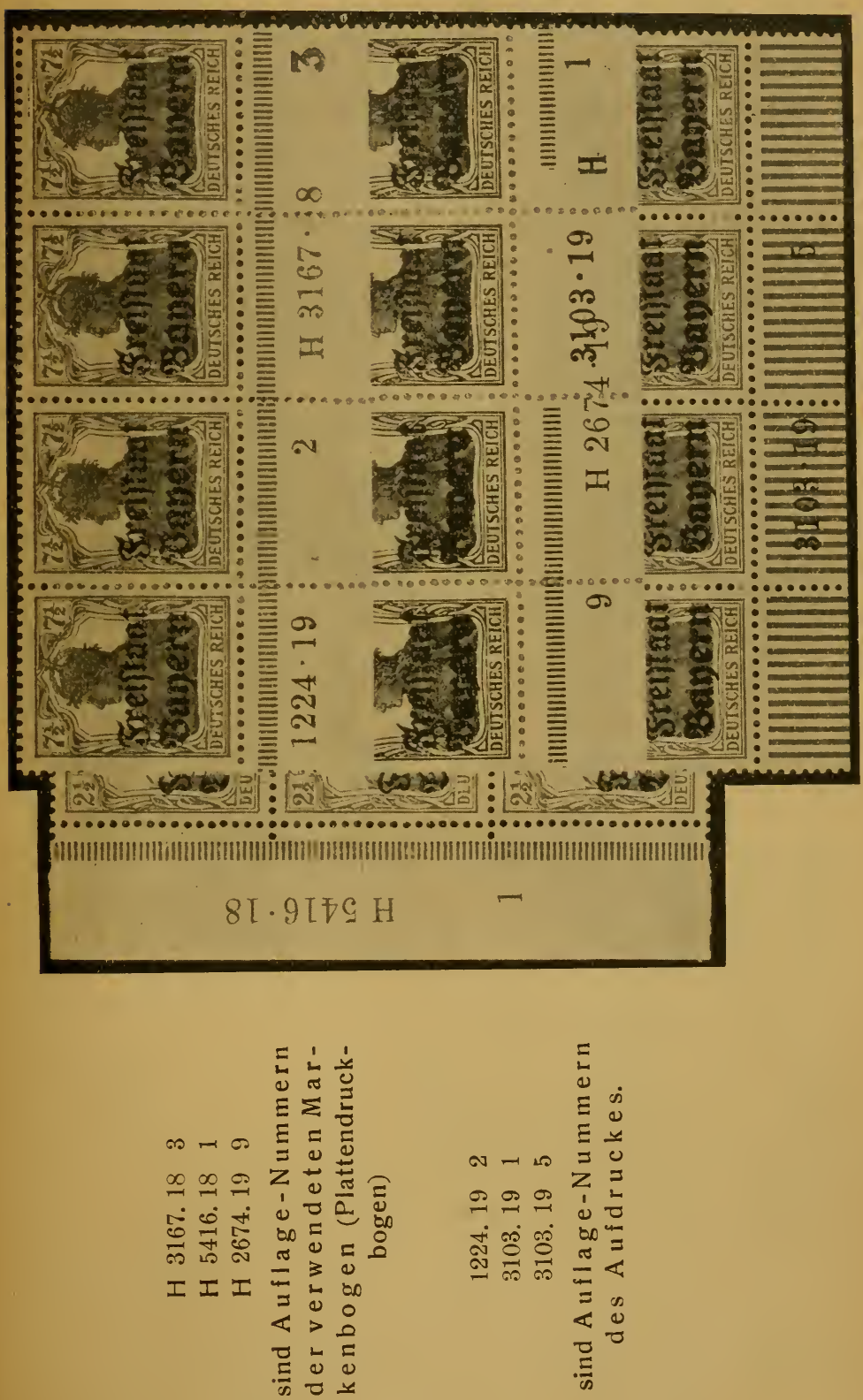
ehe die „Auftragsnummer" (hier 1224) dem Buchdrucker bekanntgegeben war; so erkläre ich das Vorkommen von 5 Pfennig-Bogen mit der Auflagenummer ,000.19.“ Von besonderem Interesse ist auch ein Fehldruck der Auflagenummer 1224.18 statt 1224.19, welcher von Professor Dr. H. Molz bei der 1 Mark-Marke gefunden wurde.

Ich will noch erwähnen, daß es die Markwerte in zwei Zähnungen geringer Verschiedenheit gibt, welche der Größenveränderung des in angefeuchtetem Zustande bedruckten Kupferdruckpapieres angepaßt sind, nämlich in Zähnung: $14^{1} / 2=26$ Zahnlöcher an der Markenlängsseite, "Die Zähnung 25 findet sich bei "den Werten 1, 2, 3, 5 Mark.

Die Zähnung 26 bei den Werten 2 und 5 Mark.

Die Auflagehöhe des Wertes zu 5 Mark muß auf 400000-500000 Einzelstücke geschätzt werden, diejenige aller anderen Werte ist größer.

Anmerkung: Liste der Auflage-Nummern auf Seite 93. 


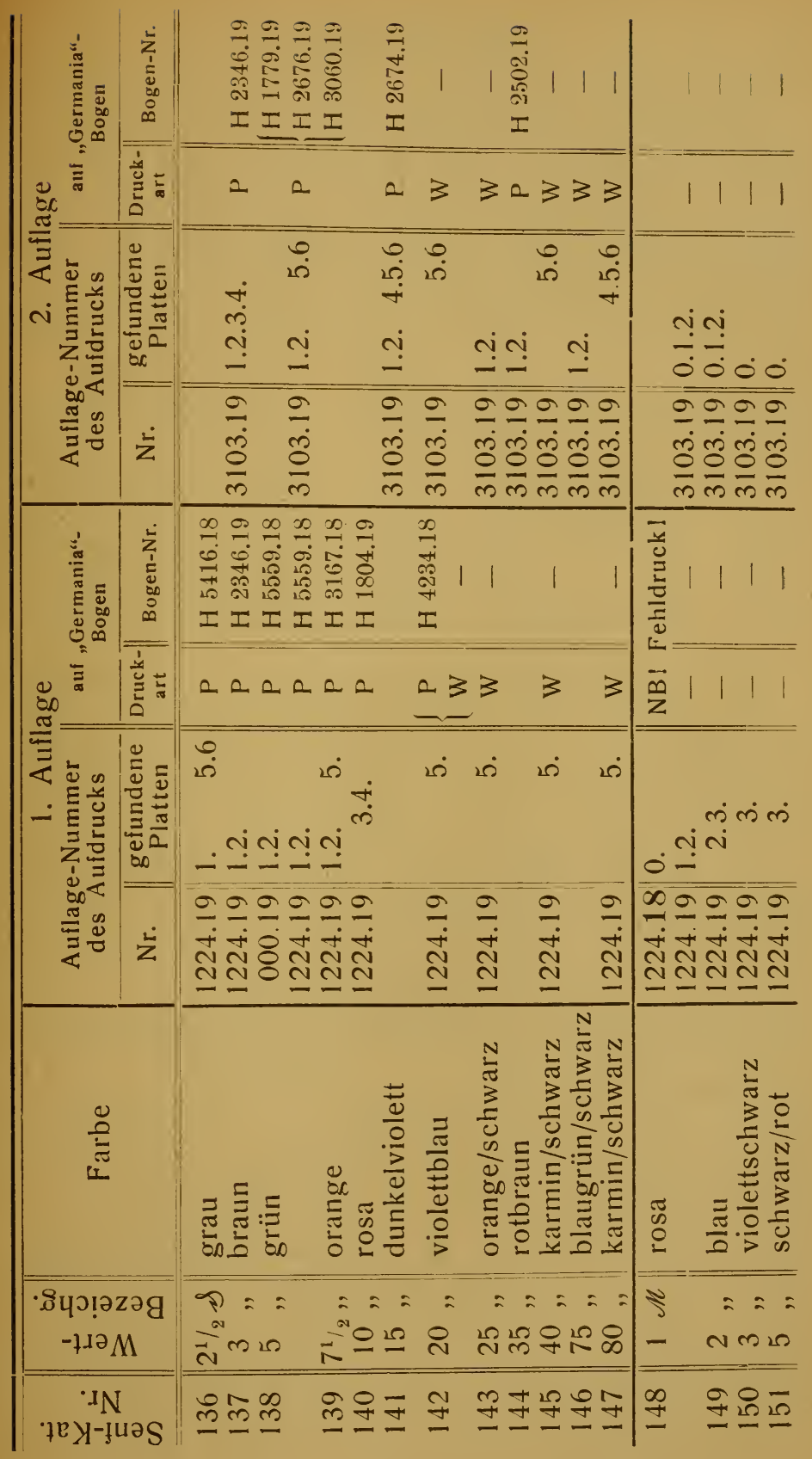




\section{Dienstmarken.}

Für die Kgl. bayerische Eisenbahn-Verwaltung.

Die Eisenbahndienstmarken, welche entstanden sind durch Uberdrucken der gleichzeitigen Briefmarken in Wappenzeichnung mit einem ,E“, finden sich in den Auflagen 35 (1908) bis 37 (1910), letztere in den drei vorher beschriebenen Bogeneinteilungen (37/I, 37/II, 37/III.)

\begin{tabular}{|c|c|c|c|c|}
\hline$\stackrel{4}{1}$ & Wertbezeichnung & 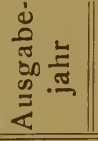 & 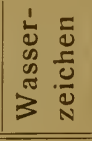 & $\begin{array}{l}\text { Vorkommende } \\
\text { Auflagezahlen }\end{array}$ \\
\hline \begin{tabular}{l|l}
1 & \\
$?$ & \\
3 & \\
4 & \\
5 &
\end{tabular} & $\begin{aligned} 3 & \text { Pfg. dunkelbraun } \\
5 & \text { " dunkelgrün } \\
10 & , \text { rot } \\
20 & \text { " blau } \\
50 & \text { " braunviolett }\end{aligned}$ & $\stackrel{\text { \& }}{.}$ & 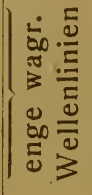 & 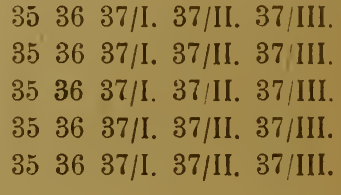 \\
\hline
\end{tabular}

Die Eisenbahndienstmarken, hergestellt durch Einlochung eiries „E“ aus den gleichzeitigen Briefmarken in Kopfzeichnung, zerfallen in Luitpold-Marken (seit 1912) und in Ludwig-Marken (seit 1914).

Ich konnte feststellen, daß folgende Platten- bezw. Walzennummern der genannten Ausgaben zur Herstellung der „E“-Marken verwendet wurden.

Luitpold.Zeichnung.

\begin{tabular}{|c|c|c|c|}
\hline \multirow{2}{*}{$\begin{array}{l}\sum_{1} \\
\frac{\pi}{\pi} \\
\underline{1} \\
\end{array}$} & \multirow{2}{*}{ Wertbezeichnung } & \multicolumn{2}{|c|}{ Plattennummern } \\
\hline & & Zeichnung A & Zeichnung $B$ \\
\hline 6 & 3 Pfg. braun & & XXXIX, XLI, 43. \\
\hline 7 & 5, dunkelgrün & 1 & $\begin{array}{l}\text { LXXXIX, XC, XCII, } \\
\text { XCIV, XCVII, IIC, IC, } \\
19.21 .32 .35 .42 .51 .52 .53 .62 .\end{array}$ \\
\hline 8 & 10, rot & LXXVI, LXXVII & $\begin{array}{l}\text { 80. 1. 2. 19. 21. 33. 40. } 41 . \\
44.45 .46 .58 .59 .\end{array}$ \\
\hline 9 & 20 , blau & & XV, XVII, 3. 7. 8.9.10. 18. \\
\hline 10 & 2.5, violettschw. & & IX, X, 3. \\
\hline 11 & 50 , braunrot & & XIII, 14. 15. 3. \\
\hline
\end{tabular}


Der die Auflage-Nummern tragende Rand ist stets weggerissen; dies geschah stets, um den Bogen in die E-Lochungsmaschine gleichmäßig (und unabhängig von dem in seiner Breite wechselnden Papierrand) einlegen zu können.

, $\exists$ “ statt E findet sich bei 5 Pfennig Platte 63 und 63 A. Nur die Marke zu 10 Pfennig 'konnte ich in Zeichnung $\mathrm{A}$ in einwandfreien Randnummernstücken nachweisen.

Ludwig-Zeichnung.

\begin{tabular}{|c|c|c|}
\hline 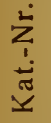 & Wertbezeichnung & Walzennummern \\
\hline 12 & 3 Pfg. braun & 6. 9 . \\
\hline 13 & 5 , dunkelgrün & 29. 30. 34. 36. 39. 42.48 .49$. \\
\hline 14 & $10, \quad \operatorname{rot}$ & 16. 18. 26. 28. 38. 45. 46. 59. \\
\hline 15 & 20 \# blau & 5. 6. 7. 10. 12. \\
\hline
\end{tabular}

Auch bei dieser Ausgabe ist der die Auflagenummer tragende Rand stets weggerissen.

Ich bin dankbar für Meldung und Vorlage weiterer Plattennummern, welche mit eingelochtem „E“ gefunden wurden; es gibt von diesen sicher noch eine größere Anzahl.

Anschließend an diese Ausgabe bringt der Senf-Kata$\log 1921$ eine unvollständige Aufstellung der durch Lochung geschaffenen Dienstmarken für Kriegsbeschädigten-Ausschüsse (,K“), staatlichen Lastkraftwagenverkehr. (,L K“) und Beamtenräte (,R“). Der Katalog der Sammler-Woche bringt eine wesentlich umfassendere Aufstellung und führt auch an: Betriebsräte (,B“), im ganzen 31 Verschiedenheiten (I-XXXI). Diese Lochungen kommen vor auf der Ludwig-Ausgabe mit Aufdruck „Freistaat Bayern“, auf der Bilderzeichnung und auf dieser mit Aufdruck „Deutsches Reich“. Alle diese Dienstwertzeichen sind schwer erhältlich und ich konnte nur folgende Auflagenummern feststellen: 
K Ludwig-Freistaat 10 Pfg. Auflage 3 Platte 107

$\begin{array}{rrrrrr}\text {,Deutsches Reich" } 30 & \text { " } & \text { " } & 30 & \text { " } & 7\end{array}$

$\begin{array}{llll}\text { LK Ludwig-Freistaat } 5, & \text { - } & \text { " } & 68\end{array}$

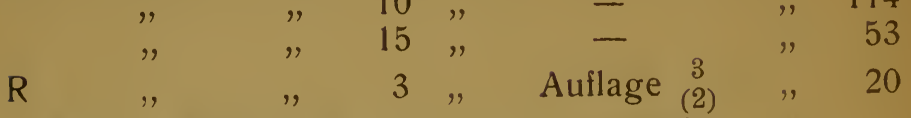

Weitere Meldungen sind sehr erwünscht.

Allgemeine Ausgabe der Dienstmarken in

Wappenzeichnung.

Diese Ausgabe ohne und mit zweizeiligem Aufdruck „Volksstaat Bayern" ist nur ohne Auflagevermerke gedruckt worden. (Senf Kat.-Nr. 16-43.)

\section{Ziffernzeichnung}

auch später mit zweizeiligem Aufdruck „Deutsches Reich“.

Die Ausgabe erfolgte im Frühjahr 1920 gleichzeitig mit der Briefmarkenausgabe in Bilderzeichnung. Die Anordnung der Plattennummern entspricht derjenigen der gleichzeitigen Freimarken.

Die Stellung der Plattennummern ist bei den Werten 5-90 Pfennig stets unten links oder rechts, nie gleichzeitig links und rechts; bei den Werten von 1-5 Mark, welche in Querform erschienen sind, entspricht die Stellung der Plattennummern zum Markenbilde den Angaben der folgenden Tabelle (auf Seite 97).

\section{Zahlmarken.}

Die Zahlmarken in Ziffernzeichnung (Ausgaben 1862 und 1870, Senf-Kat.-Nr. 1-3) sind ohne Auflagenvermerke gedruckt worden entsprechend den gleichzeitigen Briefmarken.

Für die Zahlmarken in Wappenzeichnung (Ausgaben 1876-1895, Senf Kat.-Nr. 4-13) haben alle Angaben zu den. gleichzeitigen Briefmarken Gültigkeit. Nachweislich sind die Zahlmarken mit den gleichen Platten gedruckt worden wie die Briefmarken. Es ist deshalb anzunehmen, daß gleichzeitig mit der Einführung der Auflagenummern bei den Briefmarken dieselbe auch bei den Zahlmarken erfolgte. Die in Klammern stehenden Auflagenummern habe ich noch nicht gesehen. (Tabelle S. 98.) 
Plattennummern der Dienstmarken in Ziffernzeichnung

(später mit zweizeiligem Aufdruck „Deutsches Reich“)

(zu Seite 96).

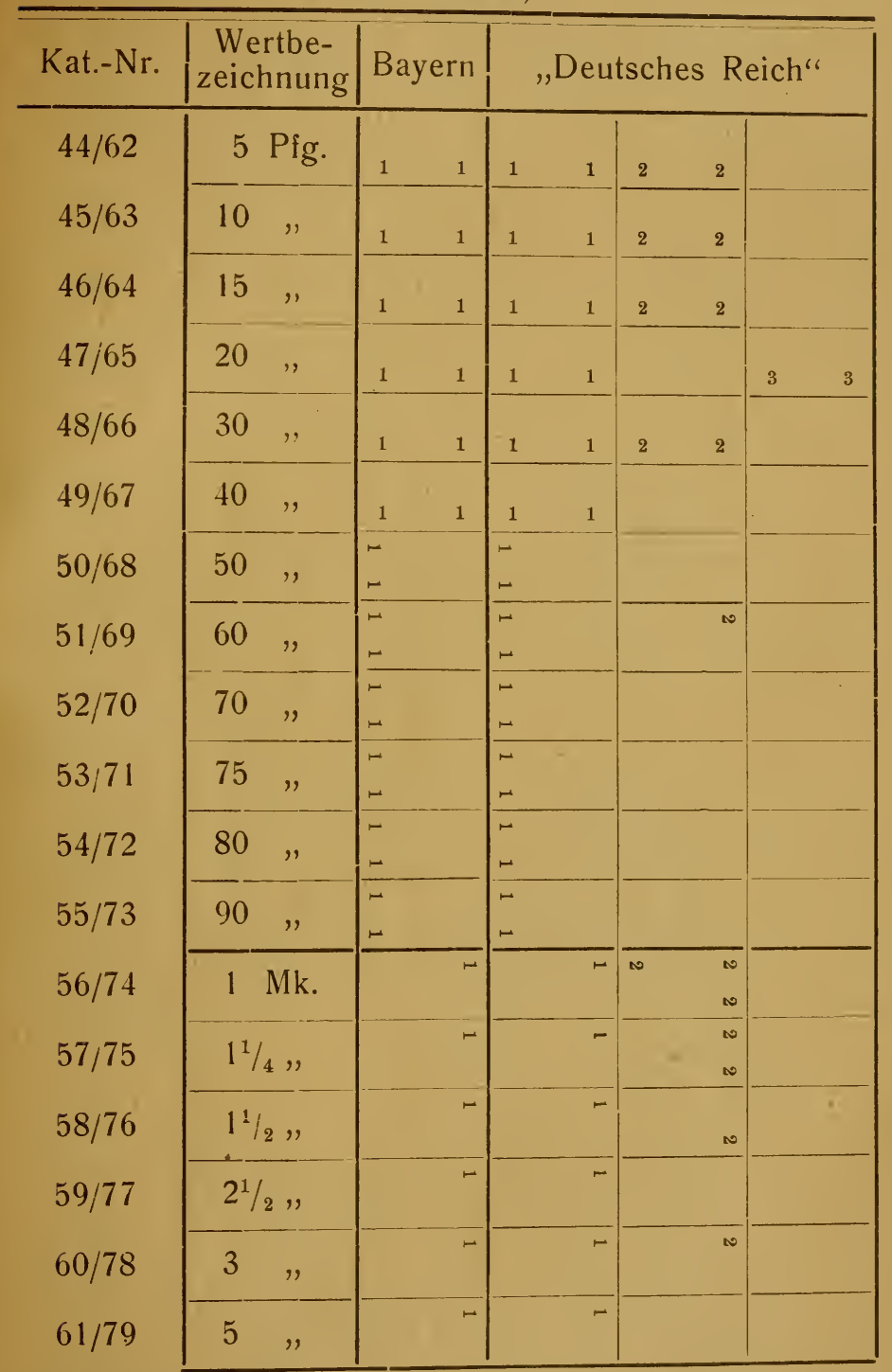

Auch diese Ausgabe befindet sich einstweilen noch im Druck, sodaß weitere Plattennummern erscheinen werden. 


\section{$-98-$}

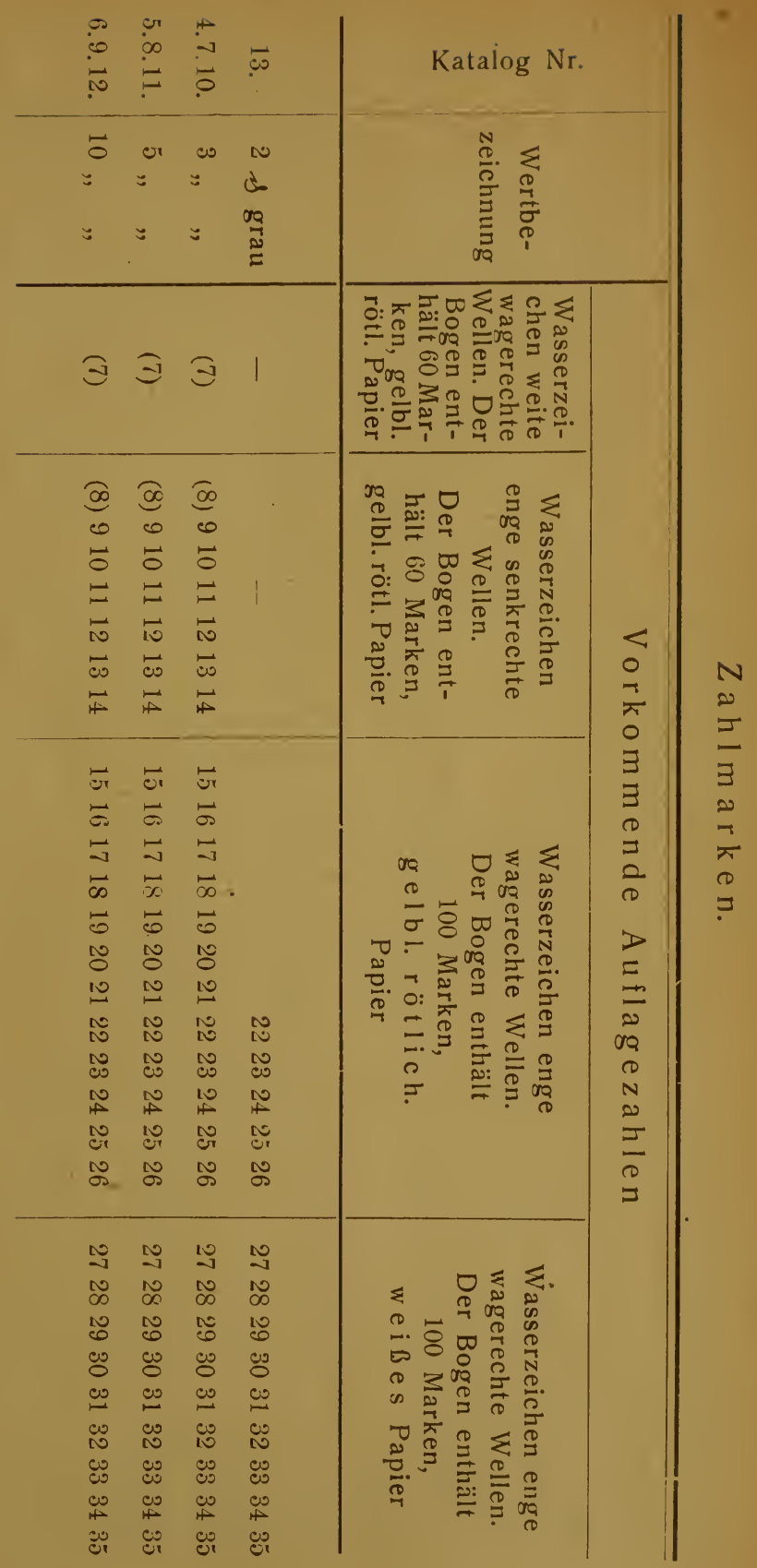




\section{Telegraphenmarken.}

Bei den Telegraphenmarken Bayerns (Senf-Kat. Nr. 1-25) hat eine eigentliche Kenntlichmachung der Auflagen nie stattgefunden, entsprechend dem Fehlen der Auflagenummern bei den gleichzeitigen Briefmarken usw. Zeitweise wurden die Bogen der Telegraphenmarken der Pfennigwährung mit Wasserzeichen Wellenlinien (Ausgabe 1876. Senf-Katalog Nr. 16-25) fortlaufend auf dem Markenbogenrand nummeriert, wohl nur zu Kontroll- oder Abrechnungszwecken, keinesfalls zur Bezeichnung einzelner Auflagen. In den von einzelnen Werten noch zahlreich vorhandenen Restbestände finden sich gelegentlich solche fortlaufend gezählte Bogen.

Die "T elephon-Billets" sind stets ohne Auflagenummern gedruckt worden.

Um meine Aufstellung der Auflagenummern möglichst vollständig zu gestalten und dem Sondersammler einen Hinweis auf weitere Ausbaumöglichkeiten zu geben, will ich noch erwähnen, daß die

Gebührenmarken und

Eisenbahnmarken

(Frachtmarken zur Verrechnung von Frachtgebühren auf Frachtbriefen) Auflagenummern besitzen. Gebührenmarken sind mir mit Auflagenummer 11 beginnend bekannt. Doch weiß ich nicht, ob die mir bekannten Randnummern 1 und 2 der Frachtmarken Druckplattenbezeichnungen oder Auflagenummern sind. 


\section{Schlußwort.}

Statistische Zusammenfassung - Ergänzungen -

Berichtigungen.

Jeder Leser, welcher mir durch die langen Wege der Auflage-, Platten- und Walzennummern der Postwertzeichen Bayerns gefolgt ist, dem wird der innere, logische Zusammenhang zwischen der Bogeneinteilung und dieser Zahlenfolge klar geworden sein, wie ihm auch bewußt sein wird, daß diese Zahlen, ursprünglich eine undurchsichtige Wirrnis darstellend, in Wirklichkeit einem folgerichtigen Aufbau angehören. Jeder eingefleischte Sammler empfindet als besonders reizvoll, gleichartige, in sich nach bestimmten Regeln unterschiedliche Dinge zusammenzutragen, jeder denkende Sammler erkennt aber auch, daß das Sammeln dieser drucktechnischen Merkmale die Grundlage jeder Spezialisierung bilden muß. Diese Nummernfolgen, sicherlich nicht zu Sammelzwecken den Markenbogen beigegeben, gewähren Einblick in die innere Struktur der einzelnen Markenausgaben; wir Sammler greifen gern nach diesem Hilfsmittel, welches durch kein gleichwertiges uns ersetzbar ist.

Welchen Umfang eine Bayern-Sammlung dieser Nummernfolgen annimmt, mögen folgende Zahlen lehren. Die vorliegende Bearbeitung weist etwa

\section{Auflage-u.s.w. Nummern}

nach, ohne Zählung der kleineren Unterschiede, deren Berücksichtigung die Zahl auf etwa 6000 erhöhen könnte. Die Ludwig-Ausgabe zusammen mit den Aufdruckausgaben „Volksstaat" und „Freistaat" bietet etwa 750 Hauptnummern, die Luitpold-Ausgabe etwa 500, während die Jahresauflagenummern der alten Wappenausgabe etwa 275 Stück 


\section{$-101-$}

umfassen. Die die größte Nummernzahl aufweisenden Werte sind:

Luitpold-Ausgabe 5 Pfennig mit etwa 165 Platten

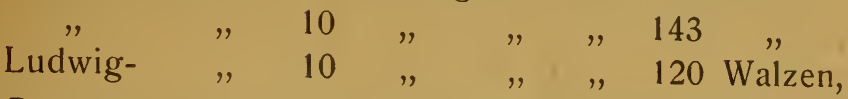

bei Berücksichtigung der Aufdrucke und Zähnungsunterschiede mit fast 160 Zahlen.

Wer nicht schon eine Grundlage in seiner Sammlung besitzt, der wird nur mit großen Schwierigkeiten und deshalb mit um so größerer Freude und Genugtuung seine Bayern-Sammlung in der von mir gewiesenen Richtung ausbauen können.

Zum Schlusse spreche ich nochmals die Bitte um Meldungen von Ergänzungen und Berïchtigungen aus. 
Nachweis

aller Postwertzeichen Bayerns.

Wo finde ich in vorliegendem Buche Angaben über einzelne Marken?

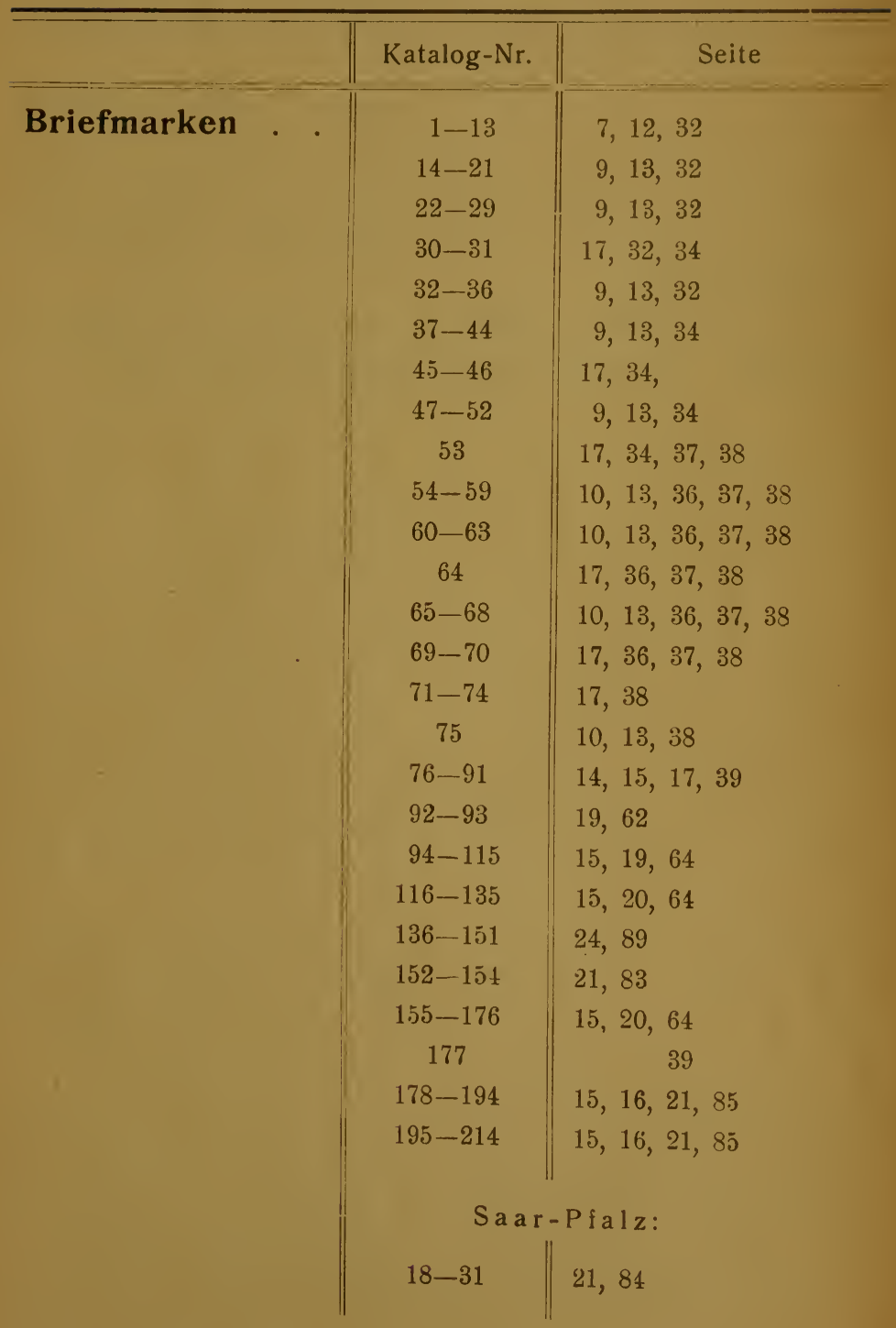




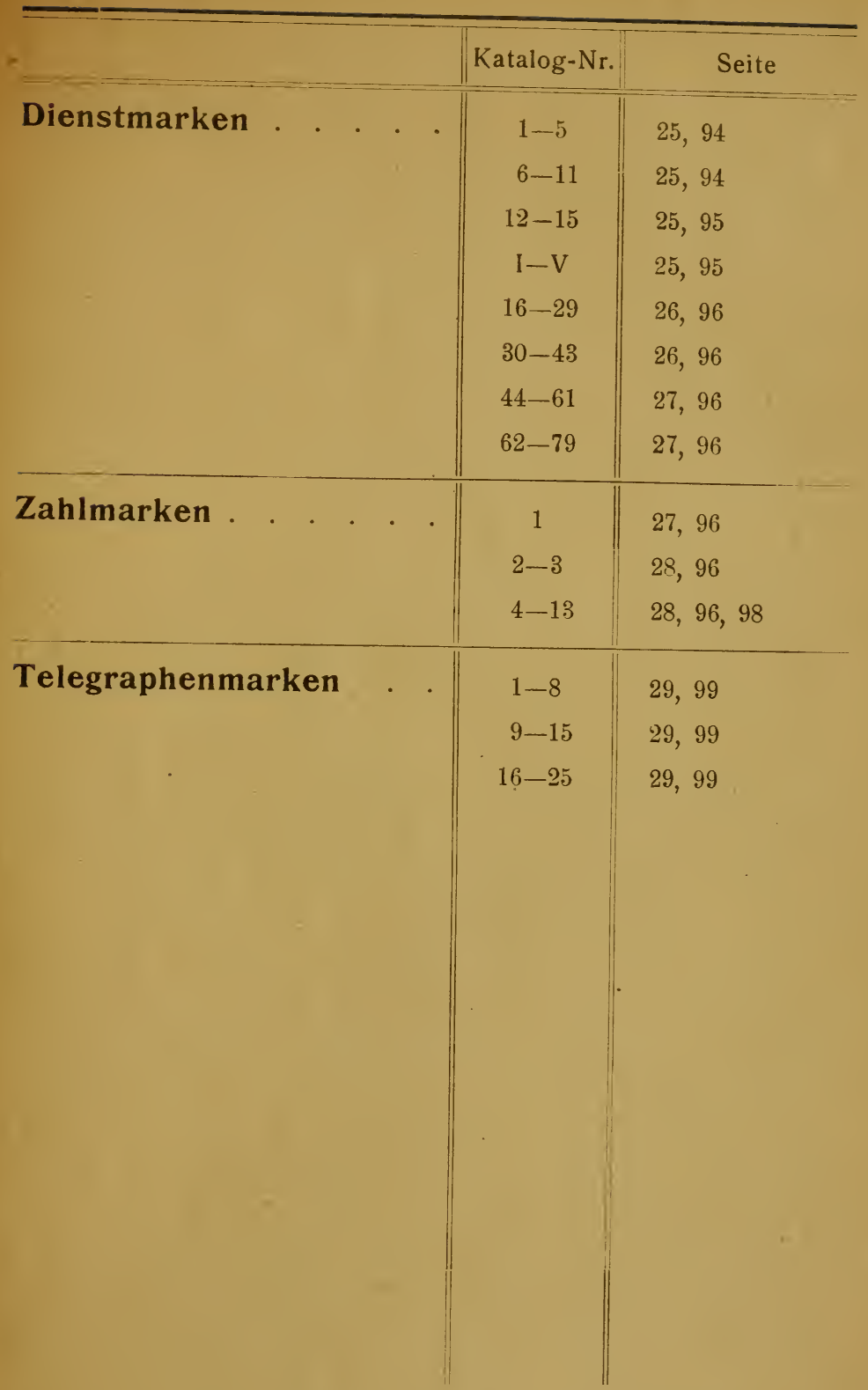

NB. Nummern nach Gebrüder Senfs Illustriertem Postwertzeichenkafalog 1921: 

